\title{
Alessandra Choqueta de Toledo
}

Efeitos do treinamento físico aeróbio sobre a lesão pulmonar induzida por exposição à fumaça de cigarro em camundongos C57BI6

Tese apresentada à Faculdade de Medicina da Universidade de São Paulo para obtenção do título de Doutor em Ciências.

Área de concentração: Processos Inflamatórios e Alérgicos

Orientador: Prof. Dr. Mílton de Arruda Martins

São Paulo

2009 


\section{Alessandra Choqueta de Toledo}

Efeitos do treinamento físico aeróbio sobre a lesão pulmonar induzida por exposição à fumaça de cigarro em camundongos C57BI6

Tese apresentada à Faculdade de Medicina da Universidade de São Paulo para obtenção do título de Doutor em Ciências.

Área de concentração: Processos Inflamatórios e Alérgicos

Orientador: Prof. Dr. Mílton de Arruda Martins

São Paulo

2009 
DEDICATÓRIA 
Junior, pelo amor, companheirismo e amizade João, Tereza e Fabíola, meu alicerce

Pelo apoio em todas as etapas de minha vida.

À vocês dedico este trabalho 
À Deus por caminhar sempre comigo.

Ao Junior, meu primeiro e grande amor; à minha família e amigos, especialmente aos meus pais, Tereza e João, minha irmã Fabiola, André Zambaldi, Maria de Paula, Elias, Rodrigo, Josiana e Isadora, amo muito todos vocês.

Ao querido Professor Mílton de Arruda Martins, a principal bússola deste laboratório e dos meus passos nos últimos anos, pelo privilégio da convivência, pela generosidade na transmissão do conhecimento $e$ principalmente pela amizade. A admiração que sinto por você é imensurável, sua retidão de caráter e de justiça é algo a se espelhar. Obrigada pelo privilégio!

Ao Renato Moschella Magalhães, aluno de iniciação científica $e$ grande amigo. Renatinho, você foi o maior presente que recebi durante a pós-graduação. Aprendi muito com você, mas principalmente a delegar tarefas e a entender o funcionamento do processo ensino-aprendizagem, tão discutido com a querida Professora Cida Basile. Muito obrigada por tudo!

Ao Professor Celso Carvalho, pelo apoio e por acreditar neste trabalho quando ele era ainda uma idéia. 
À grande pesquisadora Mariângela Macchione, "abelhinha", por me guiar no mundo da biologia celular. Vamos à cultura! Desistir jamais! Macchi, você é uma grande Professora e se tornou uma grande amiga.

Aos amigos e colaboradores deste trabalho. Fernanda Lopes, pelo apoio sempre, paciência, sugestões e principalmente pela amizade; Renato Moschella, pelo empenho; Rodolfo de Paula Vieira, pelas orientações, fé e força em todos os momentos de nossa amizade; Paolo Biselli, pela dedicação, disponibilidade e amizade; Henrique Moriya, pelo apoio e ajuda sempre que necessário; Déborah Hizume (e D. Ercília) pela ajuda não só neste trabalho, mas também durante minha mudança para Higienópolis; e à Professora Thais Mauad, possuidora de uma personalidade marcante, pelas sugestões e disposição em ajudar.

Ao Prof. Paulo Saldiva por nos contagiar sempre com suas idéias e por manter as portas de sua mente e do seu laboratório abertas à todos.

Aos amigos do Laboratório do Muco, especialmente à Elnara, Regiane, Luciana Rabello, Andréa, Kelly, Vivien, e aos amigos do LIM 05, Jose Mara, Eliane Tigre, Dolores, Ana Julia, Juliana Andrietta, Débora Jã, Adriana, Márcia, Dalva, Márcia Hage, Luiz, Heloisa e Nilda, pela torcida desde sempre. 
Aos amigos do LIM 20, especialmente à Fernanda Arantes, minha primeira grande mestra, pela dedicação em me ensinar; Edna Leick, pelos conselhos, pelo bem-querer e pela excelente companhia nas viagens que as tornam únicas; Carla Prado, pela generosidade e disposição em ajudar, nunca vou esquecer seu empenho em Berlim; Rafael, Fabi, Tatiana, Petra e Ricardo, pelo apoio e pela troca de experiências; Bia, pela vontade de ajudar sempre; Clarice (manezinha), pelo bom humor e pela força; Professora Iolanda Tibério e Professora Maria Lucia Garcia, pela força; Adenir, pelas palavras certas no momento apropriado; Francine e Claúdia Fló, por estarem sempre por perto quando precisei; Ronaldo e Ana Cecília, pela grande torcida; David Ferreira (querido David do biotério) pela disponibilidade sempre; David Kasahara (sua mãe e irmã Deise) pelas demonstrações de amizade durante estes anos, e a todos que mesmo indiretamente colaboraram para a realização deste trabalho.

Aos amigos Claúdia Simeire Yagi e seu marido Kenji, pela confiança depositada em mim, sem vocês eu ainda estaria sem um teto.

À querida Rosana, pela amizade, pelos conselhos, incentivo e força desde o primeiro dia. Estou torcendo por você, hoje e sempre! 
Aos Professores Roger Chammas e Chin por terem cedido espaço em seus laboratórios para o cultivo de células e à Mara por nos guiar no caminho das pedras.

À Angélica e Rose da secretaria de Ciências Médicas, simplesmente pela excelência do trabalho que prestam a todos os alunos e orientadores deste Programa de pós-graduação.

À Kelly, Celina e Cássia pela confecção das lâminas histológicas.

Às queridas, Ângela, Cristina, Sandrinha e Esmeralda do Laboratório de Imunohistoquimica da FMUSP pela amizade, pelo prazer que demonstram em ajudar e pela dedicação ao trabalho que fazem.

À Professora Ercy Mara Cipulo Ramos, do curso de Fisioterapia da UNESP, pela oportunidade em vivenciar a relação ensino-aprendizagem com seus alunos durante sua licença maternidade. E principalmente por poder voltar à Faculdade de minha formação.

À FAPESP, pelo apoio financeiro e pela liberação do estágio docente, que acredito ser de extrema importância na formação do pós graduando. 
Aos amigos da UTI neurológica do Hospital Santa Catarina, por tudo que me ensinaram durante nossos sete anos de convivência, em especial ao Dr. Ioannis Liontakis, Dr. Rubens, Dr. Hélio, Dr. Adley, Dra Maristela, Dr. José Manuel, Enf ${ }^{\text {as }}$ Mara, Nilza, Érika e Simone. Agradeço pela abertura a discussões e pela confiança em meu trabalho. Às fisioterapeutas Kelcy Venâncio e Juliana Fonsatti agradeço pelo companheirismo e à Izabel, Daniela e Cristiane, por entenderem que a pesquisa era o meu caminho.

Aos amigos do CAP (Clube Alpino Paulista) e do CERJ (Centro Excursionista do Rio de Janeiro). Nossas escaladas e caminhadas fizeram o trajeto até aqui mais prazeroso.

A realização de uma pesquisa requer o somatório de recursos, tempo e disposição. Agradeço à FAPESP, FMUSP e LIM 20, sem os quais a disponibilidade de tempo e a motivação para a pesquisa seriam inócuos. 
Este trabalho recebeu apoio financeiro da FAPESP:

Bolsa de doutorado: Processo 06/50361-6

Projeto Temático: $n^{\circ}$ 02/08422-7 


\section{EPÍGRAFE}


Salmo 23 
Esta tese está de acordo com as seguintes normas, em vigor no momento desta publicação:

Referências: adaptado de International Committee of Medical Journals Editors (Vancouver)

Universidade de São Paulo. Faculdade de Medicina. Serviço de Biblioteca e Documentação. Guia de apresentação de dissertações, teses e monografias. Elaborado por Anneliese Carneiro da Cunha, Maria Julia de A. L. Freddi, Maria F. Crestana, Marinalva de Souza Aragão, Suely Campos Cardoso, Valéria Vilhena. São Paulo: Serviço de Biblioteca e Documentação; 2005.

Abreviaturas dos títulos dos periódicos de acordo com List of Journals Indexed in Index Medicus. 
SUMÁRIO 


\section{SUMÁRIO}

Lista de abreviaturas, siglas e acrônimos

Lista de figuras

Resumo

Summary

1 INTRODUÇÃO

2 OBJETIVOS

3 REVISÃO DA LITERATURA 07

3.1 DPOC - Definição e epidemiologia 07

$\begin{array}{ll}\text { 3.2 Fisiopatologia } & 11\end{array}$

3.2.1 Desequilíbrio oxidante - antioxidante 11

3.2.1.1 Espécies reativas de oxigênio e estresse oxidativo 11

$\begin{array}{ll}\text { 3.2.1.2 Sistema antioxidante } & 14\end{array}$

$\begin{array}{ll}\text { 3.2.2 Fatores genéticos } & 21\end{array}$

3.2.3 Desequilíbrio protease antiprotease 22

3.2.4 Inflamação pulmonar $\quad 24$

3.2.5 Participação de fatores de crescimento 27

3.3 Alteração da mecânica pulmonar 28

$\begin{array}{lr}3.4 \text { Histopatologia } & 29\end{array}$

3.5 Modelos experimentais de DPOC 31

3.6 Atividade física aeróbia $\quad 34$

3.6.1 Atividade física aeróbia e DPOC 37

4 MÉTODOS 39

4.1 Animais $\quad 40$ 
4.2 Protocolo Experimental $\quad 40$

4.2.1 Grupos experimetais $\quad 41$

4.2 Exposição à fumaça de cigarro 42

4.3 Treinamento físico aeróbio e teste físico 45

4.4 Avaliação da mecânica pulmonar 47

4.5 Coleta e mensuração do óxido nítrico exalado 49

4.6 Coleta e análise do lavado broncoalveolar 50

4.7 Coleta e mensuração de espécies reativas de oxigênio (ROS) no lavado broncoalveolar $\quad 50$

4.8 Histoquímica e imunohistoquímica 51

$\begin{array}{ll}\text { 4.8.1 Histoquímica } & 52\end{array}$

$\begin{array}{ll}\text { 4.8.2 Imunohistoquímica } & 52\end{array}$

4.9 Análise morfométrica dos pulmões 54

4.9.1 Mensuração do intercepto linear médio 54

4.9.2 Mensuração de marcadores de imunohistoquímica 55

4.9.3 Mensuração de fibras colágenas no parênquima $\begin{array}{ll}\text { pulmonar } & 56\end{array}$

4.10 Análise estatística $\quad 57$

5 RESULTADOS $\quad 58$

5.1 Massa, velocidade e tempo do teste físico 59

5.2 Avaliação da mecânica pulmonar 63

5.3 Mensuração do óxido nítrico exalado 66

5.4 Análise do lavado broncoalveolar $\quad 67$

5.5 Mensuração do intercepto linear médio 69 
5.6 Análise das fibras colágenas e elásticas

5.7 Mensuração de espécies reativas de oxigênio no lavado broncoalveolar 74

5.8 Análise de marcadores de imunohistoquímica 75

6 DISCUSSÃO 90

7 CONCLUSÔES 110

REFERÊNCIAS 112 


\section{Lista de abreviaturas, siglas e acrônimos}

\begin{tabular}{|c|c|c|}
\hline CAPPesq & - & $\begin{array}{l}\text { Comissão de Ética para Análise de Projetos de Pesquisa } \\
\text { Células }\end{array}$ \\
\hline cels & - & Células \\
\hline $\mathrm{CO}$ & - & Monóxido de carbono \\
\hline DATASUS & - & Banco de dados do Sistema Único de Saúde \\
\hline DPOC & - & Doença pulmonar obstrutiva crônica \\
\hline ECRHS & - & Comunidade Européia de pesquisa em Saúde Respiratória \\
\hline ENA78 & - & Peptídeo epitelial ativador de neutrófilos \\
\hline FEV1 & - & Volume expiratório forçado em 1 segundo \\
\hline FGFR & - & Receptor do fator de crescimento de fibroblastos \\
\hline $\mathbf{g}$ & - & gramas \\
\hline G-CSF & - & fator de estimulação de colônias de granulócitos \\
\hline GOLD & - & Global iniciative for chronic obstructive lung disease \\
\hline GPx & - & Glutationa peroxidase \\
\hline GROa & - & Fator de crescimento relacionado a oncogenico $\alpha$ \\
\hline GSH & - & Glutationa \\
\hline GM-CSF & - & Fator estimulador de colônia de macrófagos e granulócitos \\
\hline Gp91phox & - & Subunidade da enzima NADPH-oxidase \\
\hline GROa & - & Oncogene relacionado ao crescimento $\alpha$ \\
\hline Gtis & - & Resistência de tecidos \\
\hline $\mathbf{h}$ & - & hora \\
\hline Htis & - & Elastância de tecidos \\
\hline $\mathrm{HOCl}$ & - & Ácido hipocloroso \\
\hline $\mathrm{H}_{2} \mathrm{O}_{2}$ & - & Peróxido de hidrogênio \\
\hline law & - & Inertância de vias aéreas \\
\hline IL & - & Interleucinas \\
\hline INFy & - & Interferon $\mathrm{y}$ \\
\hline eNOS & - & Enzima oxido nítrico sintase endotelial \\
\hline iNOS & - & Enzima oxido nítrico sintase indutivel \\
\hline $\mathrm{Km}$ & - & Quilometros \\
\hline Lm & - & Intercepto linear médio \\
\hline LBA & - & Lavado broncoalveolar \\
\hline LIM & - & Laboratório de investigação médica \\
\hline LTB4 & - & Leucotrieno B4 \\
\hline LPS & - & Lipopolissacaride \\
\hline$\mu \mathrm{m}$ & - & Micrometro \\
\hline $\min$ & - & Minutos \\
\hline mL & - & Mililitro \\
\hline MCP1 & - & Proteína quimiotática de monócitos \\
\hline MIP-1 & - & Proteína 1 macrofágica inflamatória \\
\hline MMP & - & Metaloproteinase de matriz \\
\hline NF-kB & - & Fator de transcrição nuclear kb \\
\hline NADPH & - & Nicotinamida adenina dinucleotídeo-fosfato \\
\hline NAP-1 & - & Nucleossomo de montagem da proteína 1 \\
\hline NIH & - & "National Institute of Health" \\
\hline NO & - & Óxido nitrico \\
\hline NOs & - & Enzima oxido nítrico sintase \\
\hline
\end{tabular}



$\mathrm{O}_{2} \quad-$ Oxigênio
-02 - Anion superóxido
$\mathrm{OH}$ - $\quad$ - Radical hidroxila
PBS - Salina tampão fosfato
PDGFA - Fator de crescimento derivado de plaquetas A
Raw - Resistência das vias aéreas
ROS - Espécies reativas de oxigênio
SOD - - Superóxido dismutase
SODCuZn - Superóxido dismutase Cobre, zinco
ou SOD1
SODMn ou - Superóxido dismutase Manganês
SOD2
SOD-EC ou - Superóxido dismutase Extracelular
SOD3
TNF- $\alpha$
SLPI
- Fator de necrose tumoral alpha
Inibidor das leucoproteases
TGB- $\beta \quad$ - Fator de crescimento transformador $\beta$
TIMP $\quad-$ Inibidores das metaloproteinases de matriz
TNFa - Fator de necrose tumoral $\alpha$
VEGF - Fator de crescimento endotelial vascular
VEGFR - Receptor do fator de crescimento endotelial vascular
Z(f) _ Impedância 


\section{Lista de Figuras}

Figura 1 - Geração de espécies reativas de oxigênio e sistema de defesa antioxidante

Figura 2 - Esquema ilustrativo da caixa de exposição à fumaça de cigarro

Figura 3 - Foto da esteira ergométrica adaptada para camundongos 46

Figura 4 - Esquema do protocolo experimental.

Figura 5 - Massa corporal $(\mathrm{g})$ dos animais nos tempos inicial, 8, 16 e 24 semanas.

Figura 6 - Velocidade $(\mathrm{Km} / \mathrm{h})$ adquirida pelos animais no teste físico 61

Figura 7 - Tempo (minutos) adquirido pelos animais no teste físico 62

Figura 8 - Mecânica Pulmonar: Resistência de vias aéreas (Raw) 63

Figura 9 - Mecânica Pulmonar: Resistência de tecidos (Gtis) 64

Figura 10 - Mecânica Pulmonar: Elastância (Htis) 65

Figura 11 - Concentrações de NO exalado 66

Figura 12 - Células no lavado broncoalveolar 68

Figura 13 - Fotografias das regiões próximas à pleura dos quatro grupos estudados.

Figura 14 - Diâmetro alveolar médio próximo à pleura 70

Figura 15 - Diâmetro alveolar médio próximo à via aérea 71

Figura 16 - Conteúdo de fibras colágenas no parênquima pulmonar 72

Figura 17 - Conteúdo de fibras elásticas no parênquima pulmonar 73

Figura 18 - Mensuração de espécies reativas de oxigênio no LBA 74

Figura 19 - Conteúdo de 8-Isoprostano no parênquima pulmonar 76

Figura 20 - Densidade parenquimal de células inflamatórias iNOS+ 77

Figura 21 - Densidade parenquimal de células inflamatórias GPx+ 78

Figura 22 - Densidade parenquimal de células inflamatórias SODCuZn+

Figura 23 - Densidade parenquimal de células inflamatórias SODMn+

Figura 24 - Densidade parenquimal de células inflamatórias SODEC+

Figura 25 - Densidade parenquimal de células inflamatórias Gp91phox+

Figura 26 - Densidade parenquimal de células inflamatórias MMP9+ 83

Figura 27 - Densidade parenquimal de células inflamatórias TIMP1+ 84

Figura 28 - Densidade parenquimal de células inflamatórias MCP1+ 85

Figura 29 - Densidade parenquimal de células inflamatórias TNF- $\alpha+86$

Figura 30 - Densidade parenquimal de células inflamatórias IL-10+ 87

Figura 31 - Densidade parenquimal de células inflamatórias IL1-ra+ 88 
RESUMO 
Toledo AC. Efeitos do treinamento físico aeróbio sobre a lesão pulmonar induzida por exposição à fumaça de cigarro em camundongos C57BI6. [tese]. São Paulo: Faculdade de Medicina, Universidade de São Paulo; 2009. 146p.

O exercício aeróbio foi recentemente descrito como capaz de reduzir a função pulmonar e diminuir o risco de desenvolver DPOC entre fumantes ativos. A plausibilidade biológica da influência da atividade física sobre o declínio da função pulmonar está relacionada aos efeitos anti-inflamatórios efeitos da atividade física, que tem sido descritos em estudos experimentais. A hipótese é que haveria uma interação entre exercício aeróbio e o desenvolvimento da doença. A fim de explorar mais a fisiopatologia da DPOC induzida pela exposição à fumaça de cigarro e os efeitos do exercício no desenvolvimento do enfisema, utilizamos um modelo experimental de DPOC. C57BI6 foram divididos em quatro grupos: Controle, Fumo, Exercício e Fumo/Exercício. Os animais dos grupos Fumo foram expostos à fumaça de cigarro por 30 minutos por dia, 5 dias por semana, durante 24 semanas. Os animais dos grupos Exercício foram treinados em intensidade moderada durante 60 minutos por dia, 5 dias por semana durante 24 semanas. Os resultados demonstraram que o treinamento físico aeróbio regular de intensidade moderada inibiu o desenvolvimento de enfisema, o aumento do total de células inflamatórias e a produção de espécies reativas de oxigênio no LBA, além do aumento na geração de óxido nítrico exalado, induzido pela exposição à fumaça do cigarro, e inibiu o aumento de 8-isoprostano e MCP1, além de aumentar a expressão da GPx, SODCuZn, TIMP1 e IL-10 por 
células inflamatórias na parede alveolar. O estudo também mostrou que o treinamento físico aeróbio foi capaz de inibir a diminuição da elastância pulmonar induzida pela exposição à fumaça de cigarro, mas não reduziu o aumento de colágeno no parênquima pulmonar. Estes resultados sugerem que o treinamento físico regular aeróbico de intensidade moderada pode desempenhar um papel importante durante a instalação da doença devido ao seu efeito antioxidante e antiinflamatório.

Descritores: doença pulmonar obstrutiva crônica; exercício; modelos animais; lesão por inalação de fumaça/fisiopatologia; tabaco/efeitos adversos; fumaça; camundongos 
Toledo AC. Aerobic exercise attenuates pulmonary alterations induced by exposure to cigarette smoke in mice [thesis]. São Paulo: "Faculdade de Medicina, Universidade de São Paulo"; 2009. 146p.

Aerobic exercise was recently described as capable to reduce lung function decline and risk of developing COPD among active smokers. The biological plausibility of the influence of physical activity on the decline of lung function relies on the anti-inflammatory effects of physical activity, which have been described in experimental studies. We hypothesized there would be an interaction between aerobic exercise and development of disease. In order to further explore the physiopathology of COPD induced by exposure to cigarette smoke and the effects of exercise in development of emphysema, we used an experimental model of DPOC. C57BI6 were divided in four groups: Control, Smoke, Exercise and Smoke/Exercise. Smoke groups were exposed to cigarette smoke for 30 minutes a day, 5 days a week, for 24 weeks. Exercise groups were trained at moderate intensity exercise for 60 minutes/day, 5 days/week for 24 weeks. The results demonstrated that regular aerobic physical training of moderate intensity inhibited alveolar distension, the increase of total inflammatory cells and production of reactive oxygen species in BAL and the increase in the generation of exhaled nitric oxide induced by exposure to cigarette smoke, and reduced the expression of 8-isoprostane and MCP1 and increased the expression of GPx, SODCuZn, TIMP1 and IL-10 by inflammatory cells in the alveolar wall. The study also showed that aerobic physical training was able to inhibit the decrease in lung elastance induced by exposure to cigarette smoke, but not 
the content in collagen fibers. These results suggest that regular aerobic physical training of moderate intensity may play an important role during the installation of disease due to its antioxidant and antiinflammatory effects. Keywords: chronic obstructive pulmonary disease; aerobic exercise; animal models; smoke 
INTRODUÇÃO 


\section{INTRODUÇÃO}

A Doença Pulmonar Obstrutiva Crônica (DPOC) é uma doença caracterizada por limitação ao fluxo aéreo não completamente reversível, geralmente progressiva e associada a uma resposta inflamatória anormal a partículas ou gases tóxicos (1)

A DPOC pode ter diferentes apresentações clínicas e muitos pacientes são diagnosticados como portadores de enfisema pulmonar ou bronquite crônica. Enfisema pulmonar refere-se à destruição das superfícies alveolares dos pulmões. É um diagnóstico anatomo-patológico, embora seja usado muitas vezes na prática clínica. Bronquite crônica é definida como a presença de tosse com expectoração por pelo menos 3 meses, por 2 anos consecutivos. No entanto, muitos pacientes apresentam graus variados das duas alterações patológicas: tosse produtiva e destruição do parênquima pulmonar. Assim, a definição proposta atualmente não utiliza os termos enfisema e bronquite crônica, mas caracteriza a doença por sua manifestação principal, a limitação do fluxo aéreo.

O tabagismo é o mais importante fator ambiental na patogênese da doença pulmonar obstrutiva crônica, no entanto, apenas cerca de $20 \%$ dos fumantes desenvolvem a doença, independentemente da quantidade de cigarros consumidos (2). Isso indica que a suscetibilidade à doença provavelmente resulte de múltiplos componentes genéticos e de efeitos ambientais.

Em menos de $2 \%$ de todos os casos relatados, a DPOC ocorreu como uma doença devido à deficiência de a1-antitripsina. 
A melhor estratégia para redução dos riscos mórbidos de um tabagista é certamente parar de fumar. De fato, um tabagista que para de fumar começa a ter redução dos seus riscos, entre eles a redução do declínio da função pulmonar $(3,4)$.

Entretanto, muitos tabagistas não querem ou não conseguem parar de fumar. Qual é a melhor estratégia para estes fumantes? É possível que um programa adequado de atividade física possa reduzir parte dos riscos impostos pelo tabagismo. A redução do risco cardiovascular em pacientes que se submetem a treinamento físico já foi adequadamente demonstrada. Tais indivíduos parecem ter benefícios com redução de mortalidade geral, menor incidência de doenças coronarianas e menor mortalidade por eventos coronarianos (5).

Existem dados que mostram que mesmo indivíduos tabagistas beneficiam-se dos efeitos protetores de um programa de atividade física regular (6-9). Fló demonstrou uma piora do enfisema pulmonar já instalado, induzido por papaína, em ratos quando estes foram submetidos à atividade física (10). Nesse modelo experimental onde há enfisema pulmonar na ausência de bronquite, o aumento do volume corrente e volume minuto durante a atividade física poderiam favorecer uma piora da lesão pulmonar já instalada. Mas não sabemos os efeitos do exercício físico durante a instalação da lesão pulmonar pelo tabagismo.

Um estudo de coorte prospectiva realizado em Copenhagem, com avaliação a cada 5-10 anos, mostrou que fumantes ativos que realizavam moderado ou alto grau de atividade física tinham o risco reduzido de 
desenvolver DPOC comparados ao grupo que realizava pouca atividade física (11).

No modelo experimental aqui proposto, em que a doença pulmonar estabelecida pela inalação de fumaça de cigarros por tempo prolongado deve ser caracterizada por bronquite e enfisema, o efeito da atividade física durante a instalação da doença não está devidamente estudado.

Neste contexto, faremos uma breve revisão sobre os mecanismos determinantes para a instalação da doença e os efeitos do treinamento físico aeróbio. 
OBJETIVO 


\section{OBJETIVO}

Avaliar o efeito da atividade física sobre os pulmões de camundongos durante a instalação da lesão pulmonar induzida por inalação de fumaça de cigarro. 
REVISÃO DA LITERATURA 


\section{REVISÃO DA LITERATURA}

\subsection{DPOC - Definição e epidemiologia}

A Doença Pulmonar Obstrutiva Crônica (DPOC) é uma doença caracterizada por limitação ao fluxo aéreo não completamente reversível, geralmente progressiva e associada a uma resposta inflamatória anormal a partículas ou gases tóxicos. A limitação ao fluxo aéreo característica da DPOC é causada por uma mistura entre doença de pequenas vias aéreas (bronquiolite obstrutiva) e a destruição do parênquima pulmonar (enfisema), e a contribuição relativa de cada uma delas varia de indivíduo para indivíduo. A DPOC tem uma história natural variável e nem todos os indivíduos seguem o mesmo curso. A cessação da exposição ao agente nocivo pode resultar em redução na progressão da doença. O maior fator de risco para o desenvolvimento da DPOC é a exposição à fumaça do cigarro. No entanto, outros fatores de risco, como a poeira ocupacional e agentes químicos, podem estar associados ao desenvolvimento da doença. $\mathrm{O}$ fator de risco genético melhor documentado é a deficiência de alpha 1 antitripsina (1).

O risco para desenvolvimento de DPOC em fumantes está relacionado à dose (3). Idade em que começou a fumar, quantidade total de pacotes de cigarros consumidos/ano e estado do consumo atual são preditivos de mortalidade de DPOC. O fato de apenas uma parcela dos fumantes desenvolverem clinicamente DPOC sugere que fatores genéticos possam modificar o risco individual (12).

A prevalência mundial da DPOC, em adultos com mais de 40 anos, é cerca de $9-10 \%$, quando definida pela limitação do fluxo aéreo (13). No 
entanto, há grande variação regional desta medida, quer por diferenças na exposição das populações aos fatores de risco, quer por diferenças nas definições de DPOC usadas nos diferentes estudos epidemiológicos.

Em São Paulo, um estudo iniciado em 2002 mostrou que a prevalência de DPOC, definida com espirometria, foi 15,8\% em indivíduos acima de 40 anos (14). Embora maior que a prevalência descrita na metaanálise global discutida acima, este valor é compatível com uma medida anterior, feita em Pelotas, que identificou uma prevalência de 15,2\% (15).

A prevalência da doença aumenta progressivamente com a idade, acompanhando a perda funcional pulmonar que ocorre em todos os indivíduos. No estudo realizado em São Paulo, a prevalência de DPOC foi 8,4\% nos indivíduos entre 40 e 49 anos; $16,2 \%$ na faixa entre 50 e 59 anos; e $25,7 \%$ nos indivíduos com 60 anos ou mais.

Dados do DATASUS* mostram que bronquite crônica e enfisema pulmonar foram responsáveis por cerca de 170.000 internações em 2007 no sistema público de saúde em todo o Brasil, representando $1,5 \%$ do total de internações em hospitais públicos.

O cigarro constitui o principal fator de risco para o desenvolvimento da doença. A incidência cumulativa pode dobrar ou triplicar com a exposição a este agente (16). Dados do DATASUS* mostraram que a prevalência de tabagismo na cidade de São Paulo foi $19,9 \%$ em 2002. No mesmo ano, a prevalência de DPOC na população tabagista da capital paulista foi $21,8 \%$. Os ex-fumantes tinham uma prevalência de DPOC de 15,6\%. Nos não fumantes, esta prevalência foi $12,5 \%$ (14). A exposição ao cigarro também 
está associada a uma maior queda da função pulmonar ao longo do tempo. A abstinência ao cigarro, por sua vez, reduz esta velocidade de declínio (3, 4).

A mortalidade e morbidade do DPOC é um sério problema de saúde pública global; em 1990 a DPOC era a sexta causa de morte mundial, mas é esperado ser a terceira mais comum causa de morte em 2020 (17). A prevalência de DPOC no médio prazo deve aumentar. Ainda que haja um programa eficiente que consiga reduzir a exposição à fumaça de cigarro, projeta-se que o envelhecimento populacional suplantará o efeito da redução deste fator de risco (18). Portanto, esta é uma doença que continuará a afetar grande parcela da população por vários anos.

De acordo com a Comunidade Européia de pesquisa em Saúde Respiratória (ECRHS) a DPOC pode ser o maior problema de saúde entre adultos jovens (19). Dessa forma, os custos com a doença são consideráveis (20). 


\subsection{Fisiopatologia}

\subsubsection{Desequilíbrio oxidante - antioxidante}

O estresse oxidativo, um desequilíbrio entre oxidantes e antioxidantes, está aumentado em pacientes com DPOC, principalmente durante exacerbações (21), e espécies reativas de oxigênio (ROS) contribuem para a fisiopatologia da doença (22).

O fumo, diretamente ou por meio das células inflamatórias, pode aumentar a concentração de oxidantes e também levar a uma redução da capacidade antioxidante pulmonar. Há associação entre dieta pobre em antioxidantes e o risco para o desenvolvimento de enfisema e detecta-se aumento de Isoprostano 8 , um produto do estresse oxidativo, no ar exalado e na urina de pacientes com DPOC $(23,24)$.

Assim, o estresse oxidativo pode ser uma via para o desenvolvimento da doença, no entanto, o exato papel desta via de lesão e sua relação com os mecanismos inflamatórios na fisiopatologia da DPOC ainda precisam ser melhor esclarecidos.

\subsubsection{Espécies reativas de oxigênio e estresse oxidativo}

A geração de espécies reativas de oxigênio nos pulmões é reforçada após exposição exógena a numerosos agentes químicos e físicos, que incluem poeiras minerais, ozônio, óxidos de nitrogênio, radiação ionizante e ultravioleta (25), e fumaça de cigarro (26).

A fumaça de cigarro é uma mistura altamente complexa de mais de 4.700 produtos químicos distribuídos nas fases aquosa, gasosa e de 
alcatrão do fumo. Na fase gasosa a fumaça é composta por altas concentrações de oxidantes de curta duração (>10 ${ }^{15}$ moléculas por puff) (26) como o ânion superóxido e o óxido nítrico. O óxido nítrico e o ânion superóxido reagem imediatamente à forma altamente reativa da molécula de peroxinitrito.

As espécies reativas de oxigênio (ROS) são moléculas muito instáveis formadas a partir da redução do oxigênio $\left(\mathrm{O}_{2}\right)$. Em concentrações moderadas, essas moléculas participam de funções importantes em nosso organismo como na mediação de processos de sinalização celular, eliminação de microorganismos invasores e modulação dos processos inflamatórios (27). O termo espécies reativas de oxigênio é um coletivo que inclui não somente radicais de oxigênio como o radical superóxido $\left(\mathrm{O}_{2}\right)$ ou hidroxila $(\mathrm{OH})$, mas, também, alguns derivados não radicalares, como o peróxido de hidrogênio $\left(\mathrm{H}_{2} \mathrm{O}_{2}\right)$ e o ácido hipocloroso (HOCl) (28). Dentre as principais espécies reativas de oxigênio estão: o ânion superóxido (-O2), o peróxido de hidrogênio $\left(\mathrm{H}_{2} \mathrm{O}_{2}\right)$, o radical hidroxila $(\mathrm{OH}-)$, e o óxido nítrico (NO). A mitocôndria e o complexo enzimático da NADPH-oxidase são considerados as principais fontes celulares de ROS no organismo (29).

Na mitocôndria a produção de ROS está associada à metabolização da glicose (30). Nesse processo, durante a fosforilação oxidativa, grande parte do oxigênio consumido é reduzido à água. Entretanto, uma fração pequena, porém significativa, de oxigênio consumido pode sofrer escape da cadeia transportadora de elétrons e ser transformado em ROS (31). Estima- 
se que dois a cinco por cento do oxigênio utilizado pela mitocôndria sejam convertidos em radicais livres (32).

Outra fonte celular de ROS, e tão importante quanto a mitocôndria, é através do complexo enzimático da NADPH-oxidase. A NADPH-oxidase é constituída por várias subunidades, estando algumas localizadas no citoplasma como a p47fox, p67fox e a p40fox e outras na membrana plasmática como a gp91fox e a p22fox 26. Quando a NADPH oxidase é estimulada, as subunidades do citoplasma p47fox, p67fox e p40fox são fosforiladas e migram para a membrana plasmática, onde estão os componentes gp91fox e p22fox, com os quais se associam. Ao mesmo tempo a subunidade rac2 se dissocia de seu inibidor e, também, migra para o complexo na membrana (29). Uma vez estando a associação de todos os componentes da NADPH oxidase completa, tem início a redução do oxigênio e formação do ânion superóxido, radical hidroxila e peróxido de hidrogênio.

A fase aquosa do condensado da fumaça de cigarro pode sofrer uma reciclagem redox por um período de tempo considerável no fluido de revestimento epitelial de fumantes. A fase de alcatrão da fumaça de cigarro contém radicais orgânicos, como os radicais semiquinona de longa duração, que podem reagir com oxigênio de modo a formar O2-, $\mathrm{OH}$ e $\mathrm{H}_{2} \mathrm{O}_{2}$ (33). Esta fase também possui um efetivo quelante de metais, onde o ferro é quelado para produzir alcatrão-semiquinona+alcatrão- $\mathrm{Fe}^{2+}$, que pode gerar continuamente peróxido de hidrogênio (34). 
O estresse oxidativo pode conduzir a peroxidação de lipídios de membrana, aumento nos íons de cálcio intracelular, ruptura do citoesqueleto e danos ao DNA (28).

As principais fontes celulares de espécies reativas de oxigênio no pulmão incluem não só neutrófilos, eosinófilos e macrófagos alveolares (35), mas também células epiteliais alveolares, células epiteliais e células endoteliais brônquicas (36-38).

\subsubsection{Sistema antioxidante}

Os pulmões são expostos diariamente a grandes quantidades de oxigênio e a desafios oxidativos, por isso é imperativo que esse órgão possua mecanismos de defesa: os antioxidantes endógenos.

Os principais antioxidantes não enzimáticos dos pulmões são a glutationa, vitaminas $\mathrm{C}$ e $\mathrm{E}$, beta-caroteno e ácido úrico e os enzimáticos são a superóxido dismutase (SOD), catalase e peroxidases. Estes antioxidantes são as primeiras linhas de defesa contra os oxidantes.

A superóxido dismutase (SOD) está essencialmente presente em todas as células do corpo e tem sido demonstrado que essa enzima desempenha um papel importante na proteção das células e dos tecidos contra o estresse oxidativo. As três grandes formas de SOD são relatadas com base em sua estrutura, localização, indutibilidade e íon de metal requerido e todas tem um mecanismo comum de dismutação do ânion superóxido para uma molécula menos potente, o peróxido de hidrogênio $\left(\mathrm{H}_{2} \mathrm{O}_{2}\right)$. 
A superóxido dismutase cobre, zinco (SODCuZn ou SOD1), é essencialmente localizada no citosol (39). Embora mais abundante do que a forma superóxido dismutase manganês (SODMn), não é induzivel na mesma medida (40). A SODCuZn é uma proteína homodimérica (MWt, 32,5 kDa) e requer tanto $\mathrm{Cu}$ quanto $\mathrm{Zn}$ em seu sítio ativo (41). O cobre é essencial para a atividade catalítica da enzima, e o zinco transmite estabilidade à estrutura da proteína (42). CuZn SOD é induzível e está expressa nas células epiteliais brônquicas, células epiteliais alveolares do tipo II, pneumócitos tipo II, fibroblastos, macrófagos alveolares e endotélio capilar dos pulmões (43, 44). No epitélio brônquico, a SODCuZn é altamente expressa em células epiteliais ciliadas. No pulmão humano, a expressão da SODCuZn tem sido encontrada no epitélio brônquico (45), pneumócitos tipo II, e macrófagos alveolares (46). A enzima antioxidante SODCuZn bem como, sua atividade total mostrou-se diminuída no epitélio das vias aéreas em asmáticos (47) e um aumento na produção do ânion superóxido foi observado em pacientes asmáticos (48). Cobaias pré tratadas com SOD recombinante mostraram proteção contra liberação de citocinas mediada por NF-KB induzida pela exposição à fumaça de cigarro e posterior inflamação leucocitária (49). Estudos recentes têm mostrado também baixa regulação de SODCuZn e SODMn em vias aéreas de asmáticos (50) e sugerem que o tratamento com SODCuZn humana recombinante ao nascimento pode reduzir a lesão pulmonar, resultando em melhora clínica mensurada no primeiro ano de vida (51). A sobrevivência dos animais foi associada aos níveis de SODMn, camundongos deficientes morreram entre os dias 10/21 após o nascimento 
de cardiomiopatia, acidose metabólica e neurodegeneração (52). Apenas $50 \%$ de atividade da SODMn tem sido relatada ser suficiente para a resistência normal à hiperóxia (53). No entanto, os estudos com camundongos transgênicos hiperexpressando SODMn têm mostrado resultados inconclusivos quanto à resistência à toxicidade ao oxigênio em condições hiperoxicas (54).

A superóxido dismutase manganês (SODMn ou SOD2) é considerada um dos mais importantes componentes antioxidantes de uma célula. É uma enzima homotetramerica ( $\mathrm{MWt}, 88 \mathrm{kDa}$ ) e exige manganês em seu centro ativo (42). SODMn constitui cerca de 10 a $15 \%$ do total das SODs e está localizada na mitocôndria de pneumócitos tipo II, macrófagos alveolares e epitélio brônquico em ratos e, pelo menos, nas células epiteliais brônquicas do pulmão de humanos (55). A SODMn é expressa em células de paredes das vias aéreas, nos septos de ductos alveolares e nas paredes arteriais adjacentes às vias aéreas. Citocinas inflamatórias tais como interleucina-1 e 6 , interferon- $\alpha$, fator de necrose tumoral - $\alpha$, fumaça de cigarro e hiperóxia induzem aumento na expressão de $\operatorname{SODMn}(52,56)$. A expressão de SODMn foi encontrada elevada em epitélio brônquico e alveolar de fumantes com doença pulmonar obstrutiva crônica comparada a indivíduos normais, provavelmente devido ao aumento da carga oxidante nos pulmões dos fumantes (57). Estudos demonstram que a SODMn está inativada nas vias aéreas de indivíduos asmáticos (devido à sua oxidação e nitração) o que induz apoptose epitelial. Além disso, a oxidação e a nitração da SODMn foram identificadas nas vias aéreas de asmáticos, correlacionando-se com a 
gravidade da doença (58). Mecanismos semelhantes ocorrem nas vias aéreas de doenças induzidas pelo cigarro e, portanto, a superexpressão de SODs e catalase pode proteger contra a lesão pulmonar induzida pelo cigarro.

A superóxido dismutase extracelular (SOD-EC ou SOD3) é a principal SOD extracelular do fluido pulmonar e dos espaços intersticiais de pulmões de ratos e humanos. A SOD-EC está presente nos vasos sangüíneos e vias aéreas. É uma glicoproteína tetramérica (MWt, 135 kDa) e exige Cu e Zn para realizar suas atividades (59). Caracteristicamente, SOD-EC exibe afinidade heterogênea à heparina (60), regulamenta a biodisponibilidade do óxido nítrico e modula os níveis de NO (61). A expressão de SOD-EC é induzida pelo interferon- $y$ e deprimida pelo fator de necrose tumoral- $\alpha$, fator de crescimento tumoral- $\beta$ e interleucina-1 $\alpha$ em fibroblastos (62). Macrófagos alveolares e neutrófilos podem expressar alta quantidade de SOD-EC sobre estimulação antigênica pelo lipopolissacaride (63). Em pulmões de seres humanos, a SOD-EC é expressa em células epiteliais brônquicas, células alveolares tipo II, macrófagos alveolares, condrócitos e células endoteliais pulmonares $(64,65)$. A maior localização da enzima foi encontrada na matriz extracelular, principalmente em torno dos vasos sangüíneos, vias aéreas, e nas regiões em torno dos alvéolos e dos capilares. SOD-EC em conjugação com glutationa peroxidase constituem a primeira linha de defesa contra oxidantes inalados.

As glutationa peroxidases são uma família de enzimas antioxidantes dependentes de selênio e enzimas antioxidantes independentes e podem 
ser divididas em dois grupos, celulares e extracelulares. Em geral, a glutationa peroxidase é uma proteína tetramérica ( $\mathrm{MWt}, 85 \mathrm{kDa}$ ), e exige quatro átomos de selênio vinculados que conferem sua atividade catalítica. $A$ glutationa peroxidase reduz o peróxido de hidrogênio a $\mathrm{H}_{2} \mathrm{O}$ pela oxidação da glutationa (GSH) (35). A redução da forma oxidada, dissulfurica da glutationa (GSSG), é em seguida, catalisada pela glutationa redutase através do ciclo da glutationa (66). A capacidade de reciclar GSH faz o ciclo GSH crucial para o mecanismo de defesa antioxidante de uma célula e impede o esgotamento dos tióis celulares (67).

Estas enzimas estão presentes no citosol da maioria das células. Outras variedades incluem fosfolípides, hidroperóxido, glutationa peroxidase (68) e glutationa peroxidase gastrointestinal (69). Uma forma de glutationa peroxidase extracelular dependente de selênio tem sido relatada no fluido de revestimento epitelial pulmonar e em outras células (70). Alguma atividade da glutationa peroxidase também foi encontrada nas mitocôndrias $(71,72)$. O fluido de revestimento epitelial alveolar contém uma quantidade muito elevada de glutationa peroxidase clássica e extracelular em consonância com uma elevada quantidade de GSH (73). Células epiteliais primárias brônquicas, macrófagos alveolares, e outras linhas celulares podem sintetizar glutationa peroxidase clássica e extracelular e também secretar glutationa peroxidase extracelular (70). A glutationa peroxidase clássica é induzida pela hiperóxia (74) e pela combinação de hiperóxia e fator de necrose tumoral - $\alpha$ (75). Os níveis de ambas as glutationas (clássica e extracelular) são diminuídos após a exposição ao ozônio, mas não pela 
exposição ao dióxido de nitrogênio (76). A GSH é considerada mais importante do que a catalase em condições fisiológicas. Além disso, o ciclo redox GSH tem a capacidade de metabolizar hidroperóxidos diferentes do peróxido de hidrogênio. Células epiteliais brônquicas primárias, macrófagos alveolares, e linhas celulares pulmonares sintetizam glutationa peroxidase clássica e extracelular que é secretada para o fluido de revestimento epitelial. Estas enzimas contribuem, cada uma, com cerca de metade da glutationa peroxidase no fluido de revestimento epitelial. A glutationa peroxidase extracellular tem atividade diminuida em crianças asmáticas comparadas a crianças normais (77). Em pacientes com fibrose cística, os níveis de GSH extracelular em vias aéreas inferiores, obtido por lavagem brônquica foram inferiores aos dos indivíduos sem fibrose cística (78). Em contraste, o escarro de indivíduos com fibrose cística contém altos níveis de antioxidantes, tais como GSH, glutationa peroxidase e catalase (79).

A glutationa peroxidase e a catalase reduzem o peróxido de hidrogênio em $\mathrm{H}_{2} \mathrm{O}$. O aumento de peróxido de hidrogênio lentamente inativa a SODCuZn. Portanto, catalase e glutationa peroxidase, por redução de peróxido de hidrogênio, conservam a SOD, e a SOD, por redução do anion superóxido, por sua vez, conserva a catalase e a glutationa peroxidase. Um baixo nível constante no estado da SOD, glutationa peroxidase e catalase, bem como de anion superóxido e peróxido de hidrogênio são, assim, mantidos por um mecanismo de "feedback".

A espécie reativa de oxigênio mais nociva é o radical hidroxila, que pode ser formado através da reação do ânion superóxido com o óxido nítrico 
para produzir peroxinitrito, que se decompõe para formar o radical hidroxila e também, nas reações de íons de metais de transição $(\mathrm{Fe} 2+)$ com o peroxido de hidrogênio (80) (Figura 1).

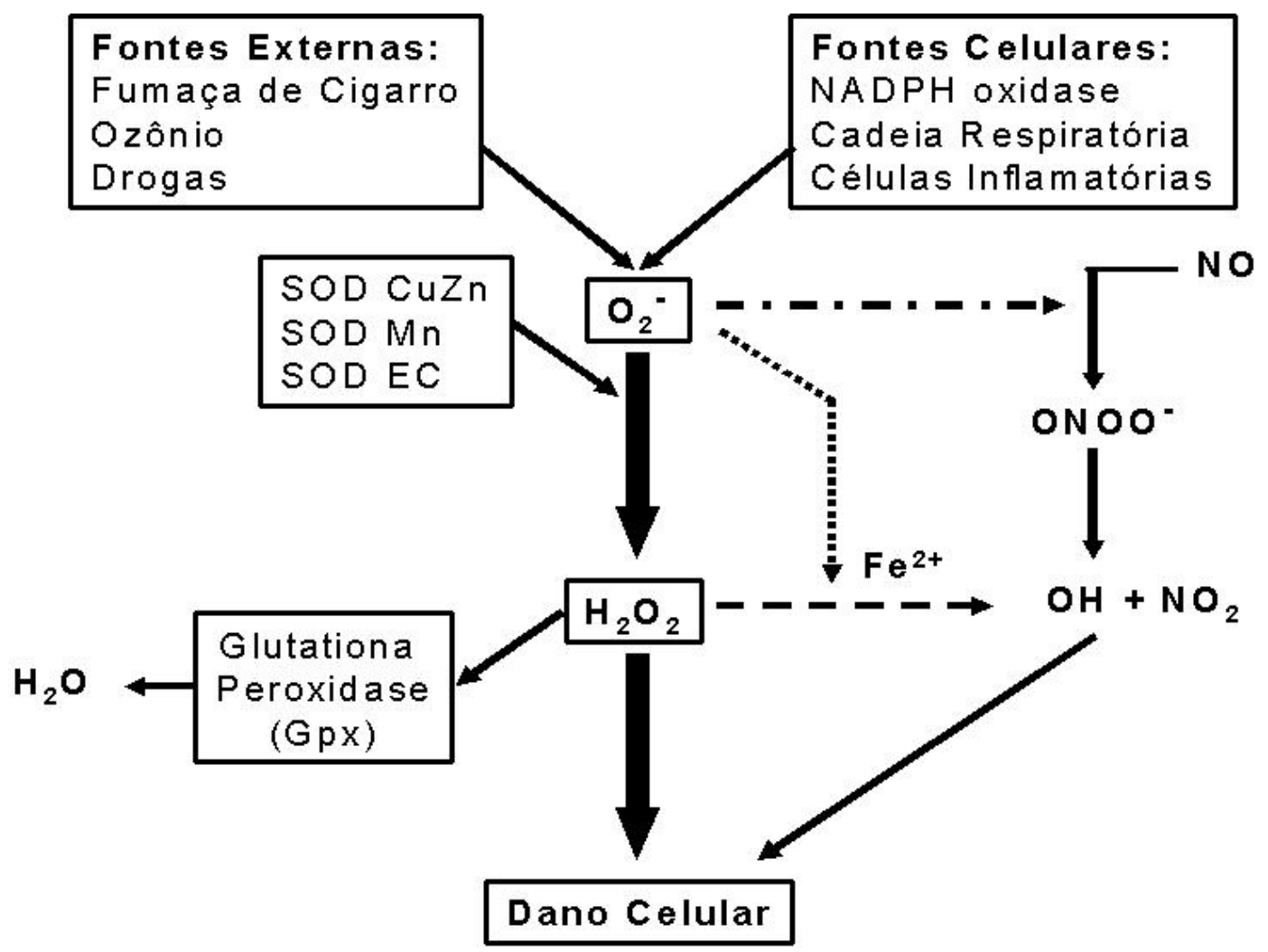

Figura 1 - Geração de espécies reativas de oxigênio e sistema de defesa antioxidante. Espécies reativas de oxigênio: $\mathrm{O}_{2^{-}}=$ânion superóxido, $\mathrm{NO}=$ óxido nítrico, $\mathrm{H}_{2} \mathrm{O}_{2}$ = peróxido de hidrogênio, $\mathrm{OH}=$ radical hidroxila, $\mathrm{NO}_{2}=$ dióxido de nitrogênio, NOO- peroxinitrito, $\mathrm{Fe}^{2+}=$ íon ferroso, Antioxidantes SOD $=$ Superóxido dismutase . $O$ peróxido de hidrogênio é gerado da dismutação do ânion superóxido pela SOD e a GPx reduz o peróxido de hidrogênio a $\mathrm{H}_{2} \mathrm{O}$ pela oxidação da glutationa. 


\subsubsection{Fatores genéticos}

DPOC é uma doença poligênica e um clássico exemplo de interação gene-ambiente. $O$ fator de risco genético mais bem documentado é a deficiência hereditária de a1-antitripsina. Este traço recessivo raro é mais freqüente em indivíduos de origem do norte europeu. O desenvolvimento prematuro e acelerado de enfisema panlobular e declínio na função pulmonar ocorrem em ambos, fumantes e não fumantes com a deficiência grave, entretanto em fumantes o risco é aumentado. Há considerável variação entre indivíduos na extensão e intensidade do enfisema e no declínio da função pulmonar. Apesar da deficiência de a1-antitripsina ser relevante para uma pequena parte da população mundial, ela ilustra a interação entre genes e exposição ambiental na DPOC e fornece um modelo de como outros fatores de risco genéticos podem ser considerados em contribuir para a DPOC (1).

Um significante risco familiar de obstrução ao fluxo aéreo tem sido observado em irmãos fumantes de pacientes com DPOC grave, sugerindo que fatores genéticos podem influenciar esta suscetibilidade. Análises ligadas à genética tem identificado genes de suscetibilidade à DPOC, incluindo o cromossomo 2q. Uma região no cromossomo $2 q$ (SERPINE2) foi apontada como um gene de susceptilidade à DPOC em um estudo populacional (973 pacientes com DPOC e 956 indivíduos controle). Outros estudos de associação genética tem implicado uma variedade de genes na patogênese da DPOC incluindo TGF-b (81), mEPHX1 (Smith, 1997) e TNFa (82). Entretando, os estudos genéticos têm se mostrado inconsistentes, e 
variantes genéticas funcionais que influenciem o desenvolvimento da DPOC não foram definitivamente identificadas (1).

\subsubsection{Desequilíbrio protease antiprotease}

O achado clínico por Laurell e Erikkson em 1963 em que os doentes com deficiência de a1-antitripsina tinham maior risco de desenvolver enfisema, combinado aos achados experimentais de Gross et al em 1965 de que a administração intratraqueal de papaína resultou em enfisema em ratos, formaram a base científica para a hipótese elastase - antielastase na patogênese do enfisema $(83,84)$. Hoje, 45 anos mais tarde, a hipótese elastase-antielastase ainda é uma teoria bastante discutida no desenvolvimento de enfisema, e os modelos animais de DPOC permanecem uma ferramenta experimental importante (84).

Existem evidências na literatura que apóiam a hipótese de que o principal mecanismo patogênico no enfisema seja um desequilíbrio nos sistemas de proteases e antiproteases. Segundo esta hipótese, a inalação de fumaça de cigarro induz um aumento no número de neutrófilos e macrófagos nos pulmões, que liberam enzimas proteolíticas. A liberação de proteases, não totalmente inibida pelas antiproteases, leva a proteólise do tecido conectivo pulmonar (mais especificamente elastina) e enfisema (85, 86).

O lavado broncoalveolar de pacientes com DPOC associado a grave deficiência de a1-antitripsina comparado a pacientes sem essa deficiência, 
mostrou diminuição na concentração de a1-antitripsina e aumento de neutrófilos, no entanto o LBA conseguiu inibir a elastase neutrofilica (87).

O papel patogênico da elastase neutrofilica no enfisema de indivíduos deficientes em a1-antitripsina é sustentado pela correlação do aumento da concentração de elastase em leucócitos com a intensidade do enfisema (88).

Várias enzimas presentes na matriz extracelular ou produzidas por células inflamatórias são capazes de fazer proteólise: MMP12, MMP9, elastase neutrofílica, catepsina K, L, S, proteinase $3(23,89-93)$. Se houver um aumento na produção destas enzimas, suplantando o efeito das antiproteases, haverá destruição de septos alveolares.

Por outro lado, um maior efeito das antiproteases pode prevenir o desenvolvimento do enfisema pulmonar. A administração intraperitoneal de a1-antitripsina pode impedir a quebra de tecido conectivo que se segue à exposição aguda ao cigarro (94). Outras enzimas com papel de antiproteases, como SLPI (inibidor das leucoproteases) e TIMPs (inibidores da MMP), podem reduzir a quebra de fibras elásticas e impedir a destruição do parênquima pulmonar (23).

A base da teoria protease / anti-protease da patogenia do enfisema é o desenvolvimento de um aumento na carga de elastase nos pulmões e uma "deficiência" funcional de $\alpha-1$ antitripsina, devido a sua inativação pelos oxidantes. Supõe-se que esta "deficiência" funcional de $\alpha-1$ antitripsina seja devido à sua inativação pela oxidação da metionina no seu sítio ativo por oxidantes da fumaça do cigarro. Esta é uma simplificação, mas também outras proteases e antiproteases são susceptíveis aos oxidantes presentes 
na fumaça de cigarro. Alguns trabalhos mostraram redução da atividade funcional da a1-antitripsina no lavado broncoalveolar (LBA) de fumantes sem deficiência de a1-antitripsina comparados a não-fumantes (95, 96). Entretanto, estudos avaliando a inativação da a1-antitripsina em fumantes crônicos não conseguiram produzir um claro apoio a esta hipótese (97-100).

\subsubsection{Inflamação pulmonar}

O tabagismo é a maior causa de inflamação crônica pulmonar e esta inflamação não para após a cessação do fumo (101-103).

O desequilíbrio protease antiprotease pode ser produzido por uma resposta inflamatória ao agente agressor inalado. Várias células inflamatórias são encontradas nas vias aéreas, no lavado broncoalveolar e no parênquima pulmonar dos pacientes, em diferentes fases da doença. Porém, os tempos de surgimento de cada uma destas células, seu papel no desenvolvimento da doença e suas inter-relações não são suficientemente conhecidos.

Os neutrófilos estão presentes em pacientes com DPOC em fases mais avançadas e podem estar relacionados à produção de muco, que é potencialmente estimulada por muitas das proteases neutrofílicas (proteinase 3, catepsina G e elastase neutrofílica). Estas proteases, bem como a MMP8 e MMP9, também produzidas por neutrófilos, podem destruir o parênquima pulmonar e as fibras elásticas.

Detecta-se a presença de vários fatores quimiotáticos para neutrófilos nos pulmões de indivíduos expostos ao cigarro: LTB4, IL8, GROa, ENA78. O 
aumento do número de neutrófilos no sangue periférico correlaciona-se com a queda de FEV1 (104) e o número destas células na biópsia brônquica e escarro induzido está associado à gravidade da doença (105). Muitos autores mostraram aumento no número de neutrófilos em pacientes portadores de DPOC (106-108). Estudos em animais mostraram que a presença do neutrófilo e da elastase neutrofílica parece ser importante para o desenvolvimento do enfisema $(109,110)$.

No entanto, alguns pesquisadores não conseguiram encontrar aumento de neutrófilos nos pulmões dos pacientes com DPOC quando comparados a fumantes assintomáticos (111-114). Ainda, pode haver uma associação negativa entre o número de neutrófilos no pulmão e a destruição do parênquima (115). Portanto, com alguns dados conflitantes, o papel do neutrófilo no desenvolvimento do enfisema é ainda obscuro.

Os macrófagos são encontrados mais freqüentemente em estudos de pacientes com DPOC, o que sugere que podem ser uma célula central no desenvolvimento da doença. Ativados por substâncias do cigarro, podem secretar IL8, TNFa, MCP1 (peptídeo quimiotático para monócitos), LTB4 e espécies reativas de oxigênio. Ainda podem secretar MMP2, MMP9, MMP12, elastase neutrofílica e catepsinas K, L e S. Assim, podem ser mediadores do processo lesivo iniciado pelas toxinas do cigarro, bem como efetores da lesão pulmonar, produzindo destruição do parênquima (23).

Há aumento do número de macrófagos no parênquima, glândulas submucosas e lavado broncoalveolar de pacientes com DPOC (107, 111, 113, 116). Ainda, a presença de elastase macrofágica parece ser necessária 
para o desenvolvimento do enfisema em alguns modelos experimentais (117).

Há evidências de cooperação entre macrófago e neutrófilo na geração do processo lesivo pulmonar. Aparentemente, as duas células são necessárias, em um modelo agudo, para produzir a quebra do tecido conectivo (110).

No entanto, alguns autores não conseguiram mostrar aumento de macrófagos em fumantes sintomáticos quando comparados a fumantes assintomáticos $(114,116)$. Embora esta diferença possa ocorrer por variação amostral, isto dificulta a interpretação dos resultados e a criação de um modelo inflamatório que explique adequadamente o desenvolvimento da doença.

Por sua vez, os linfócitos T CD4 e CD8 são amplamente encontrados nos pulmões dos pacientes com DPOC $(105,106,111,112,114,118)$. Aparentemente há predomínio dos clones Th1, produtores de INFY. Algumas análises feitas em infiltrados de linfócitos B mostram que esta população de células é predominantemente mono ou oligoclonal.

O papel dos linfócitos nesta doença não é bem esclarecido. Podem estar presentes como resposta a agentes microbiológicos, que colonizam ou infectam freqüentemente as vias aéreas inferiores destes pacientes. Podem ser estimulados, também, por alguns dos antígenos presentes na fumaça do cigarro. E, ainda, é possível que o processo de lesão pulmonar exponha alguns auto-antígenos, desencadeando uma resposta linfocitária local contra estes (119). 
Eosinófilos são mais raramente encontrados em paciente com DPOC e sua presença pode marcar a coexistência de asma (120). Podem estar presentes nas exacerbações da doença. No entanto, é possível que sua presença tenha sido mascarada por um erro metodológico, uma vez que podem degranular ao serem estimulados pela elastase neutrofílica e, assim, serem confundidos com neutrófilos (121).

\subsubsection{Participação de fatores de crescimento}

Vários fatores de crescimento produzem alterações que fazem parte da instalação da DPOC. Como já descrito anteriormente, o TGF $\beta$ pode ser produzido no epitélio (122), estimulado pelo contato deste com as toxinas inaladas. Esta citocina pode induzir a deposição de fibras colágenas na via aérea, contribuindo para sua obstrução e redução ao fluxo aéreo. O TGF $\beta$ pode induzir a proliferação das células epiteliais, o que é muitas vezes observado nos pacientes com DPOC.

O VEGF (fator de crescimento endotelial) também pode participar do desenvolvimento da DPOC. O bloqueio do seu receptor (VEGFR) pode desencadear uma lesão pulmonar com alargamento dos espaços aéreos. Acredita-se que, na ausência deste fator, ocorra apoptose de células dos vasos pulmonares, com conseqüente destruição do parênquima pulmonar $(123,124)$.

A apoptose de células pulmonares, induzida pelo bloqueio do VEGFR ou desencadeada pelo processo inflamatório ou estresse oxidativo, pode ser um dos grandes mecanismos pelos quais a doença pulmonar se instala. Mas 
é também possível que a apoptose seja diretamente induzida por outras vias ainda não conhecidas. Alguns autores entendem o pulmão como um órgão em constante reparo. Segundo este modelo, deve haver um balanço entre a taxa normal de apoptose das células pulmonares e sua renovação. O cigarro poderia afetar a renovação celular, impedindo o reparo adequado, o que produziria a redução da área de parênquima pulmonar observada nos pacientes (125-127).

Portanto, apesar de haver vários dados que confirmem a hipótese inflamatória e o desequilíbrio protease antiprotease, há vários outros mecanismos que podem levar à DPOC. A maneira pela qual eles interagem é ainda pouco clara. É possível que alguns não participem da fisiopatologia da DPOC no homem, mas estejam apenas presentes em modelos animais. No entanto, os futuros avanços no entendimento desta enfermidade talvez nos levem a concluir que algumas destas vias sejam de fato participantes e, possivelmente, mais importantes para o desenvolvimento da doença do que os mecanismos hoje conhecidos.

\subsection{Alterações da mecânica pulmonar}

A principal alteração funcional da DPOC é a redução do fluxo aéreo. Há vários mecanismos que podem produzir esta alteração e podemos dividilos em fatores que aumentam a resistência de vias aéreas e fatores que diminuem a força elástica pulmonar.

Nas vias aéreas, pode haver espessamento epitelial, formação de folículos linfóides e deposição de colágeno, o que reduz seu diâmetro interno 
e sua capacidade de distensão (23). Estes fatores podem aumentar a resistência de vias aéreas, produzindo a redução de fluxo observada nos pacientes. O aumento da secreção de muco também pode contribuir para esta redução do fluxo aéreo e, em fases avançadas da doença, correlacionase com a mortalidade dos pacientes (128, 129). Ainda, a destruição da arquitetura pulmonar pode alterar a disposição normal das vias aéreas, contribuindo para o aumento da resistência destas (23).

Por outro lado, o pulmão com destruição de parênquima e fibras elásticas apresenta redução da sua elastância, produzindo um menor fluxo expiratório para uma mesma condutância. No entanto, é improvável que esta destruição do parênquima explique isoladamente a redução do fluxo aéreo do paciente, mesmo quando intensa. As alterações anatômicas em vias aéreas, aumentando a resistência desta, parecem ser predominantes na limitação ao fluxo aéreo.

\subsection{Histopatologia}

A evolução da definição de DPOC acompanhou a evolução das descrições histológicas da doença. Na primeira metade do século XX predominava o conceito da destruição da arquitetura pulmonar observada pelos patologistas. Com o tempo, a definição da doença foi progressivamente incorporando as alterações em vias aéreas.

A definição atual envolve alterações histológicas tanto em grandes como em pequenas vias aéreas e espaços alveolares. Nas grandes vias aéreas, encontramos hiperplasia de células caliciformes e aumento de 
glândulas mucosas. Estas alterações são compatíveis com o quadro clínico de tosse e produção de muco, mas não se correlacionam com a piora da função pulmonar. Podemos observar a infiltração de neutrófilos, macrófagos e linfócitos, principalmente em fases mais avançadas da doença (130).

Nas vias aéreas menores, também há infiltrado inflamatório, predominando macrófagos nas fases iniciais da doença e neutrófilos em fases mais avançadas. Pode haver metaplasia das células caliciformes e substituição das células de Clara, produtoras de surfactante, por células secretoras de muco. Pode haver ainda deposição de colágeno na parede celular e hipertrofia da musculatura lisa. Estes fatores contribuem para a obstrução da via aérea, juntamente com o edema, a produção de muco e o infiltrado inflamatório.

No parênquima pulmonar observa-se a destruição heterogênea de diversas áreas, com infiltrado inflamatório de macrófagos, neutrófilos e linfócitos. Os macrófagos parecem estar presentes nas fases mais iniciais da doença (131), enquanto os neutrófilos aparecem mais tardiamente. A destruição de pequenas vias aéreas pode também contribuir para aumentar a resistência respiratória por reduzir o diâmetro transversal total do sistema condutor de ar.

A destruição de fibras elásticas que acompanha o desenvolvimento do enfisema também pode contribuir para intensificar a obstrução da via aérea. As fibras elásticas ancoradas aos bronquíolos exercem uma tração radial, aumentando seu diâmetro. Perdida esta tração pela quebra das fibras elásticas, a obstrução ao fluxo aéreo fica ainda mais proeminente (130). 


\subsection{Modelos experimentais de DPOC}

Com o objetivo de melhor compreender a evolução da doença e encontrar medidas terapêuticas, diversos modelos animais de DPOC foram desenvolvidos em diferentes espécies.

A instilação pulmonar de enzimas elastolíticas, como elastase neutrofilica, elastase pancreática porcina, papaína ou proteinase 3 é capaz de induzir enfisema em diversos modelos animais. $O$ alargamento dos espaços aéreos que se segue à instilação de elastase surge em cerca de um mês, estabilizando-se a seguir. Há recrutamento agudo de neutrófilos e subagudo de macrófagos (84). A instilação de papaína também leva ao desenvolvimento de enfisema em cerca de um mês, com concomitante formação de novas fibras elásticas no parênquima pulmonar.

Camundongos geneticamente modificados também podem desenvolver enfisema, embora isto algumas vezes ocorra por uma incompetência do desenvolvimento pulmonar e não por uma destruição do pulmão maduro. Camundongos "Tight Skin" e "Pallid Mice" podem desenvolver alargamento dos espaços aéreos por apresentarem dificuldade na formação de fibras elásticas ou produzirem a1-antitripsina em menor quantidade $(132,133)$. Diversos animais "knockout" para determinadas proteínas, como PDGFA (fator de crescimento derivado de plaquetas A), FGFR (receptor do fator de crescimento de fibroblastos), fibulina, elastina e outras, podem sofrer deficiência do processo de alveolização, com alargamento dos espaços aéreos no pulmão ainda não maduro. Em outros modelos, usando animais deficientes em TIMP3 (inibidor tecidual das 
metaloproteinases) ou proteína surfactante $D$, o desenvolvimento do alargamento dos espaços aéreos ocorre após o nascimento do animal. Modelos de superexpressão de determinadas proteínas, como IL13, INFY e MMP1 (colagenase humana intersticial), também podem produzir enfisema (134).

Por outro lado, algumas deficiências protéicas podem proteger o animal do desenvolvimento do enfisema induzido por algum agressor. Isto ocorre nas deficiências de MMP12 (metaloproteinase 12), receptor tipo 1 da IL1 $\beta$ e receptores tipo 1 e 2 do TNFa (134).

O modelo mais próximo da doença humana permanece a inalação de fumaça de cigarro, uma vez que esta é a principal substância tóxica que causa DPOC em seres humanos (135). Diversos modelos de DPOC induzida por cigarro já foram criados, usando cães, cobaias, coelhos, ratos e camundongos (84). Os modelos com camundongos parecem ser particularmente úteis, pois permitem estudos dos mecanismos responsáveis pelo desenvolvimento da doença, já que há disponibilidade de marcadores de citocinas, bem como a possibilidade de obtenção de linhagens geneticamente modificadas para a avaliação do desenvolvimento da doença em condições biológicas distintas.

No entanto, a transposição dos resultados obtidos em camundongos para a doença humana requer cuidado, já que há grandes diferenças entre as espécies. Os camundongos respiram obrigatoriamente pelo nariz e a maioria de suas células epiteliais nasais são olfatórias, com poucos cílios. Assim, podem ter menor eficiência na capacidade de filtrar partículas 
inaladas. Estes animais têm poucas glândulas submucosas, localizadas principalmente na traquéia e não têm verdadeiras células caliciformes, mas apresentam células de Clara e células epiteliais ciliadas presentes em toda a via aérea. A árvore brônquica do camundongo tem um menor número de ramificações que a de seres humanos (84).

Em modelos animais, o desenvolvimento do enfisema pulmonar medido pelo Intercepto Linear Médio (diâmetro médio dos espaços aéreos $L m$ ), requer vários meses de exposição. A maioria dos protocolos de DPOC induzido por exposição de camundongos à fumaça de cigarro utiliza períodos de exposição entre 6 e 12 meses (110). Portanto, é necessária uma exposição durante grande parte da vida do animal para que haja a instalação da doença.

Há poucos modelos que mostraram enfisema com tempos de exposição menores. Kasagi (136) conseguiu demonstrar um aumento de Lm com 2 meses de exposição ao cigarro, usando um camundongo com uma taxa de envelhecimento acelerada. Bartalesi (137) mostrou um discreto aumento no Lm com 3 meses de exposição para animais C57BI6 e DBA/2, que têm um menor poder antioxidante. Takubo (138) mostrou o aumento de Lm em 4 meses de exposição ao cigarro em camundongos "Pallid mice", que têm menor concentração de a1-antitripsina. Por sua vez, os animais C57BI6 apenas desenvolviam aumento do Lm com 24 semanas de exposição $(137,139)$.

Os modelos de exposição ao cigarro mostram que os camundongos suportam bem a exposição à fumaça por cerca de um ano, tolerando níveis 
de carboxihemoglobina de 10-14\% (117). Em 2 meses podem desenvolver alterações epiteliais com infiltrado inflamatório. Em 24 semanas de exposição, podem apresentar alargamento de espaços aéreos e uma histologia semelhante à do enfisema humano (84).

Assim, os modelos experimentais são importantes ferramentas para o entendimento da doença e podem auxiliar na descoberta de medidas terapêuticas.

\subsection{Atividade física aeróbia}

Uma atividade física é considerada aeróbia quando a maior parte da demanda energética é suprida através do metabolismo aeróbio $(140,141)$. Diretrizes de saúde pública sobre atividade física publicadas pela Universidade Americana de Medicina do Esporte recomendam um mínimo de 30 minutos diários de atividade física de intensidade moderada a fim de manter ou desenvolver aptidão idependentemente da idade (142). Aqueles que não cumprem esses requisitos mínimos são considerados insuficientemente ativos e apresentam maior risco para morbidade e mortalidade (143-147).

A atividade física aeróbia realizada de maneira sistemática e regular desencadeia uma série de adaptações crônicas benéficas em todo o organismo, tais como: redução da pressão arterial e da freqüência cardíaca de repouso em indivíduos hipertensos $(148,149)$, aumento do consumo máximo de oxigênio $(140,141)$, aumento da massa muscular e densidade óssea (140), melhora da resposta imunológica (se a atividade for 
predominantemente realizada em intensidade leve ou moderada) (150) e aumento da expressão e atividade de enzimas anti-oxidantes (151). O exercício aumenta a resistência contra o estresse oxidativo, proporcionando uma maior proteção (152-154).

Estudos epidemiológicos têm demonstrado que o exercício diminui a incidência de doenças associadas ao estresse oxidativo (155). Este fenomeno não é um paradoxo, mas é um resultado da adaptação induzida pelo exercício. O processo de adaptação envolve ativação do sistema antioxidante e influencia a transcrição redox, e assim a expressão dos genes e montagem de proteínas. Portanto, baixos níveis de ROS induzida por este processo de adaptação, evocado pelo exercício, criam um sistema que se assemelha à hormese. A teoria da hormese afirma que os sistemas biológicos respondem em uma curva em forma de sino para a exposição a substâncias químicas, toxinas e radiação. Na toxicologia, hormese é um fenômeno dose-resposta caracterizado por uma baixa dose de estímulo e de uma alta dose de inibição, resultando em uma forma de um J-invertido em forma de $U$, uma curva dose resposta não monotônica (156).

Agudamente o exercício aumenta o metabolismo oxidativo, e isso produz uma ambiente pró-oxidante (157). Em contrapartida, quando o exercício é repetido, o corpo se adapta a este estresse de tal forma que ele possa reagir rapidamente, para que o estresse oxidativo possa ser eliminado ou reduzido antes que provoque danos à estrutura celular. Assim, as adaptações a um exercício regular parecem ter uma proteção antioxidante e 
pode exercer um importante papel na redução da incidência de doenças associadas à produção de ROS (158).

Os efeitos antiinflamatórios da atividade física aeróbia têm sido extensivamente investigados (5). De maneira geral, há um consenso na literatura de que a atividade aeróbia de alta intensidade e longa duração desencadeia uma resposta pró-inflamatória enquanto que as atividades de intensidade leve e moderada e média ou longa duração desencadeiam uma resposta antiinflamatória $(5,159,160)$. Grande parte dos efeitos imunomodulatórios da atividade física aeróbia têm sido demonstrados em casos de aterosclerose, diabetes, câncer de cólon e de mama, e de doenças cardíacas isquêmicas (5). Esses estudos demonstram que essas respostas são reguladas por inúmeras citocinas e/ou quimiocinas dentre elas: IL-1, TNF-a, IL-6, IL-8, MCP-1, NAP-1, G-CSF (5, 159, 160). Aoi e colaboradores (161) sugerem que a inflamação aguda ocasionada pelo exercício físico de alta intensidade pode ser provocada pelo aumento do estresse oxidativo que proporciona uma intensa migração de fagócitos para a musculatura utilizada durante a atividade. A atividade física aeróbia é capaz de modular tanto o sistema imune inato quanto o adaptativo (162). Os mecanismos que modulam essas respostas são basicamente dependentes dos efeitos hormonais (163), metabólicos (164) e mecânicos (165). Embora o exercício seja normalmente classificado como um estímulo estressante cabe esclarecer que normalmente ocorrem duas respostas ao exercício: a resposta aguda e a adaptação crônica (162, 166, 167). De acordo com Costa Rosa, "A resposta aguda é reação transitória ao estresse, enquanto o 
estímulo crônico gera a resposta de adaptação crônica ao exercício, que habilita o organismo a tolerar de maneira mais adequada o estresse" (162).

\subsubsection{Atividade física aeróbia e DPOC}

A atividade física aeróbia oferece proteção contra as causas de mortalidade, primariamente pela proteção contra aterosclerose, diabetes tipo 2, câncer de colon e de mama (Blair), além de o treinamento físico ser efetivo no tratamento de pacientes com doença cardíaca isquêmica (168), falência cardíaca (169), diabetes tipo 2 (170) e DPOC (171).

Os resultados benéficos de programas de reabilitação pulmonar para pacientes com DPOC são bem documentados (171-174) e esses programas tem sido recomendados como um meio auxiliar efetivo para o tratamento de pacientes com DPOC.

Os mais proeminentes efeitos da reabilitação pulmonar em pacientes com DPOC são a melhora da percepção do seu estado de saúde, melhora na qualidade de vida e mudança psicológica associada ao bem estar (175180).

O estudo de Garcia-Aymerich e colaboradores (11) foi o primeiro estudo prospectivo baseado em uma amostra da população a mostrar que a prática de atividade física de moderado ou alto grau por fumantes ativos reduz o risco de desenvolver DPOC comparado ao grupo que realizava pouca atividade física.

Portanto, uma vez que a DPOC é uma doença pulmonar inflamatória crônica e que a atividade física aeróbia apresenta efeitos antiinflamatórios e 
imunoreguladores, acreditamos ser importante estudar os efeitos da atividade física no desenvolvimento da doença em um modelo experimental de exposição à fumaça de cigarro em camundongos. Além, de não termos encontrado qualquer estudo publicado que tivesse esse mesmo objetivo. 
MÉTODOS 


\section{MÉTODOS}

\subsection{Animais}

O estudo foi aprovado pela Comissão de Ética para Análises de Projetos de Pesquisa da Diretoria Clínica do Hospital das Clínicas e da Faculdade de Medicina da Universidade de São Paulo (CAPPesq -FMUSP), Protocolo $\mathrm{n}^{\circ}$ 0341/08. Os animais foram manejados de acordo com as orientações para cuidados com animais de laboratório, publicadas pelo $\mathrm{NIH}$.

Utilizamos camundongos C57BI6, machos, adultos jovens, obtidos do biotério central da Faculdade de Ciências Médicas da UNICAMP. Os animais tinham idades entre 6 a 8 semanas de vida ao saírem do biotério central e passaram por um período de ambientação de 2 semanas no biotério do laboratório (LIMs-20, 05 e 61) e mantidos em condições controladas de temperatura $\left(22-25^{\circ} \mathrm{C}\right)$ e luminosidade (ciclo $12 \mathrm{~h}$ claro/12h escuro), e $70 \%$ de umidade relativa. A alimentação constou de água e ração (Purina Labina®, São Paulo, Brasil) "ad libitum”.

Utilizamos camundongos C57BI6 por terem sido usados em outros modelos de enfisema e apresentarem maior susceptibilidade aos efeitos da fumaça de cigarro (181).

\subsection{Protocolo experimental}

Durante o período do protocolo experimental, os animais foram mantidos no biotério do laboratório em gaiolas próprias. Foram levados ao laboratório cinco dias por semana para a realização das exposições, por um 
período de 24 semanas. No biotério, os animais recebiam água e ração apropriada sem restrições.

\subsubsection{Grupos experimentais}

Os animais foram divididos aleatoriamente em 4 grupos, de acordo com o protocolo de exposição a que seriam submetidos:

- Grupo Controle - exposto a ar sintético por um período de 24 semanas e não realizou treinamento físico aeróbio $(n=33)$;

- Grupo Fumo - exposto a fumaça de cigarro por um período de 24 semanas e não realizou treinamento físico aeróbio $(n=40)$;

- Grupo Exercício - exposto a ar sintético por um período de 24 semanas e realizou treinamento físico aeróbio $(n=41)$;

- Grupo Fumo/Exercício - exposto a fumaça de cigarro por um período de 24 semanas e realizou treinamento físico aeróbio $(n=40)$.

O período de 24 semanas de exposição foi escolhido porque é suficiente para promover o aparecimento de enfisema pulmonar (137).

Devido à longa duração do protocolo experimental, alguns animais que realizavam treinamento físico aeróbio tiveram lesões na cauda ou nas patas, durante o treinamento na esteira e por isso foram excluídos no decorrer do protocolo. Devido à perda de animais ao longo do tempo quatro subgrupos de animais foram iniciados em momentos diferentes. Cada subgrupo continha todos os grupos: Controle, Fumo, Exercício e Fumo/Exercício. O número total de animais que iniciaram o protocolo 
experimental foi explicitado acima ao se descrever os grupos experimentais e o número de animais utilizado em cada avaliação será explicitado na descrição de cada método de avaliação.

\subsection{Exposição à fumaça de cigarro}

A inalação com fumaça de cigarro foi realizada em uma câmara inalatória por 30 minutos ao dia, 5 dias por semana, até que os animais fossem sacrificados ao final de 24 semanas de exposição.

A exposição foi realizada em uma caixa de plástico de $28 \mathrm{~L}$ (aproximadamente $40 \times 27 \mathrm{~cm}$ na base, com altura de $26 \mathrm{~cm}$ ), no interior de uma capela (182). O interior da caixa foi dividido em duas regiões com uma tela de metal para mantermos os grupos de camundongos separados. $\mathrm{Na}$ parte superior, colocamos um pequeno ventilador para homogeneizar o ar no interior da caixa. Havia uma saída de ar e duas entradas: uma para entrada de ar sintético e outra para fumaça de cigarro.

O fluxo na entrada de ar sintético era controlado por um fluxômetro conectado a um torpedo de ar comprimido e era mantido em 1,5 I/min. A segunda entrada da caixa recebia uma mistura de ar sintético e fumaça de cigarro, que era aspirada por um sistema de Venturi conectado a um cigarro aceso. O fluxo laminar de ar sintético, passando por uma região de menor diâmetro, era acelerado, com conseqüente redução da pressão neste ponto (efeito Venturi), permitindo a aspiração da fumaça do cigarro. A redução na pressão que ocorre no ponto de redução do diâmetro do tubo é dependente do fluxo de ar mantido. Assim, controlando o fluxo de ar sintético na segunda 
entrada, controlavamos também a quantidade de fumaça de cigarro que era aspirada para a tubulação e enviada para o interior da caixa. Isto nos permitia regular a concentração de monóxido de carbono (CO) mantida na caixa, o que era medido por um sensor de CO (Toxi/Oxy Pro, Biosystems, Connecticut, EUA) que permaneceu no interior da câmara até que a concentração de fumaça no ar inalado pelos animais ficasse aproximadamente constante. Estabeleceremos uma concentração de $\mathrm{CO}$ em torno de $250 \mathrm{ppm}$, baseados em estudos previamente realizados com inalação de fumaça de cigarro para induzir tumor pulmonar (183).

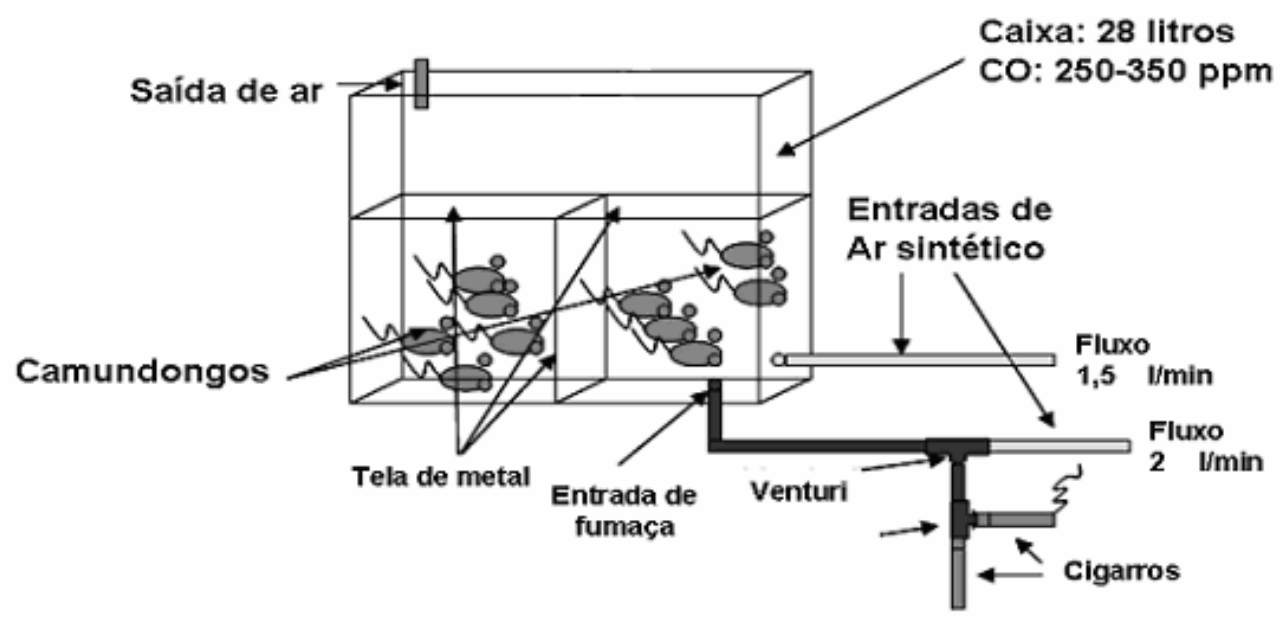

Figura 2 - Esquema ilustrativo da caixa de exposição à fumaça de cigarro. Os animais do grupo Fumo e Fumo/Exercício foram mantidos foram mantidos na caixa de exposição durante 30 minutos ao dia, cinco dias por semana, durante 24 semanas (adaptado de Biselli, 2008) (182).

Os animais alocados para receber exposição à fumaça de cigarro (grupos Fumo e Fumo/Exercício) foram mantidos na caixa de exposição 
durante 30 minutos, nos dias de exposição. Os animais restantes (grupos Controle e Exercício) permaneceram em suas gaiolas.

Após alguns testes iniciais, escolhemos manter o fluxo fixo de ar sintético na segunda entrada aproximadamente em 1,5 L/min. Isto produzia concentrações de CO variando entre 250 e 350 ppm, na maioria das medidas. Não podíamos manter o sensor de CO constantemente no interior da caixa, pois este aparelho perdia sua precisão com o tempo, por não ter sido desenvolvido para suportar longos períodos de uso.

Os cigarros utilizados foram da marca Derby Vermelho (Souza Cruz) cuja composição de Alcatrão é de 10 mg/cigarro, de Nicotina 0,8 mg/cigarro e de monóxido de carbono de $10 \mathrm{mg} /$ cigarro. Os cigarros foram colocados em uma tubulação ligada à parte lateral do Venturi, para que sua fumaça fosse aspirada, e foram trocados antes que seu filtro começasse a queimar. Em cada dia de exposição, cerca de 12 cigarros foram consumidos, para mantermos a concentração de CO desejada no interior da caixa por 30 minutos.

Os níveis de carboxi-hemoglobina não foram monitorados em todos os animais do experimento, já que para tanto seria preciso coletar grande parte de seu sangue. Dosamos a carboxi-hemoglobina em animais separados, submetidos ao mesmo protocolo: 30 minutos de exposição na caixa mantendo-se concentrações de CO entre 250 e 350 ppm. Nestes animais, os níveis de carboxi-hemoglobina foram aproximadamente de $10 \%$. Todos os camundongos toleraram as exposições a estes níveis de CO pelo 
período do protocolo sem sinais de desconforto respiratório e sem manifestações aparentes de doença.

\subsection{Treinamento físico aeróbio e teste físico}

O treinamento físico aeróbio foi realizado em esteira ergométrica

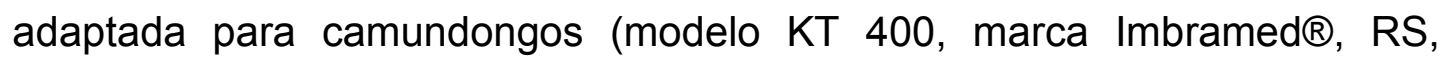
Brasil), por um período de 24 semanas (Figura 3).

$\mathrm{Na}$ semana anterior ao início do treinamento, os animais foram submetidos a três dias de adaptação na esteira ergométrica que constava de 10 minutos de atividade a uma velocidade de $0,2 \mathrm{Km} / \mathrm{h}$. Quarenta e oito horas após o terceiro dia de adaptação, os animais foram submetidos a um teste de esforço máximo. O teste consistiu de cinco minutos de aquecimento a uma velocidade de $0,2 \mathrm{Km} / \mathrm{h}$ que era aumentada em $0,1 \mathrm{Km} / \mathrm{h}$ a cada 2,5 minutos até a exaustão dos animais. 
(A)

(B)
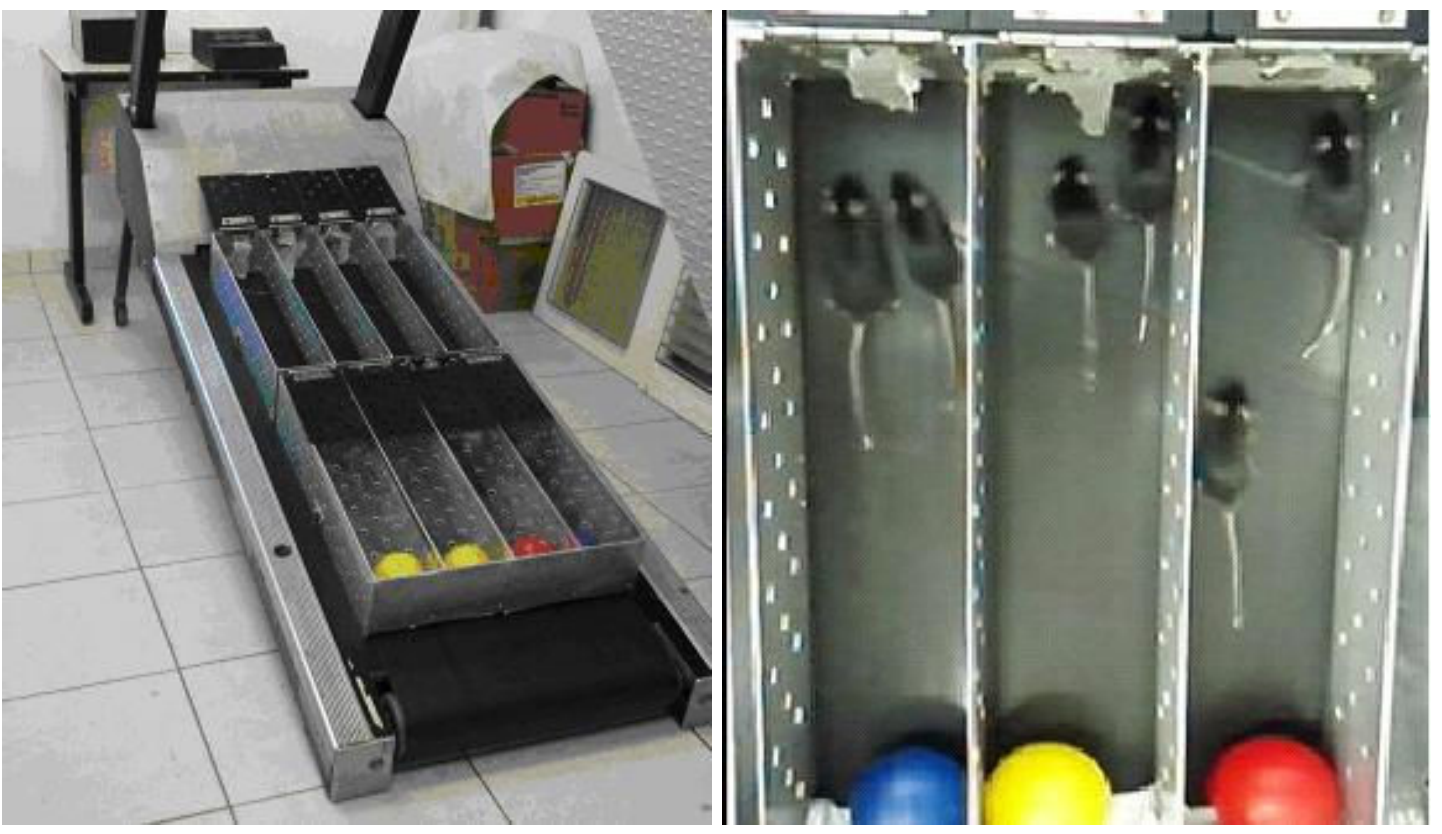

Figura 3 - (A) Foto da esteira ergométrica com inclinação de $25 \%$ e adaptada com 8 raias para a utilização no treinamento físico aeróbio de camundongos; (B) Foto aproximada das raias.

Os animais foram considerados exaustos quando não conseguiam permanecer correndo mesmo após dez estímulos mecânicos gentis. A intensidade utilizada para o treinamento foi moderada e foi calculada em $50 \%$ a partir da velocidade máxima atingida no teste. O treinamento foi realizado 5 vezes por semana, 60 minutos por sessão, durante 24 semanas com uma inclinação na esteira de $25 \%$. Durante este período, os animais foram pesados e o teste físico foi repetido nos tempos 8,16 e 24 semanas com o intuito de reavaliar o condicionamento físico dos animais, conforme $\circ$ esquema do protocolo experimental na Figura 4. (Controle $n=31$, Fumo n=26, Exercício $n=23$, Fumo/Exercício $n=36$ ). 
Os animais do grupo Fumo/Exercício, primeiramente realizavam o treinamento físico aeróbio e somente após um período de 60 minutos em suas gaiolas, eram expostos à inalação de fumaça de cigarro.

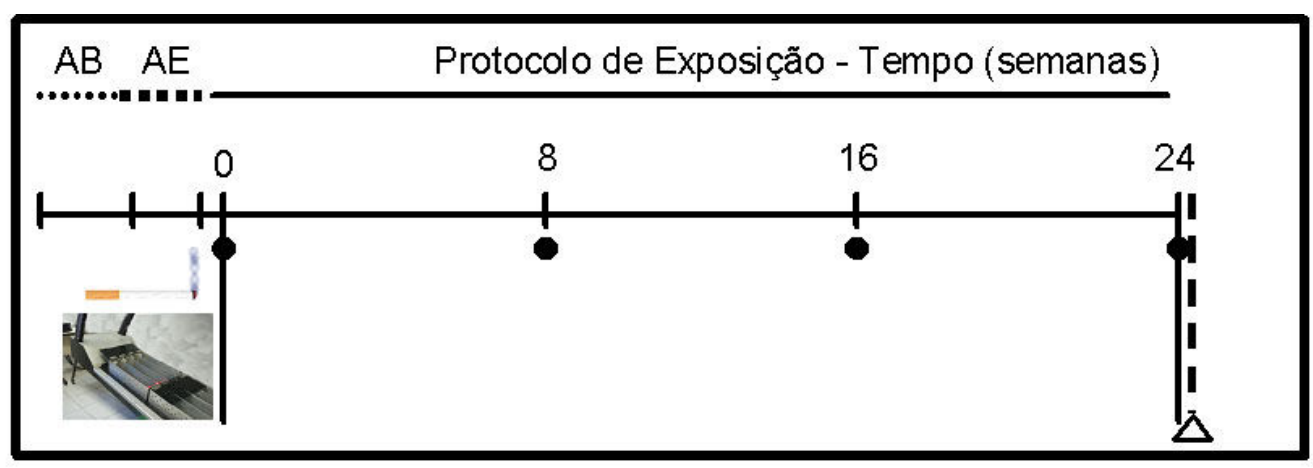

\footnotetext{
…... = AB - período de adaptação dos animais no Biotério Inicio duas semanas antes do protocolo de exposição

"." = AE - período de adaptação dos animais na esteira ergométrica (3 dias) Término $48 \mathrm{~h}$ antes do primeiro Teste Físico.

- = Avaliação do condicionamento físico (Teste Físico)

= ínicio do protocolo de exposição à fumaça de cigarro

5 vezes/ semana, $30 \mathrm{~min} /$ exposição, durante 24 semanas

= ínicio do protocolo de treinamento físico aeróbio

5 vezes/ semana, $60 \mathrm{~min} /$ sessão, durante 24 semanas

$\Delta \quad=$ Sacrifício dos animais 24 horas após a última inalação de fumaça de cigarro e/ou treinamento físico aeróbio
}

Figura 4 - Esquema do protocolo experimental.

\subsection{Avaliação da mecânica pulmonar}

Após as 24 semanas de exposição e 24 horas após a última inalação de cigarro e/ou treinamento físico, os animais foram anestesiados com Thiopental (25 mg/Kg intraperitoneal) e traqueostomizados. Inserimos uma cânula de plástico (20 gauge, BD, MG, Brasil) pelo orifício da traqueostomia, que foi fixada com fio de algodão ao redor da traquéia. Os animais foram, 
então, conectados a um aparelho de ventilação mecânica para pequenos animais (FlexiVent, Scireq, Montreal, Canadá) e ventilados com volume corrente de $10 \mathrm{~mL} / \mathrm{Kg}$, freqüência respiratória de 120 ciclos/min e curva de fluxo inspiratório senoidal. Para abolir seu esforço respiratório, os animais receberam pancurônio (0,2 mg/Kg intraperitoneal).

Quando não havia mais movimentação do animal, os dados para o cálculo da mecânica oscilatória foram obtidos. Para tanto, utilizamos um sinal que produzia oscilações do fluxo aéreo com diferentes freqüências primas $(0,25$ a 19,625$)$ por 16 segundos, mantendo-se a válvula expiratória fechada. Os valores de pressão gerados foram obtidos e a impedância de via aérea (Pressão/Fluxo) foi calculada como função das diferentes freqüências produzidas.

Usando uma janela de sobreposição de $75 \%$ no sinal de 16 segundos, três blocos de 8 segundos foram usados para o cálculo dos parâmetros da mecânica oscilatória (184), segundo a equação:

$$
Z(f)=\text { Raw }+i(2 \pi f) l a w+\frac{[\text { Gtis }-i H t i s]}{(2 \pi f)^{\alpha}}
$$

Neste modelo, Z(f) é a impedância de via aérea em função da freqüência, i é a unidade imaginária $\left(-1 \frac{1}{2}\right)$, f é freqüência, law é a inertância de vias aéreas $e=(2 / p)^{\star} \arctan (\mathrm{Htis} / \mathrm{Gtis})$. Os parâmetros que buscamos para descrever o modelo pulmonar são resistência de vias aéreas maiores (Raw), resistência de vias aéreas menores ou tecido pulmonar (Gtis) e elastância do tecido pulmonar (Htis) (Controle n=17, Fumo n=21, Exercício $\mathrm{n}=21$, Fumo/Exercício $\mathrm{n}=22$ ). 


\subsection{Coleta e mensuração do oxido nítrico exalado}

Durante a avaliação da mecânica do sistema respiratório realizamos a coleta do óxido nítrico exalado. O gás foi coletado na porção expiratória do ventilador através de um balão impermeável ao óxido nítrico (Mylar Bag, Sievers, Instruments Inc., Boulder, CO, EUA), com capacidade volumétrica de 1,5 litro, próprio para este tipo de coleta, durante 5 minutos (185). Esse procedimento já foi padronizado em nosso laboratório (186). Na porção inspiratória do ventilador foi conectado um filtro para reduzir a concentração do NO inspirado a zero. Foi coletada uma amostra imediatamente após os animais terem sido conectados ao ventilador mecânico e estarem estabilizados (Controle $n=17$, Fumo $n=22$, Exercício $n=19$, Fumo/Exercício $\mathrm{n}=12$ ). Neste momento, nosso intuito foi avaliar o efeito da exposição à fumaça de cigarro, bem como o efeito do treinamento físico aeróbio neste parâmetro. Após o término do período de coleta, os balões foram selados para posterior análise.

O óxido nítrico foi mensurado por quimioluminescência através de um analisador de resposta rápida (280 NOA - Nitric Oxide Analyzer - Sievers Instruments Inc., Boulder, CO). A concentração média de óxido nítrico foi registrada em partes por bilhão (ppb), como um índice da concentração de óxido nítrico no ar exalado. O analisador de óxido nítrico foi calibrado utilizando-se um dispositivo que filtra o óxido nítrico presente no ar ambiente e um gás de referência com uma concentração de óxido nítrico conhecida (mistura padrão para calibração de óxido nítrico em $\mathrm{N}_{2}$ a 45 ppm, White Martins Gases Industriais, São Paulo, SP, Brasil). 


\subsection{Coleta e análise do lavado broncoalveolar}

Após as medidas funcionais pulmonares, os animais ainda sob efeito anestésico foram exsanguinados via dissecção da aorta abdominal e os pulmões foram lavados com $1,5 \mathrm{~mL}(3 \times 0,5 \mathrm{~mL})$ de PBS. O volume recuperado foi centrifugado (1000 rpm, durante 10 minutos) a $5^{\circ} \mathrm{C}$, e o sobrenadante coletado e armazenado a $-70^{\circ} \mathrm{C}$ para análises futuras. $\mathrm{O}$ botão de células foi ressuspendido em 1,0 mL de PBS e utilizado para avaliação do número total e diferencial de células inflamatórias. Vinte microlitros foram utilizados para contagem total num hematocitômetro de Neubauer e 200 ㅆ para contagem diferencial após centrifugação (6 min, 450 rpm) (modelo Cytospin-2, Shandon Instruments, Sewickley, PA). As lâminas foram fixadas com o corante Grünwald-Giemsa. Foram contadas 200 células por lâmina (187) (Controle $n=5$, Fumo $n=5$, Exercício $n=6$, Fumo/Exercício $n=6)$.

\subsection{Coleta e mensuração de espécies reativas de oxigênio (ROS) no} lavado broncoalveolar

O ensaio de quimioluminescêcia é dependente de luminol (5-amino2,3-dihidro-1,4 falozinediona). Sabe-se que o luminol é um quimioluminescente pobre e que as espécies reativas de oxigênio ( $\mathrm{H} 2 \mathrm{O} 2$, $\mathrm{OH}-$, O2-), ao serem produzidas liberam uma luminosidade natural. Quando esses radicais livres reagem com o luminol, a luminosidade sofre uma amplificação que pode então ser captada pelo luminômetro. O resultado é a emissão de luz proporcional aos níveis de ROS presentes nas amostras de LBA. 
Alíquotas de $400 \mu \mathrm{L}$ do pellet do LBA fresco ressuspendido em 1,0 $\mathrm{mL}$ de PBS foi adicionada a $5 \mathrm{mM}$ de luminol (5-amino-2,3-dihydro 1,4phthalazinedione; Sigma Chemical Co, St Louis, Mo - A8511) preparado em DMSO (1:20) (Sigma Chemical Co, St Louis, Mo - D2650). A produção de ROS foi mensurada pelo método de quimioluminescência usando luminol e um luminometro (MicroBeta TriLux, version 4.7; Perkin Elmer Life Sciences, Turku, Finland) por 15 minutos.

Os resultados foram expressos em fótons por minuto por $10^{4}$ células inflamatórias $/ \mathrm{mL}$ (Controle $\mathrm{n}=6$, Fumo $\mathrm{n}=6$, Exercício $\mathrm{n}=8$, Fumo/Exercício $n=5)$.

\subsection{Histoquímica e imunohistoquímica}

Imediatamente após a coleta do LBA, a caixa torácica foi aberta e foi retirado o sistema cardiopulmonar em bloco. Os pulmões foram fixados com formaldeído $4 \%$ a uma pressão constante de $20 \mathrm{cmH}_{2} \mathrm{O}$ por $24 \mathrm{~h}$ para homogeneizar a distensão do parênquima pulmonar. Os pulmões foram, então, guardados em formalina $10 \%$ por até sete dias, e em seguida foram cortados no seu maior eixo e foram submetidos a processamento histológico de rotina.

As lâminas foram coradas com Hematoxilina-eosina, Resorcinafucsina (para análise de fibras elásticas), Picrossírius (para a análise de fibras colágenas) e também foram preparadas sem corantes para a realização posterior de imuno-histoquímica. 


\subsubsection{Histoquímica}

As lâminas contendo cortes histológicos de $5 \mu \mathrm{m}$ foram submetidas aos seguintes procedimentos:

- Hematoxilina e Eosina - coloração utilizada para avaliação do diâmetro alveolar médio;

- Picrossírius - coloração utilizada para avaliação da proporção de volume de fibras colágenas no parênquima pulmonar $(188,189)$.

\subsubsection{Imunohistoquímica}

As lâminas previamente preparadas com (3-Aminopropil-trietoxisilano) (Silane - Sigma) contendo os cortes histológicos dos pulmões foram inicialmente desparafinadas e hidratadas; e submetidas aos seguintes procedimentos:

- Etapa 1 - Recuperação antigênica: através de Proteinase K por 20 minutos $\left(37^{\circ} \mathrm{C}\right)$ seguidos de descanso de 20 minutos em temperatura ambiente. Após este período, as lâminas foram lavadas em PBS;

- Etapa 2 - Bloqueio e Incubação com Anticorpo Primário: O bloqueio da peroxidase endógena foi realizado com água oxigenada $\left(\mathrm{H}_{2} \mathrm{O}_{2}\right)$ 10V 3\% (3 x 10 minutos), seguidos de incubação com os anticorpos primários: anti-SODCuZn (sc-8637; Santa Cruz), anti-SODMn (sc18503; Santa Cruz), anti-MCP-1(sc-1784; Santa Cruz), anti-IL1-ra (sc-8482; Santa Cruz), anti-SODEC (sc-32222; Santa Cruz), anti-GPx (sc-22146; Santa Cruz), anti-Gp91phox (sc-5827; Santa Cruz), antiMMP9 (sc-6840; Santa Cruz), anti-TIMP 1 (sc-5538; Santa Cruz), 
anti-IL-10 (sc-1783; Santa Cruz), anti-iNOS (RB-9242P; Neo Markers), anti-eNOS (sc- RB-9279P; Neo Markers) , anti-8Isoprostano (IS-20; Oxford Biomedical) e anti-TNF- $\alpha$ (sc-1348; Santa Cruz), diluídos em BSA na proporção de 1:50 (eNOS), 1:150 (Gpx), 1:200 (SODMn, Gp91phox, IL-10), 1:400 (SODCuZn, SODEC) e 1:500 (IL1-ra, 8-Isoprostano), 1:800 (TNF- $\alpha$ ), 1:3500 (MCP1), os quais foram aplicados sobre os cortes relativos ao experimento e também aos controles (positivo e negativo) de tecido, e as lâminas incubadas "overnight";

- Etapa 3 - Incubação com Anticorpo Secundário e Complexo: As lâminas foram lavadas em PBS e incubadas pelo ABCKit Vectastain (Vector Elite - PK-6105 (anti-goat) / PK-6101 (anti-rabbit);

- Etapa 4 - Revelação: Seguiu-se com a lavagem das lâminas em PBS e revelação pelo cromógeno 3,3 Diaminobenzidine (DAB) (Sigma Chemical Co, Saint Louis, Missouri, EUA);

- Etapa 5 - Contra-Coloração e Montagem das Lâminas: As lâminas foram lavadas abundantemente em água corrente e contra-coradas com Hematoxilina de Harris (Merck, Darmstadt, Alemanha). Em seguida, as mesmas foram lavadas em água corrente, desidratadas, diafanizadas e montadas com resina para microscopia Entellan (Merck, Darmstadt, Alemanha). 


\subsection{Análise morfométrica dos pulmões}

Os parâmetros morfométricos foram avaliados através da técnica de pontos e retas ou através do software Image Pró Plus (versão 4.5, NIH, Maryland, EUA).

Os parâmetros avaliados pela mensuração de pontos e retas, utilizou um retículo de 50 retas e 100 pontos, com área conhecida $\left(8.700 \mu \mathrm{m}^{2}\right.$ para aumento de $1000 x ; 50.400 \mu \mathrm{m}^{2}$ para aumento de $400 x$ e $850.000 \mu \mathrm{m}^{2}$ para aumento de 200x), quando adaptado à ocular de um microscópio Olympus.

\subsubsection{Mensuração do intercepto linear médio}

Medimos o Lm (intercepto linear médio), uma medida do grau de distensão alveolar, usando um microscópio óptico com um retículo de 50 retas e 100 pontos acoplada à ocular do aparelho. Nas lâminas de pulmão coradas com hematoxilina-eosina, em um aumento de 200 vezes, contamos o número de intersecções entre o parênquima pulmonar e as retas da ocular, em 20 diferentes campos por animal. No aumento de 200 vezes o comprimento somado das 50 retas usadas para a medida do Lm é $2500 \mu \mathrm{m}$. Portanto, o Lm para cada animal foi calculado dividindo-se 2500 pela média do número de intersecções dos 20 campos observados (Controle $n=18$, Fumo n=16, Exercício $n=17$, Fumo/Exercício $n=21)$.

O preparo histológico das demais lâminas não ficou adequado, por não ter havido insuflação completa durante a fixação, geralmente por lesão do parênquima pulmonar durante o procedimento de retirada dos pulmões. 


\subsubsection{Mensuração de marcadores de imunohistoquímica}

Para a avaliação da densidade de células mononucleares, neutrófilos e células inflamatórias positivas para SODCuZn, SODMn, MCP-1, IL1-ra, GPx, Gp91phox, MMP9, TIMP 1, IL-10, iNOS, TNF- $\alpha$, foram utilizados 20 campos do parênquima pulmonar das lâminas de cada animal, escolhidos de maneira aleatória, avaliados num aumento de 1000x. A área utilizada para avaliação da inflamação tecidual foi calculada a partir do número de pontos que incidiram nos septos alveolares. A densidade de células foi determinada como o número de células positivas nos septos alveolares dividido pela área mensurada. A densidade de células foi expressa em células $/ \mu m^{2}$ e os resultados foram transformados para $10^{6} \mu \mathrm{m}^{2}$ ajustando-se as unidades (Controle $n=7-10$, Fumo $n=7-10$, Exercício $n=7-12$, Fumo/Exercício $n=7-12$ ).

Para avaliação da proporção de 8-Isoprostano e SOD3 no parênquima pulmonar, utilizamos um microscópio acoplado a uma câmera fotográfica digital Nikon, ligada a um microcomputador de padrão IBM. As imagens foram analisadas usando o software Image Pró Plus (versão 4.5, $\mathrm{NIH}$, Maryland, EUA). Fotografamos entre 15 e 20 campos de parênquima pulmonar para cada coloração em aumento de 400x vezes. Em cada imagem foi selecionada a área de interesse e aplicado um filtro pré-montado, com base em um número representativo de fotos, marcando as áreas positivas. Para cada imagem foram coletadas: (1) área total da imagem; (2) área positiva para a marcação no septo alveolar com base no padrão estabelecido; (3) área de branco. A subtração do valor do item (1) pelo item 
(3) fornece o valor da área de septo alveolar (4). A porcentagem da área positiva para a marcação no septo alveolar é igual a (2) x 100/ (4).

Obtivemos assim, a medida da proporção de 8-Isoprostano (Controle $n=7$, Fumo $n=7$, Exercício $n=7$, Fumo/Exercício $n=7$ ) e SOD3 (Controle $n=7$, Fumo $n=8$, Exercício $n=9$, Fumo/Exercício $n=8$ ) por área de parênquima pulmonar.

\subsubsection{Mensuração de fibras colágenas e elásticas no parênquima pulmonar}

A análise das fibras foi realizada em um microscópio acoplado a uma câmara Nikon, ligada a um computador, com aumento de 400 vezes. Fotografamos entre 15 e 20 campos de parênquima pulmonar coradas para fibras colágenas (Picrossírius) e elásticas (Resorcina-fucsina).

As imagens foram analisadas usando o software Image Pró Plus (NIH, Maryland, EUA). Para o cálculo das fibras no parênquima pulmonar, foi selecionada para cada imagem a área de interesse e aplicado um filtro prémontado, com base em um número representativo de fotos, marcando as áreas positivas. Para cada imagem foram coletadas: (1) área total da imagem; (2) área positiva para a marcação no septo alveolar com base no padrão estabelecido; (3) área de branco. A subtração do valor do item (1) pelo item (3) fornece o valor da área de septo alveolar (4). A porcentagem da área positiva para a marcação no septo alveolar é igual a (2) x 100/ (4).

Obtivemos assim, a medida da proporção de fibras colágenas e elásticas por área de parênquima pulmonar (Fibras colágenas e elásticas, 
respectivamente, Controle $n=6$ e $n=5$, Fumo $n=6$ e $n=5$, Exercício $n=8$ e $n=5$, Fumo/Exercício $n=5$ e $n=5)$.

\subsection{Análise estatística}

Os dados foram analisados através do software Sigma Stat 10 (Califórnia, EUA). Para a comparação entre os grupos, os dados com distribuição paramétrica foram submetidos à análise de variância de um fator seguida pelo teste de Newman-Keuls. Os dados com distribuição não paramétrica foram submetidos à análise de variância não paramétrica seguida pelo teste de Dunn para a comparação entre os grupos. Consideramos as diferenças entre os grupos como estatisticamente significantes quando o valor de p para o erro alfa era menor que 0,05 . Os gráficos foram elaborados utilizando-se o software Sigma Plot 10 (Califórnia, EUA). 
RESULTADOS 


\section{RESULTADOS}

\subsection{Massa, velocidade e tempo do teste físico obtidos durante o protocolo experimental}

Os animais foram pesados e submetidos a um teste de esforço para avaliar a performance física durante o estudo. Realizamos medidas nos tempos inicial, oito, dezesseis e vinte e quatro semanas de protocolo.

O peso dos animais no inicio do protocolo não foi diferente entre os grupos e houve um ganho estatisticamente significante do peso inicial em relação ao peso em 24 semanas em todos os grupos estudados $(p<0,001)$. Observamos uma perda de peso inicial estatisticamente significativa de $11,6 \%$ nas primeiras oito semanas nos animais que receberam inalação de fumaça de cigarro (Grupos Fumo e Fumo/Exercício) comparado ao Grupo Controle $(p<0,01)$. Na $16^{a}$ e na $24^{a}$ semanas os animais do grupo Fumo/Exercício apresentaram menor peso quando comparado ao grupo Exercício ( $p=0,02$ e $p<0,01$, respectivamente) (Figura 5). 


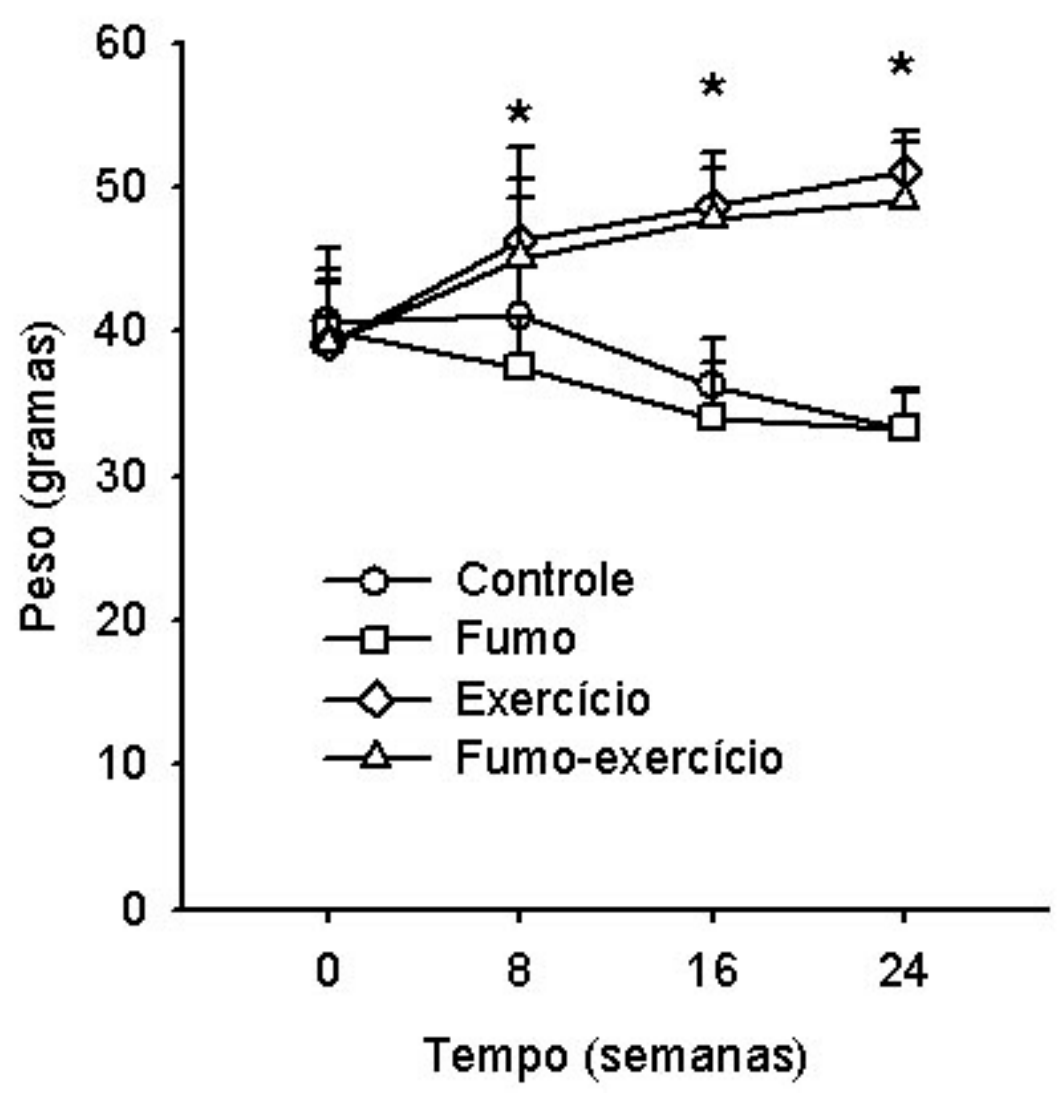

Figura 5 - Efeitos da exposição à fumaça de cigarro e do treinamento físico aeróbio regular de intensidade moderada sobre o peso corporal $(\mathrm{g})$ dos animais nos tempos inicial, 8, 16 e 24 semanas. Valores expressos como média e desvio padrão. Grupo Controle: animais expostos a ar sintético por um período de 24 semanas e que não realizaram treinamento físico aeróbio; Grupo Fumo: animais expostos à fumaça de cigarro por um período de 24 semanas e que não realizaram treinamento físico aeróbio; Grupo Exercício: animais expostos a ar sintético por um período de 24 semanas e que realizaram treinamento físico aeróbio; Grupo Fumo/ Exercício: animais expostos à fumaça de cigarro por um período de 24 semanas e que realizaram treinamento físico aeróbio. ${ }^{*} p<0,001$ quando comparado aos animais expostos à inalação de fumaça de cigarro. 
O desempenho físico inicial, quanto à velocidade e tempo do teste, não foi diferente entre os grupos, no entanto após 8 semanas de treinamento físico ficou evidente que os dois grupos que realizaram treinamento físico aeróbio regular de intensidade moderada (Exercício e Fumo/Exercício) melhoraram a velocidade e o tempo do teste físico se comparado aos grupos não treinados $(p<0,001)$ (Figuras 6 e 7$)$. A Figuras mostram um ganho significativo na velocidade e tempo do teste físico a partir da $8^{\mathrm{a}}$ semana de treinamento e esse ganho se mantém na $16^{a}$ e $24^{a}$ semana, mostrando que os animais adquiriram condicionamento físico aeróbio no período estudado.

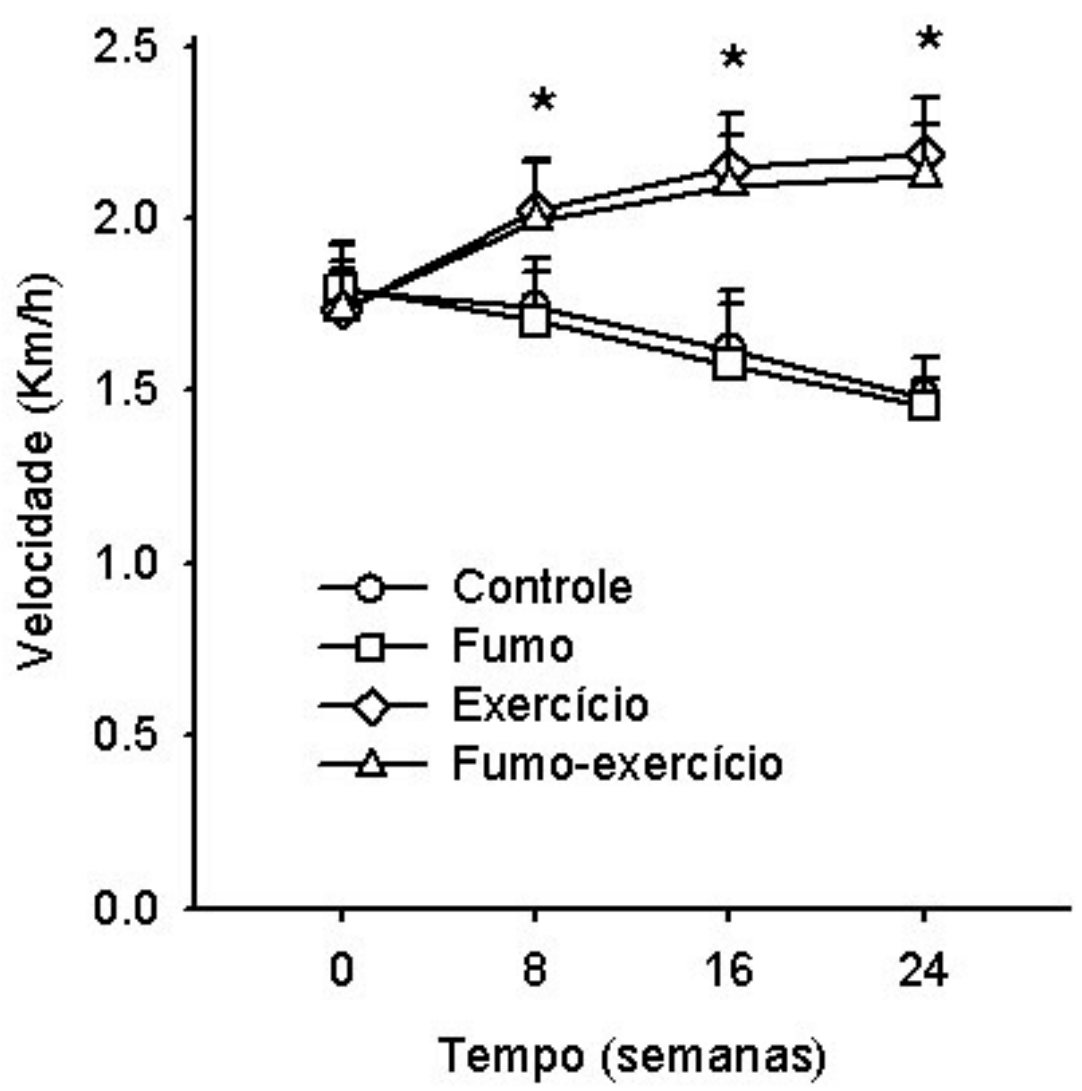

Figura 6 - Efeitos da exposição à fumaça de cigarro e do treinamento físico aeróbio regular de intensidade moderada sobre a velocidade $(\mathrm{Km} / \mathrm{h})$ adquirida pelos animais no teste físico nos tempos inicial, 2, 4 e 6 meses. Valores expressos como média e desvio padrão. * $\mathrm{p}<0,001$ quando comparado aos animais que não realizaram treinamento físico aeróbio. 


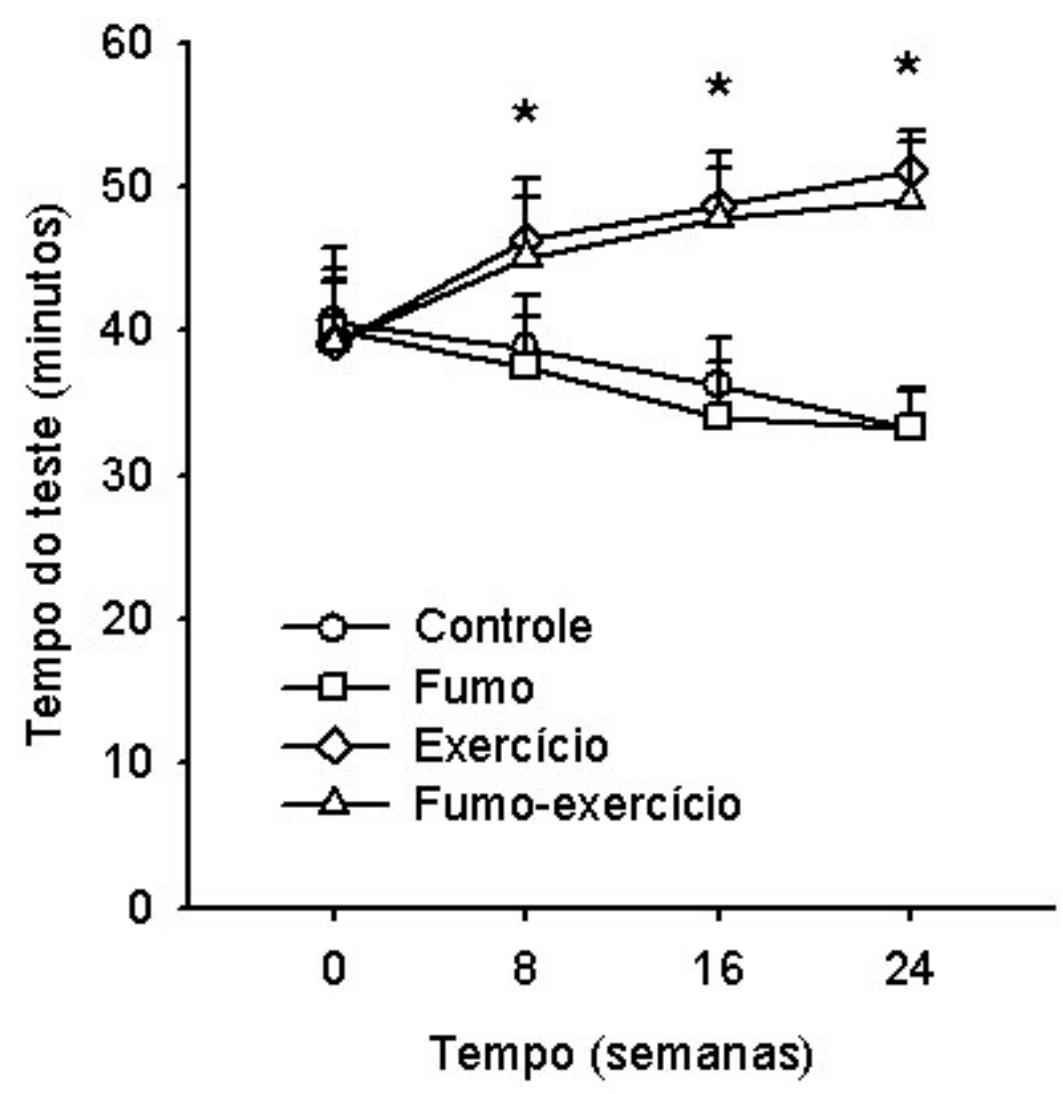

Figura 7 - Efeitos da exposição à fumaça de cigarro e do treinamento físico aeróbio regular de intensidade moderada sobre no tempo (minutos) adquirido pelos animais no teste físico nos tempos inicial, 2, 4 e 6 meses. Valores expressos como média e desvio padrão. ${ }^{*} p<0,001$ quando comparado aos animais que não realizaram treinamento físico aeróbio. 


\subsection{Avaliação da mecânica pulmonar}

A resistência de vias aéreas (Raw), resistência de tecidos (Gtis) e elastância (Htis) foram medidas de acordo com o modelo de fase constante (Figuras 8-10). Não houve diferenças estatisticamente significantes entre os grupos para as medidas de resistência de vias aéreas (Raw) e resistência de tecidos (Gtis). Houve uma queda estatisticamente significativa na Elastância dos animais do grupo Fumo comparado aos demais grupos, e o treinamento físico aeróbio inibiu esta alteração.

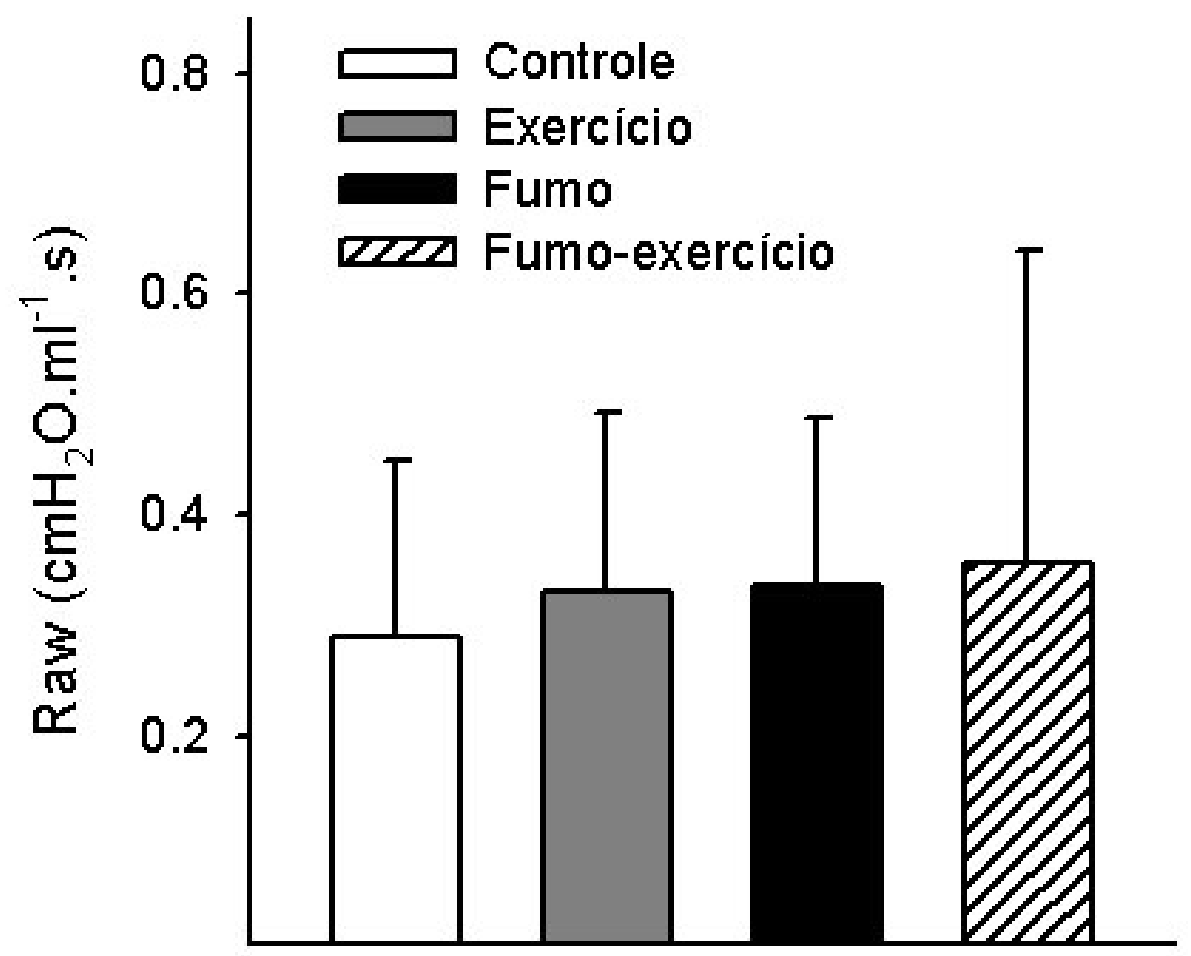

Figura 8 - Efeitos da exposição à fumaça de cigarro e do treinamento físico aeróbio regular de intensidade moderada sobre a resistência de vias aéreas (Raw). Não houve diferença significativa na resistência de grandes vias aéreas entre os grupos estudados. Valores expressos como média e desvio padrão. 


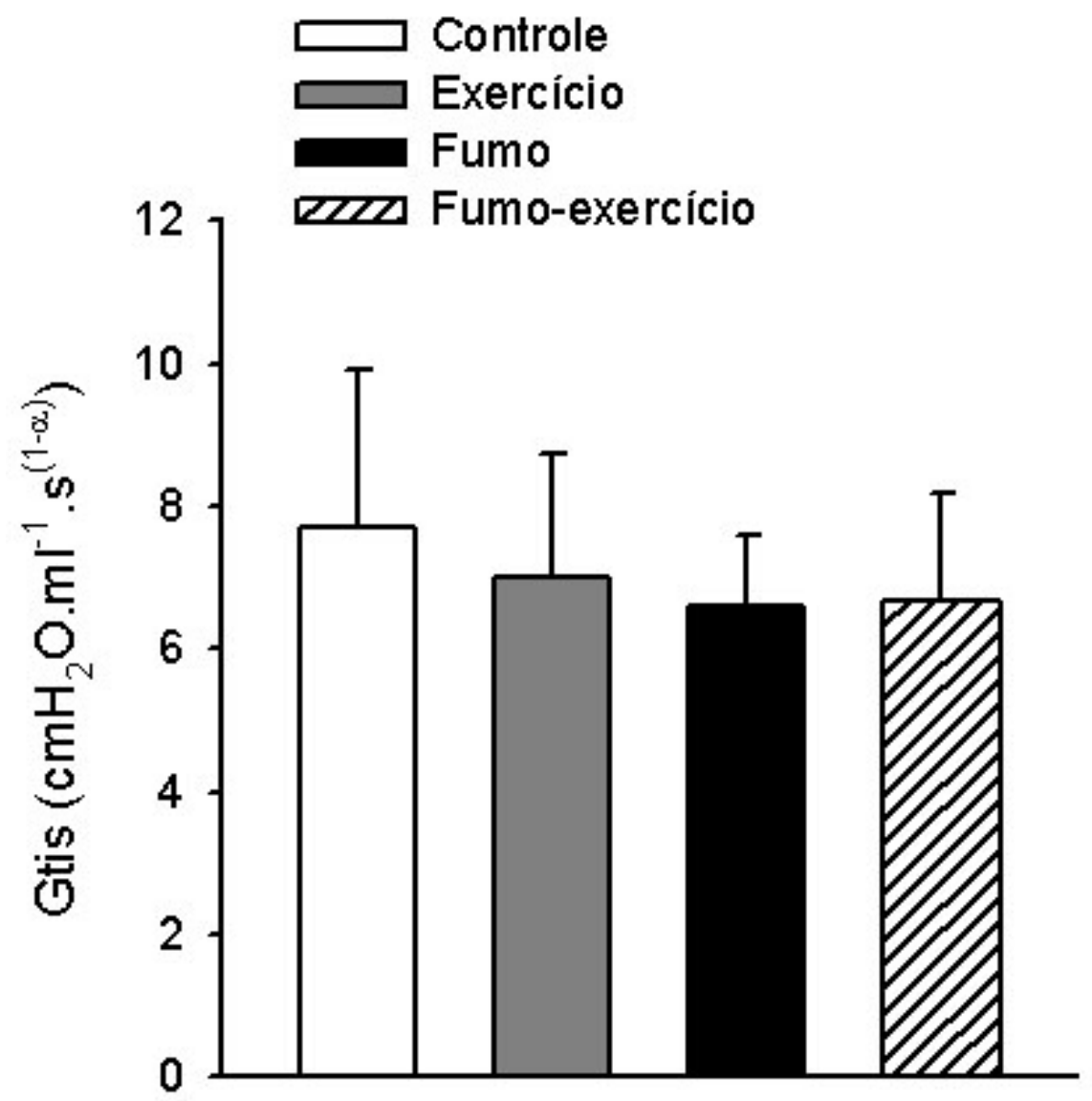

Figura 9 - Efeitos da exposição à fumaça de cigarro e do treinamento físico aeróbio regular de intensidade moderada sobre a resistência de tecidos (Gtis). Não houve diferença estatisticamente significante entre os grupos para as medidas de resistência dos tecidos. Valores expressos como média e desvio padrão. 


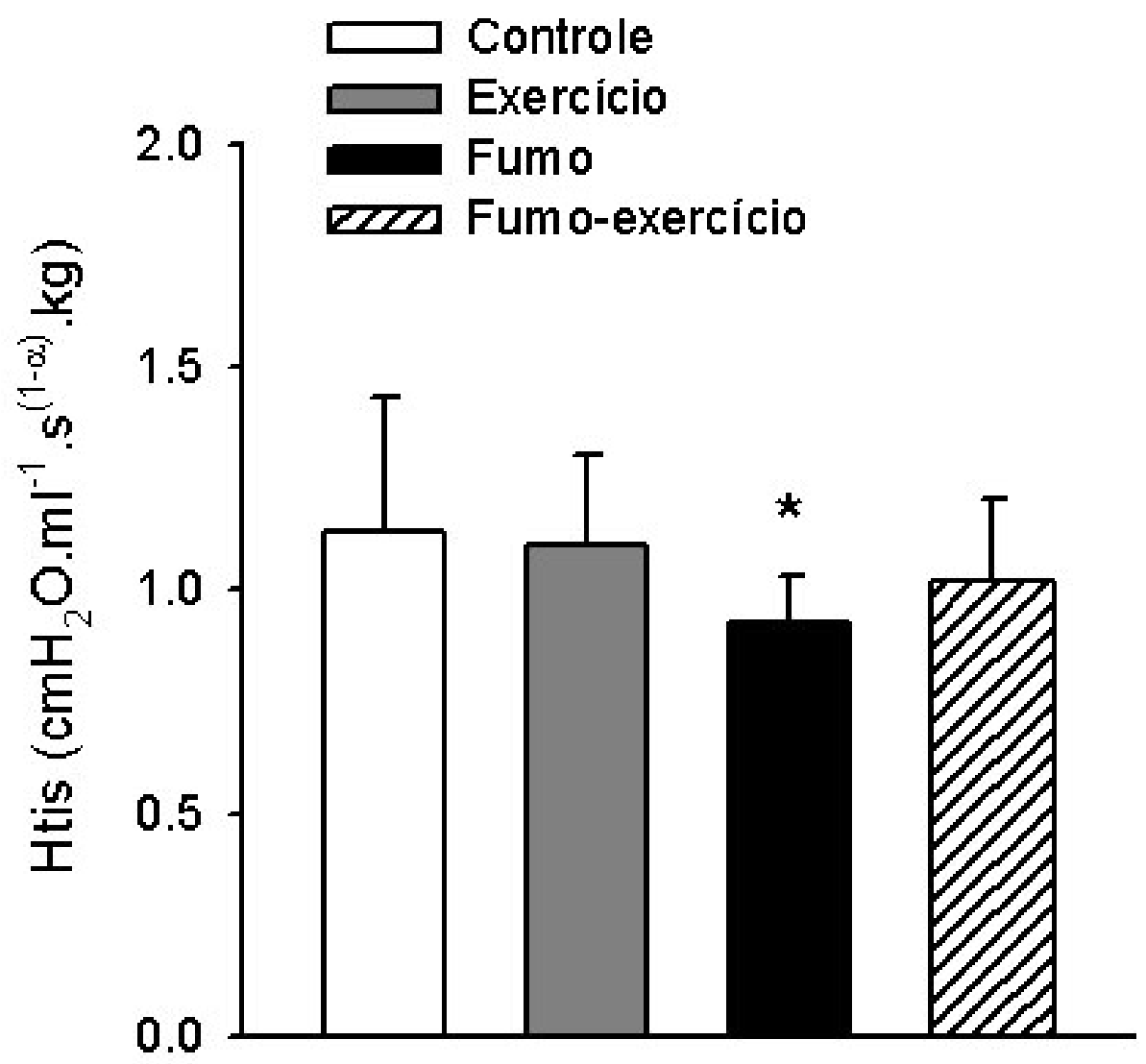

Figura 10 - Efeitos da exposição à fumaça de cigarro e do treinamento físico aeróbio regular de intensidade moderada sobre a elastância (Htis). Houve uma queda estatisticamente significativa na Elastância dos animais do grupo Fumo comparados aos demais grupos $\left({ }^{*} p<0,01\right)$. Valores expressos como média e desvio padrão. 


\subsection{Mensuração do oxido nítrico exalado}

A Figura 11 apresenta as concentrações de NO exalado dos quatro grupos em estudo. As concentrações de NO exalado nos grupos Fumo e Exercício foram maiores quando comparado ao grupo Controle, mas não houve diferença estatística quando comparados ao grupo Fumo/Exercício.

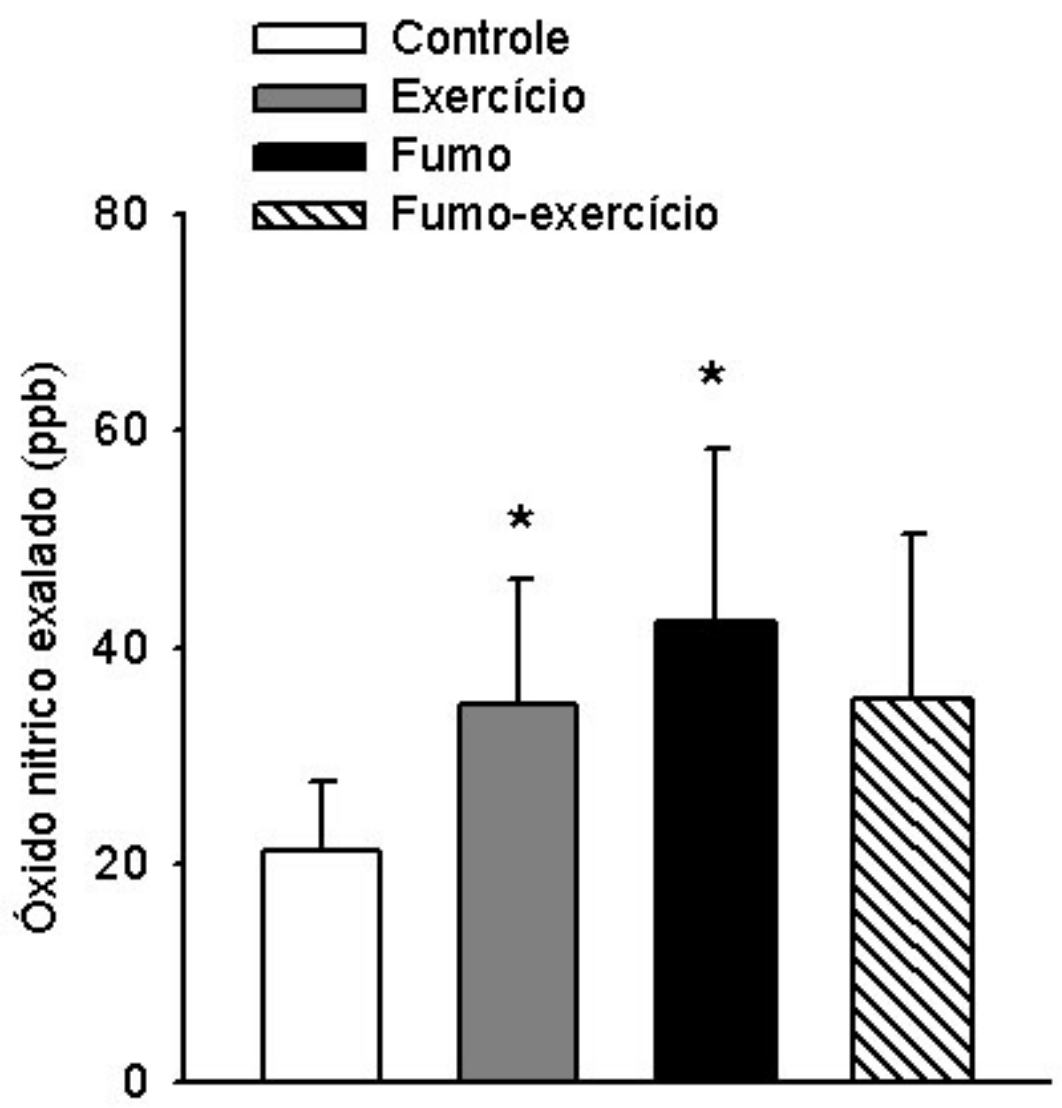

Figura 11 - Efeitos da exposição à fumaça de cigarro e do treinamento físico aeróbio regular de intensidade moderada sobre as concentrações de NO exalado. ${ }^{*} p<0,01$ quando os grupos Fumo e Exercício foram comparados ao grupo Controle. Valores expressos como média e desvio padrão. 


\subsection{Análise do lavado broncoalveolar}

Nas análises de células inflamatórias, comparamos o número total de células inflamatórias e o número de macrófagos, neutrófilos, linfócitos e células epiteliais no LBA (Figura 12). Os dados são apresentados em número total de células de células multiplicado por $10^{4}$ em $1 \mathrm{~mL}$. A inalação de fumaça de cigarro aumentou a quantidade de células totais no LBA comparado aos grupos Controle e Exercício. O treinamento físico aeróbio parece reduzir esse aumento, uma vez que não houve diferença estatística entre o grupo Fumo/Exercício e o grupo Controle. A inalação de fumaça de cigarro aumentou a quantidade de macrófagos no LBA e o treinamento físico aeróbio não modificou esse aumento. Os números de neutrófilos e linfócitos foram muito pequenos e não houve diferença estatística entre os grupos, portanto decidimos não mostrarmos no histograma. 


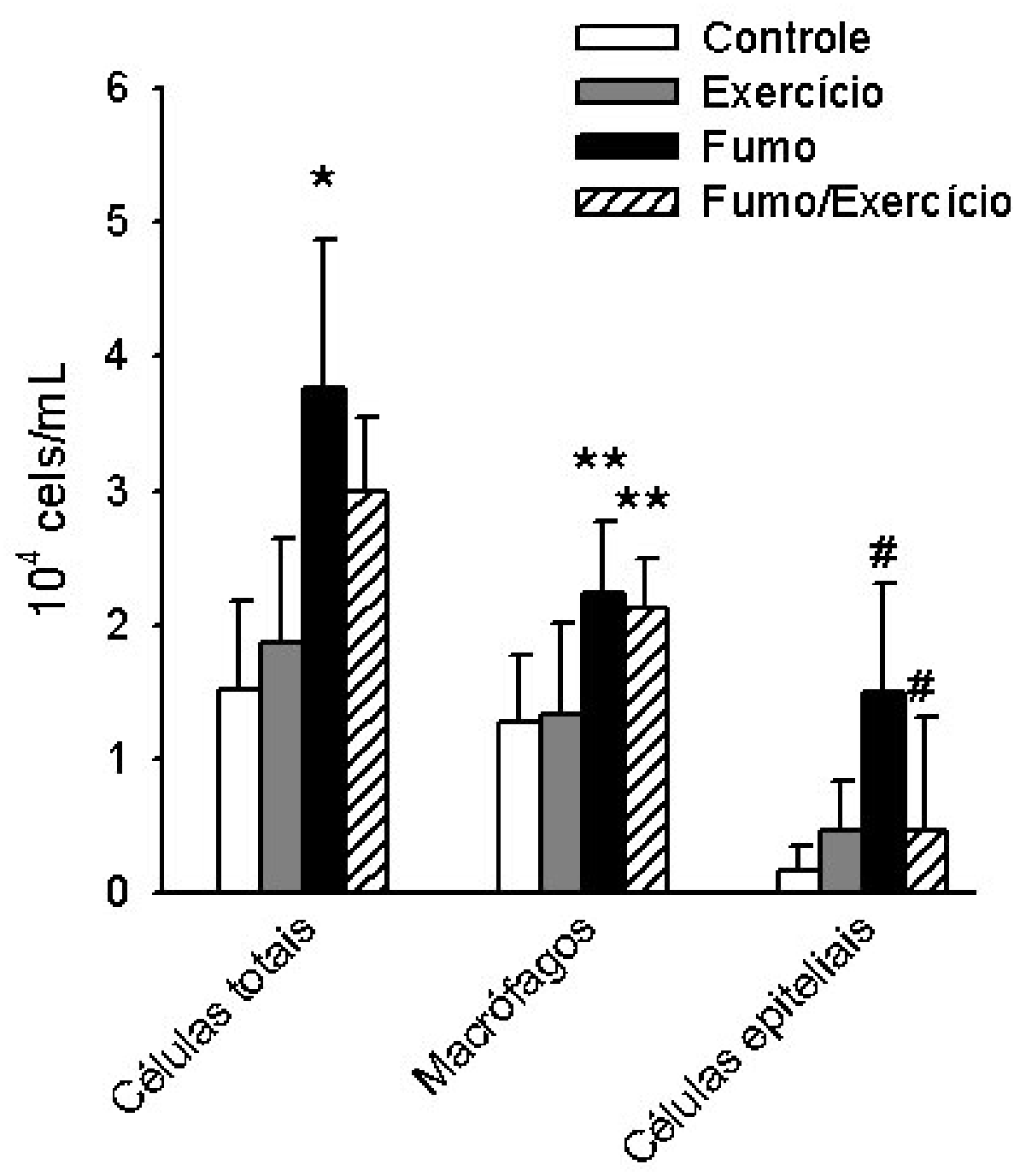

Figura 12 - Efeitos da exposição à fumaça de cigarro e do treinamento físico aeróbio regular de intensidade moderada sobre o número total de células inflamatórias no lavado broncoalveolar. Valores expressos como média e desvio padrão. ${ }^{*} p<0,01$ quando comparado aos grupos Controle e Exercício. 


\subsection{Mensuração do intercepto linear médio}

Para analisar o desenvolvimento de enfisema pulmonar, utilizamos a medida do diâmetro linear médio (Lm). Verificamos a distensão alveolar em regiões do parênquima pulmonar próxima à pleura (Figura 14) e próxima aos bronquíolos terminais (Figura 15).

Apresentamos exemplos de fotografias das lâminas coradas em hematoxilina-eosina de animais dos quatro grupos para exemplificar os resultados de Lm próximo à pleura (Figura 13). O treinamento físico aeróbio mostrou uma proteção ao parênquima pulmonar em relação à distenção alveolar causada pela inalação de fumaça de cigarro.
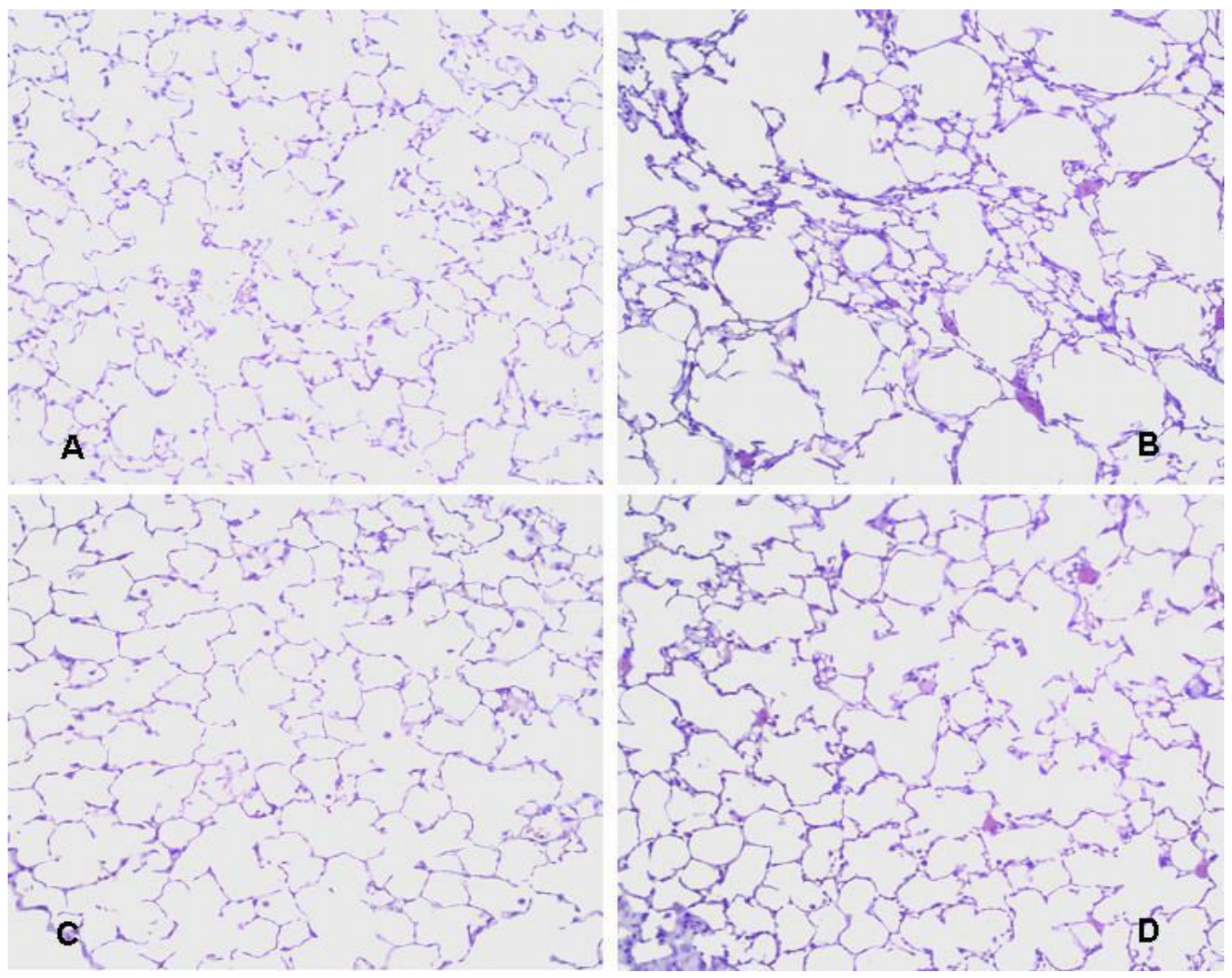

Figura 13 - Fotomicrografias de microscopia óptica das regiões próximas à pleura dos quatro grupos estudados (coloração hematoxilina-eosina, aumento de 100x). (A) Grupo Controle, (B) Grupo Fumo, (C) Grupo Exercício e (D) Grupo Fumo/Exercício. 


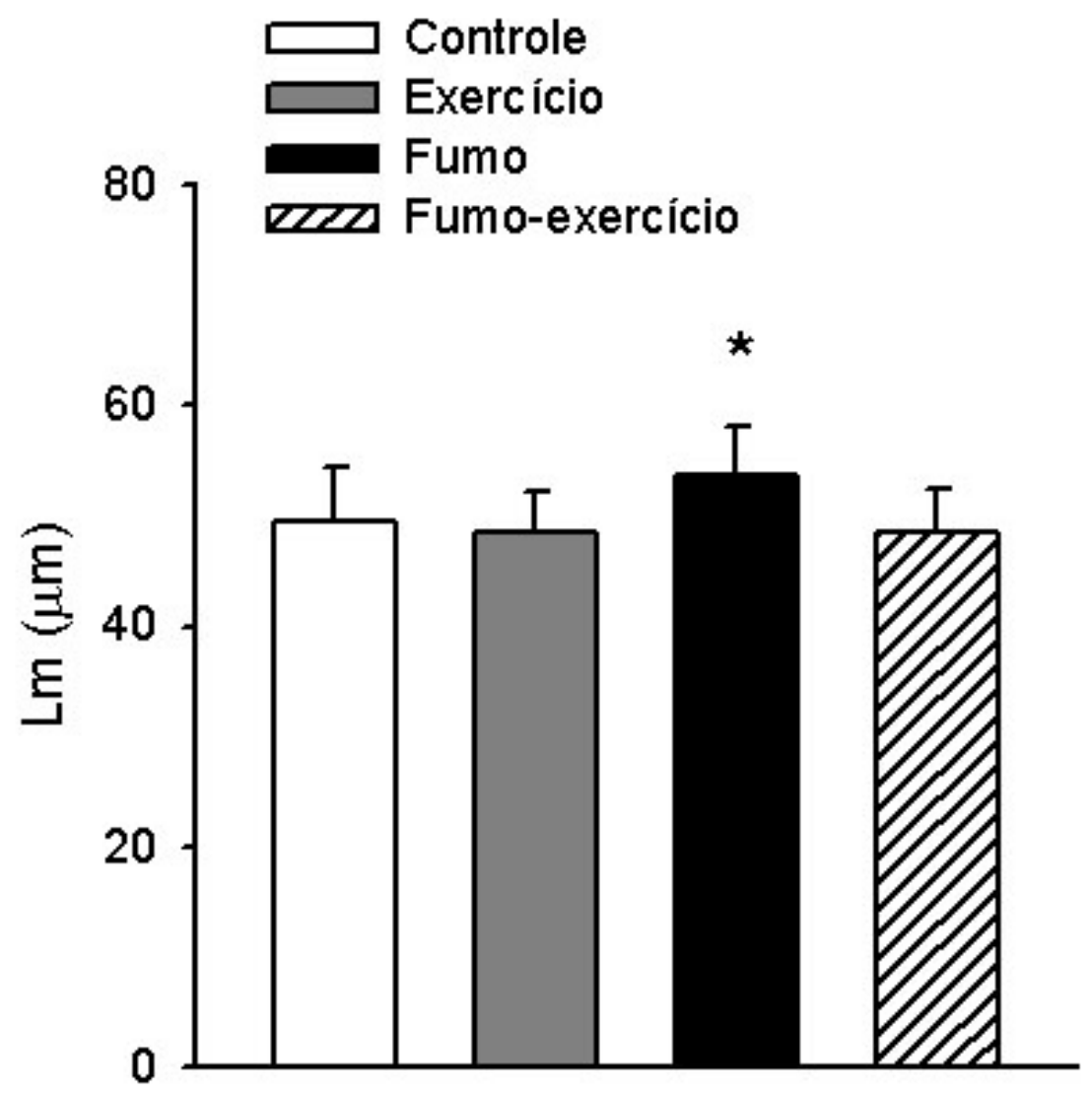

Figura 14 - Efeitos da exposição à fumaça de cigarro e do treinamento físico aeróbio regular de intensidade moderada sobre o diâmetro alveolar médio próximo à pleura. Valores expressos como média e desvio padrão. ${ }^{*} \mathrm{p}<0,01$ quando comparado aos demais grupos. 


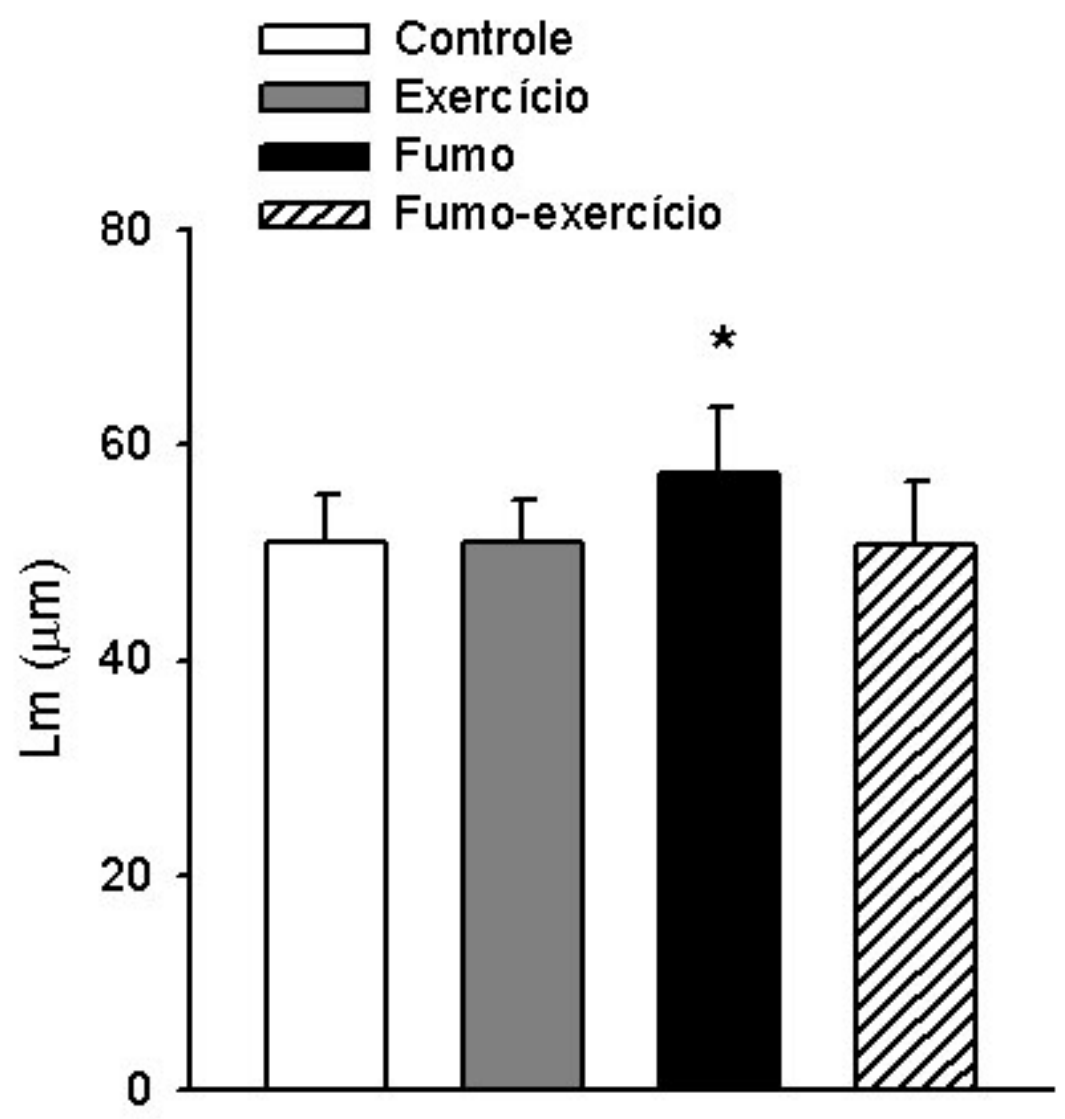

Figura 15 - Efeitos da exposição à fumaça de cigarro e do treinamento físico aeróbio regular de intensidade moderada sobre o diâmetro alveolar médio próximo à via aérea. Valores expressos como média e desvio padrão. ${ }^{*} p<0,001$ quando comparado aos demais grupos. 


\subsection{Análise das fibras colágenas e elásticas}

As fibras no parênquima pulmonar foram comparadas a partir de um índice obtido através da divisão da área da fibra colágena pela área de parênquima pulmonar. A exposição à fumaça de cigarro aumentou a proporção de fibras colágenas e o treinamento físico aeróbio nos animais expostos à fumaça de cigarro não modificou esta alteração (Figura 16). Não houve diferenças estatisticamente significantes entre os grupos para as medidas de fibras elásticas (Figura 17).

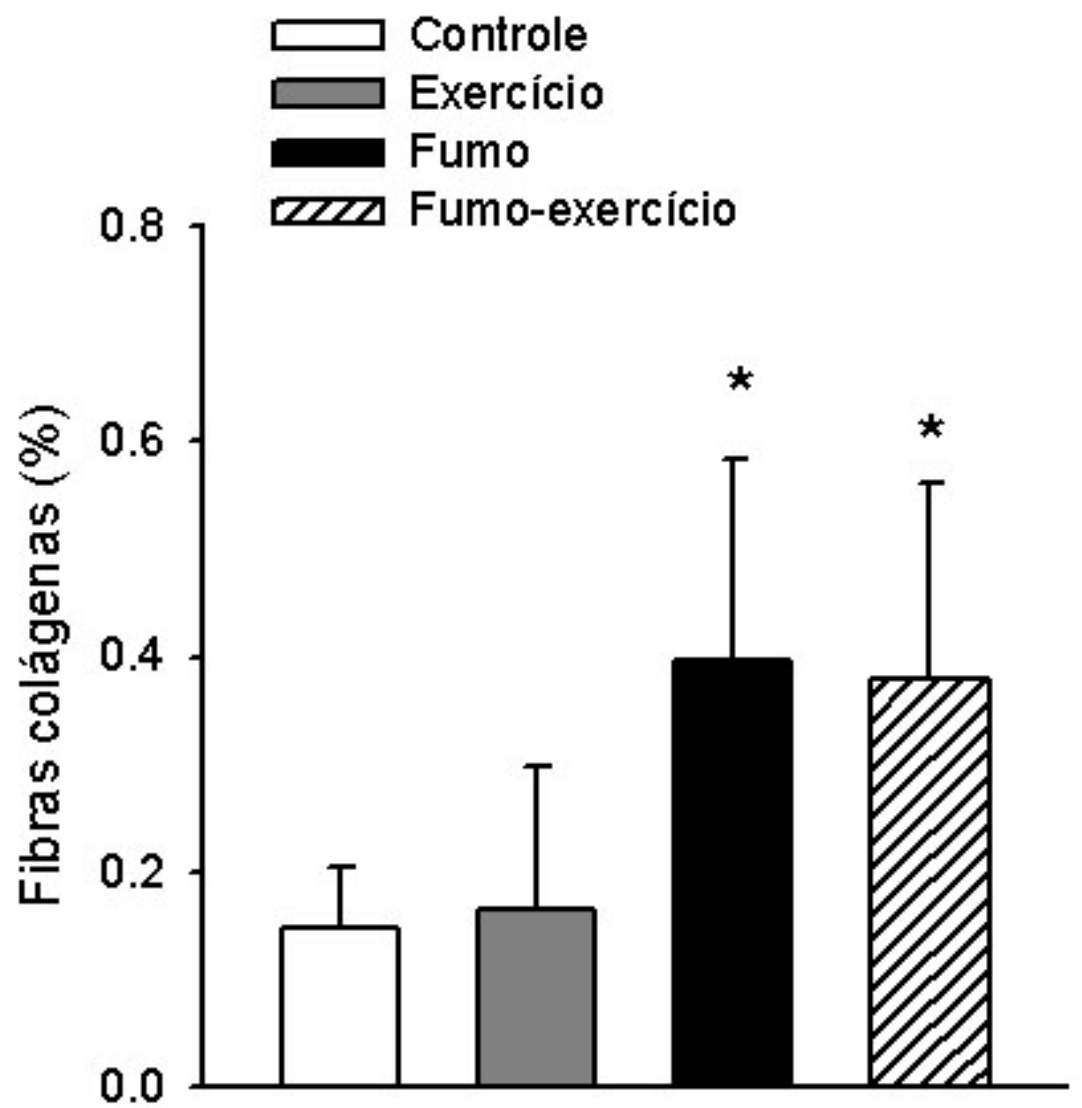

Figura 16 - Efeitos da exposição à fumaça de cigarro e do treinamento físico aeróbio regular de intensidade moderada sobre a proporção de volume de fibras colágenas no parênquima. Valores expressos como média e desvio padrão. * $p<0,001$ quando comparado aos demais grupos. 


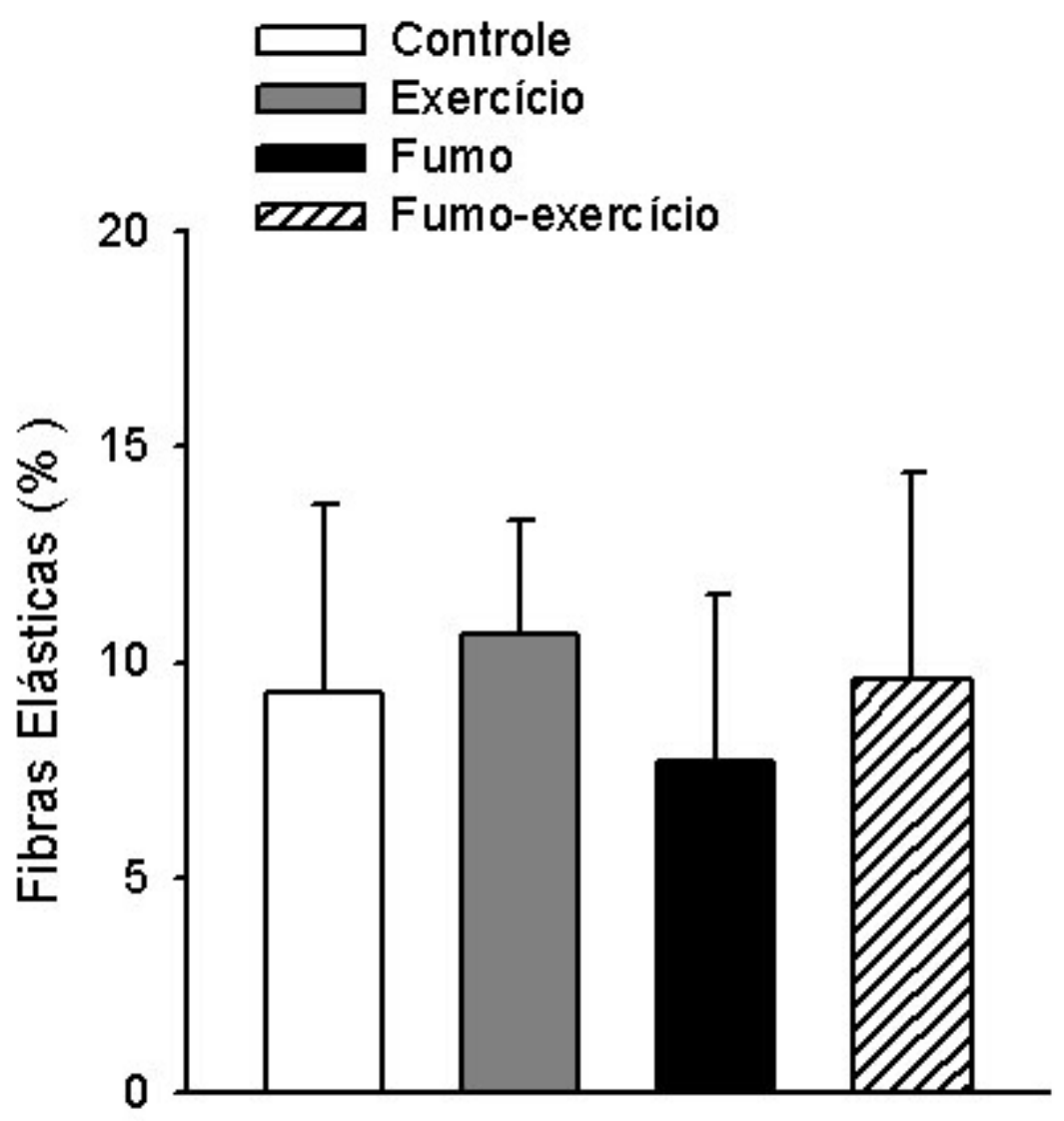

Figura 17 - Efeitos da exposição à fumaça de cigarro e do treinamento físico aeróbio regular de intensidade moderada sobre a proporção de volume de fibras elasticas no parênquima. Valores expressos como média e desvio padrão. 
5.7 Mensuração de espécies reativas de oxigênio no lavado broncoalveolar

Os dados são apresentados em número de cintilações por minuto sobre a quantidade total de células no LBA. A exposição à fumaça de cigarro aumentou a produção de ROS pelas células inflamatórias, e o treinamento físico aeróbio reduziu essa produção (Figura 18).
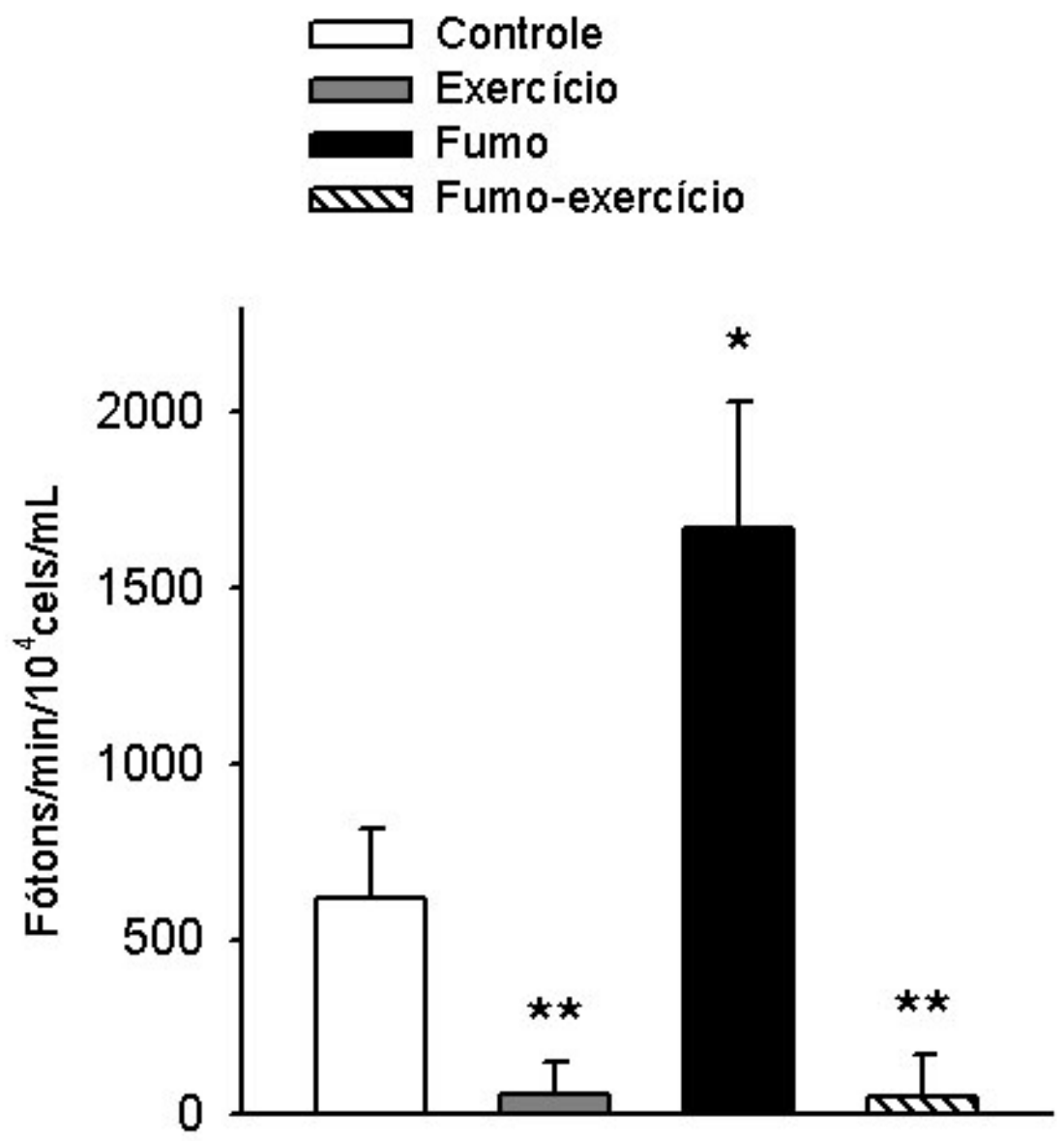

Figura 18 - Efeitos da exposição à fumaça de cigarro e do treinamento físico aeróbio regular de intensidade moderada sobre a quantidade de ROS no LBA. Valores expressos como média e desvio padrão. ${ }^{*} p<0,001$ quando comparado aos demais grupos. 


\subsection{Análise de marcadores de imunohistoquímica}

Os dados apresentados para densidade de células inflamatórias na parede alveolar positivas para iNOS, GPx, SODCuZn, SODMn, Gp91phox, MCP1, MMP9, TIMP1, TNF- $\alpha$, IL-10 e IL1ra, são de células positivas em uma área de $10^{6} \mu \mathrm{m}^{2}$. E os dados apresentados para 8-Isoprostano e SODExtracelular são dados pela área de parênquima positiva para o marcador estudado pela área total de parênquima.

A exposição à fumaça de cigarro aumentou a proporção no volume de 8-Isoprostano no parênquima pulmonar. Este aumento foi inibido quando os animais expostos foram submetidos ao treinamento físico regular de intensidade moderada (Figura 19). 

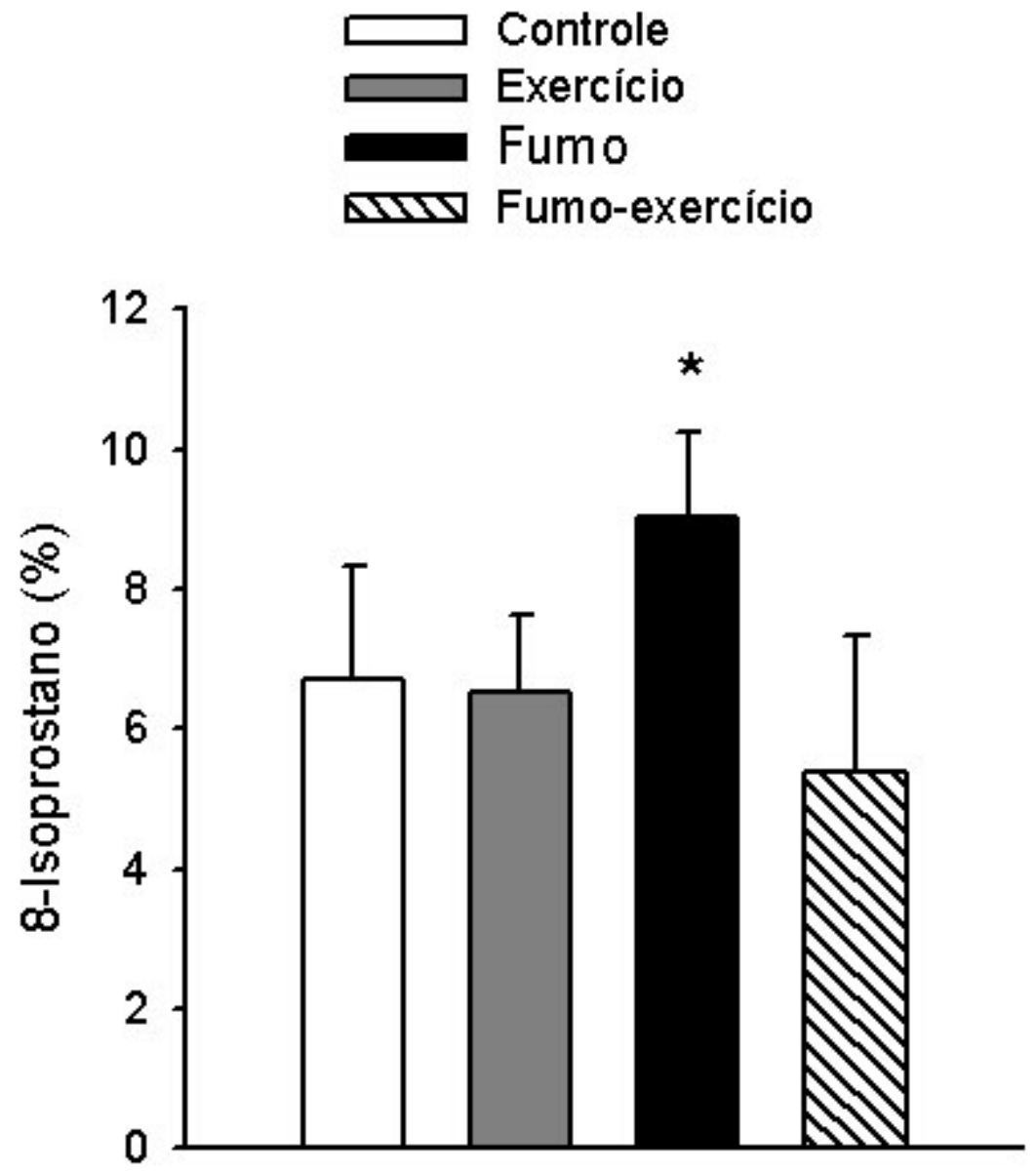

Figura 19 - Efeitos da exposição à fumaça de cigarro e do treinamento físico aeróbio regular de intensidade moderada sobre a proporção de volume de 8-Isoprostano no parênquima pulmonar. Valores expressos como média e desvio padrão. * $\mathrm{p}=0,04$ quando comparado ao grupo Fumo/Exercício. 
A exposição à fumaça de cigarro e o treinamento físico aeróbio de intensidade moderada não modificaram a densidade de células inflamatórias na parede alveolar positivas para iNOS (Figura 20).

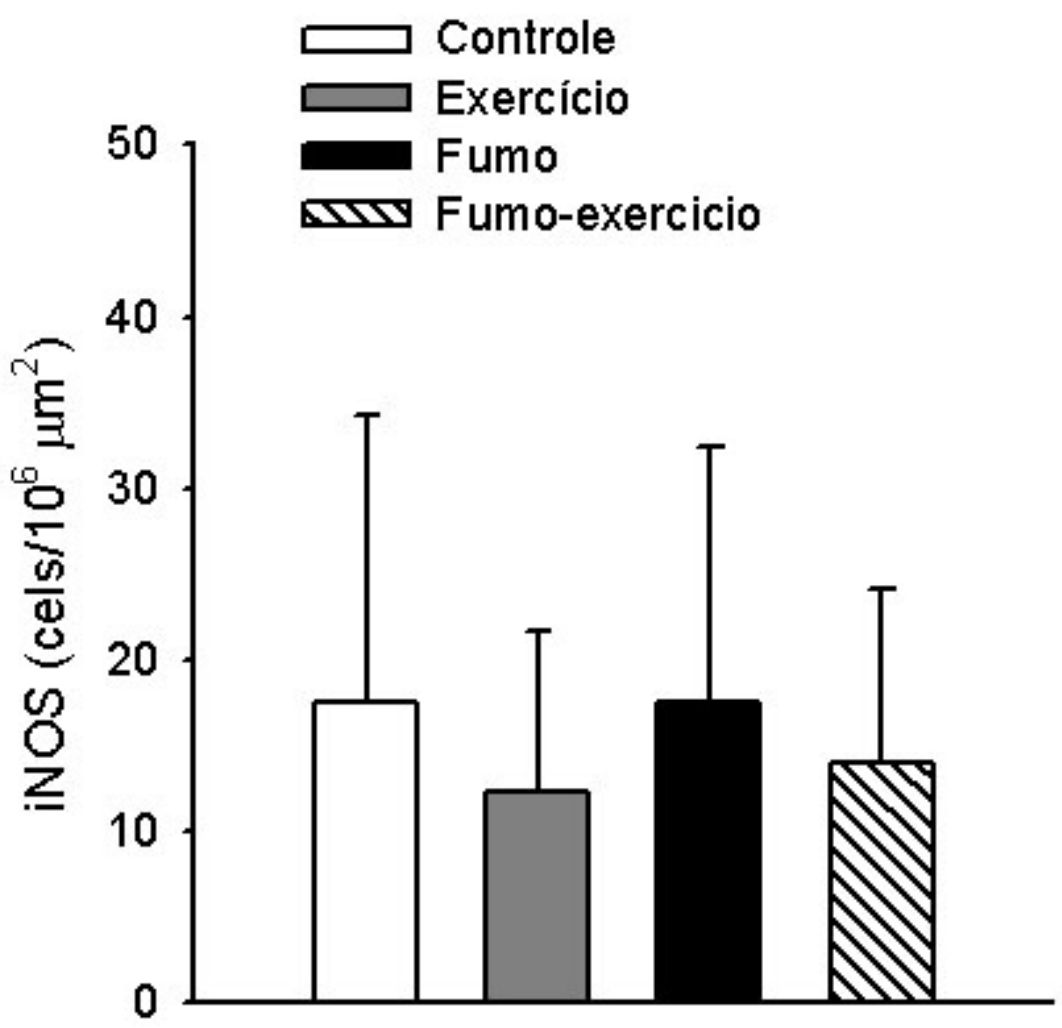

Figura 20 - Efeitos da exposição à fumaça de cigarro e do treinamento físico aeróbio regular de intensidade moderada sobre a densidade de células inflamatórias na parede alveolar positivas para iNOS. Valores expressos como média e desvio padrão. Não houve diferença estatisticamente significante entre os grupos. 
A exposição à fumaça de cigarros não modificou a densidade de células inflamatórias na parede alveolar positivas para GPx. O treinamento físico aeróbio de intensidade moderada aumentou a densidade de células inflamatórias na parede alveolar positivas para GPx quando comparado aos grupos que não realizaram treinamento físico (Figura 21).
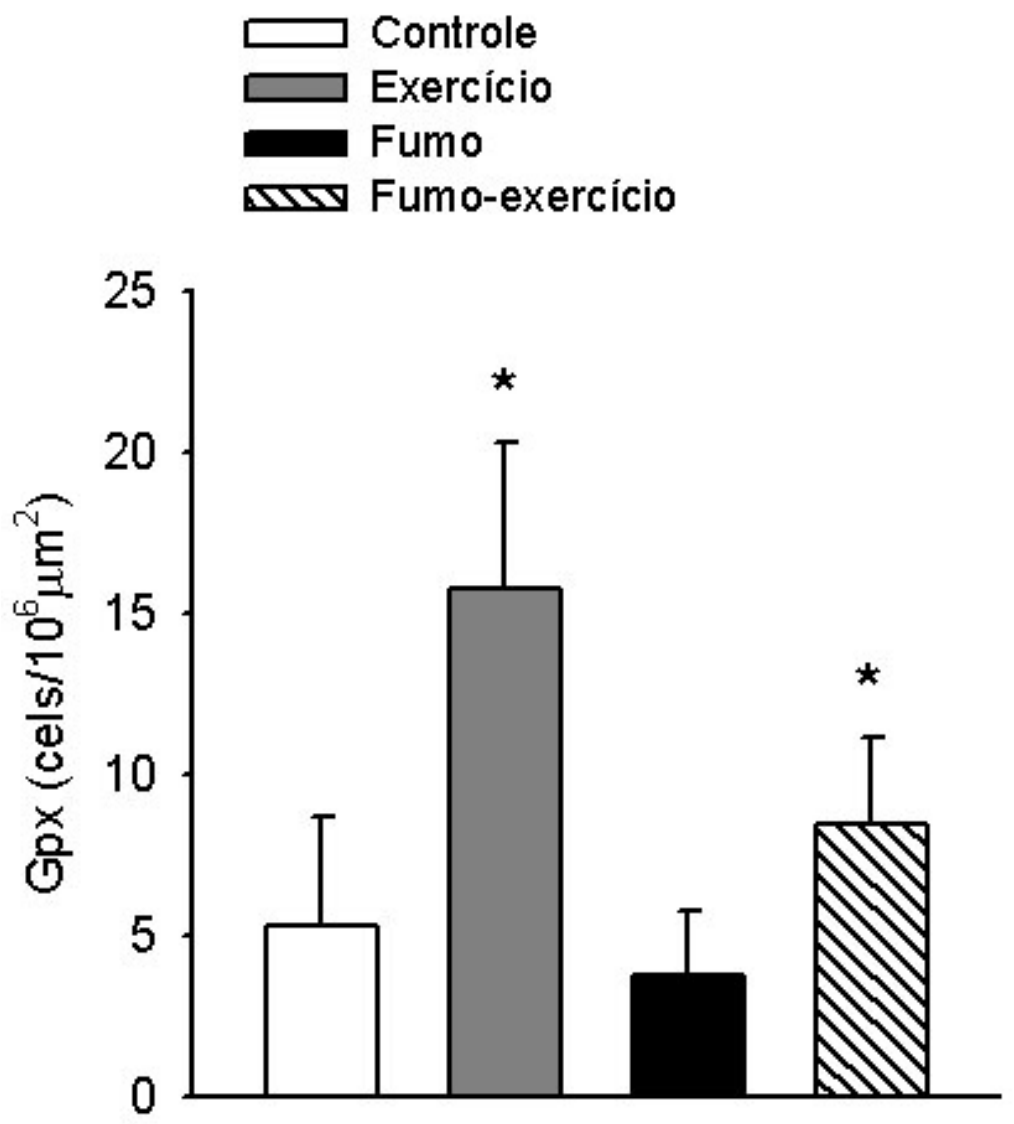

Figura 21 - Efeitos da exposição à fumaça de cigarro e do treinamento físico aeróbio regular de intensidade moderada sobre a densidade de células inflamatórias na parede alveolar positivas para GPx. Valores expressos como média e desvio padrão. ${ }^{*} p<0,001$, quando o grupo exercício foi comparado aos demais grupos e quando o grupo Fumo/Exercício foi comparado aos grupos Controle e Fumo. 
A exposição à fumaça de cigarros reduziu a densidade de células inflamatórias na parede alveolar positivas para SODCuZn e o treinamento físico aeróbio de intensidade moderada inibiu esta redução (Figura 22).

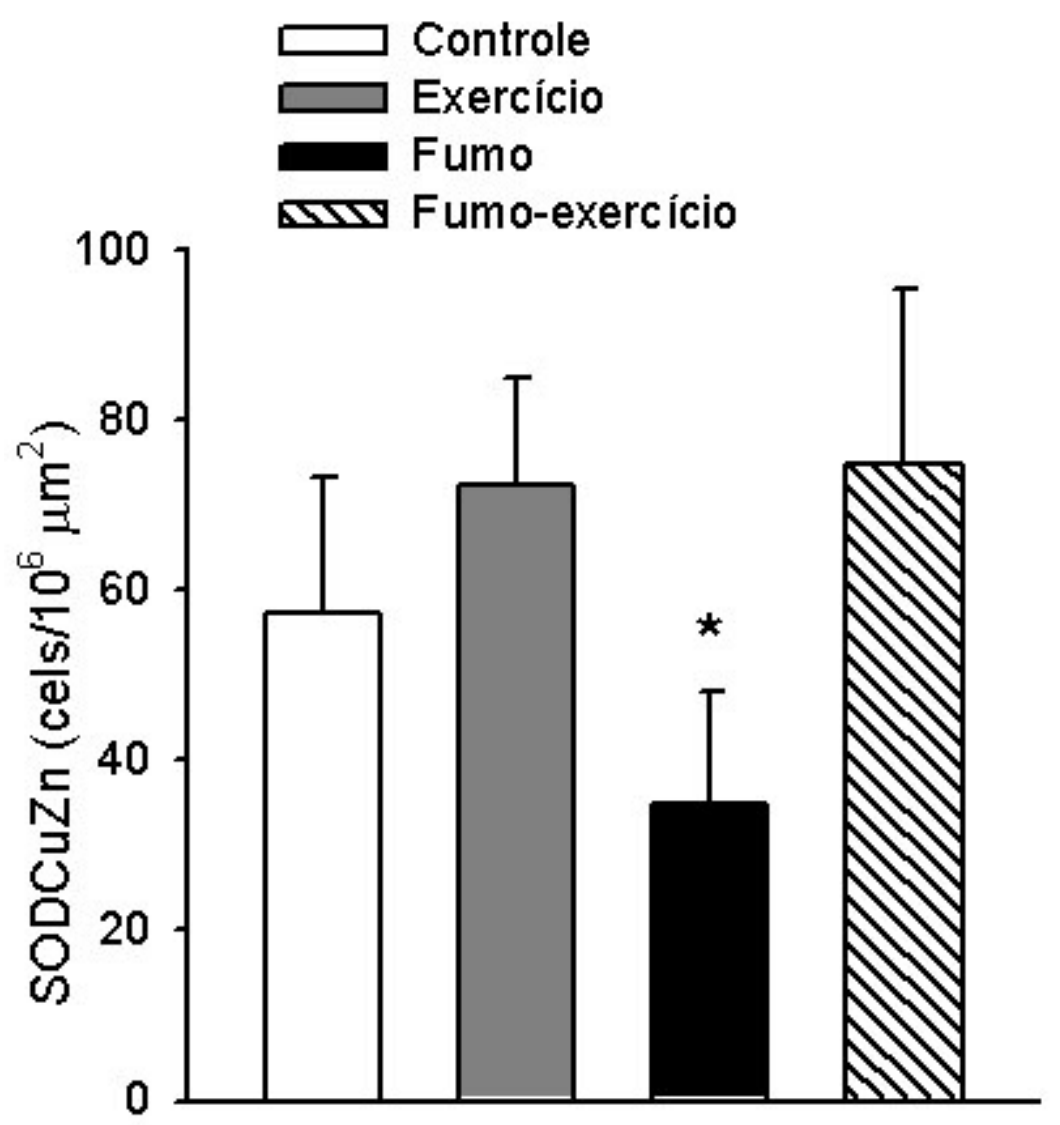

Figura 22 - Efeitos da exposição à fumaça de cigarro e do treinamento físico aeróbio regular de intensidade moderada sobre a densidade de células inflamatórias na parede alveolar positivas para SODCuZn. Valores expressos como média e desvio padrão. ${ }^{*} p<0,001$ quando comparado aos demais grupos. 
A exposição à fumaça de cigarro e o treinamento físico aeróbio de intensidade moderada não modificaram a densidade de células inflamatórias na parede alveolar positivas para SODMn, SOD-EC e Gp91phox (Figuras $23,24$ e 25$)$.

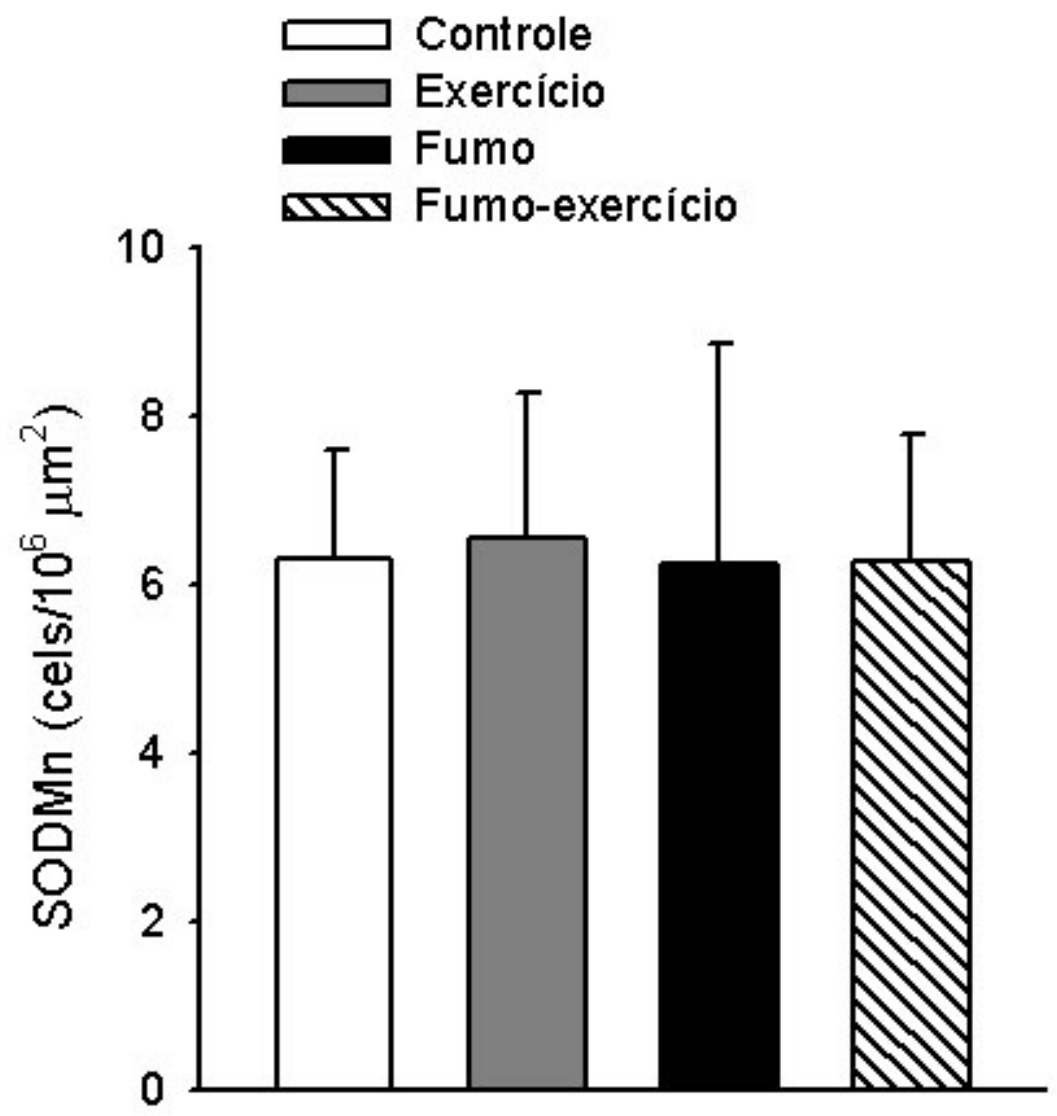

Figura 23 - Efeitos da exposição à fumaça de cigarro e do treinamento físico aeróbio regular de intensidade moderada sobre a densidade de células inflamatórias na parede alveolar positivas para SODMn. Valores expressos como média e desvio padrão. Não houve diferença estatisticamente significante entre os grupos. 


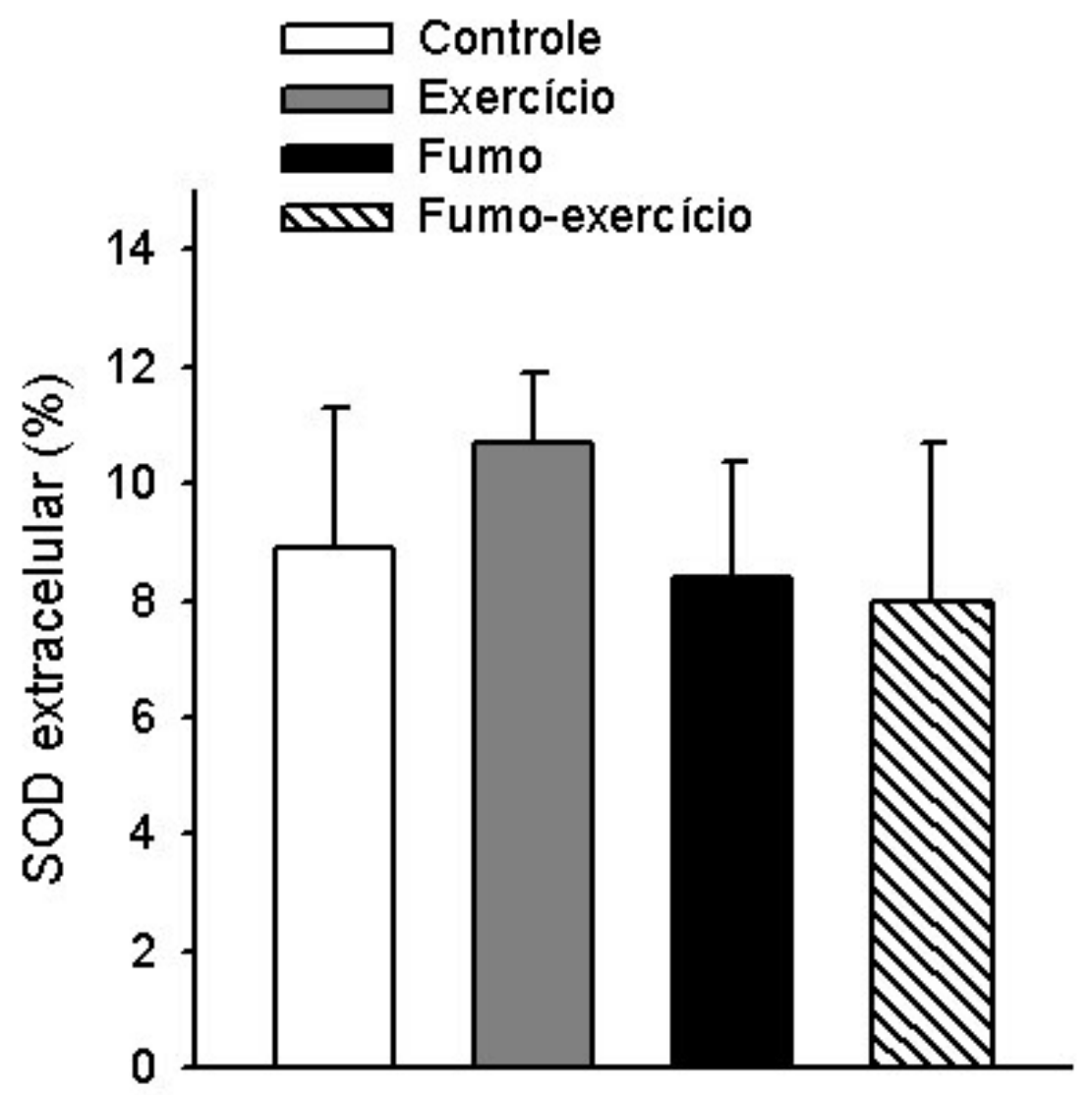

Figura 24 - Efeitos da exposição à fumaça de cigarro e do treinamento físico aeróbio regular de intensidade moderada sobre a densidade de células inflamatórias na parede alveolar positivas para SOD-EC no parênquima pulmonar. Valores expressos como média e desvio padrão. Não houve diferença estatisticamente significante entre os grupos. 


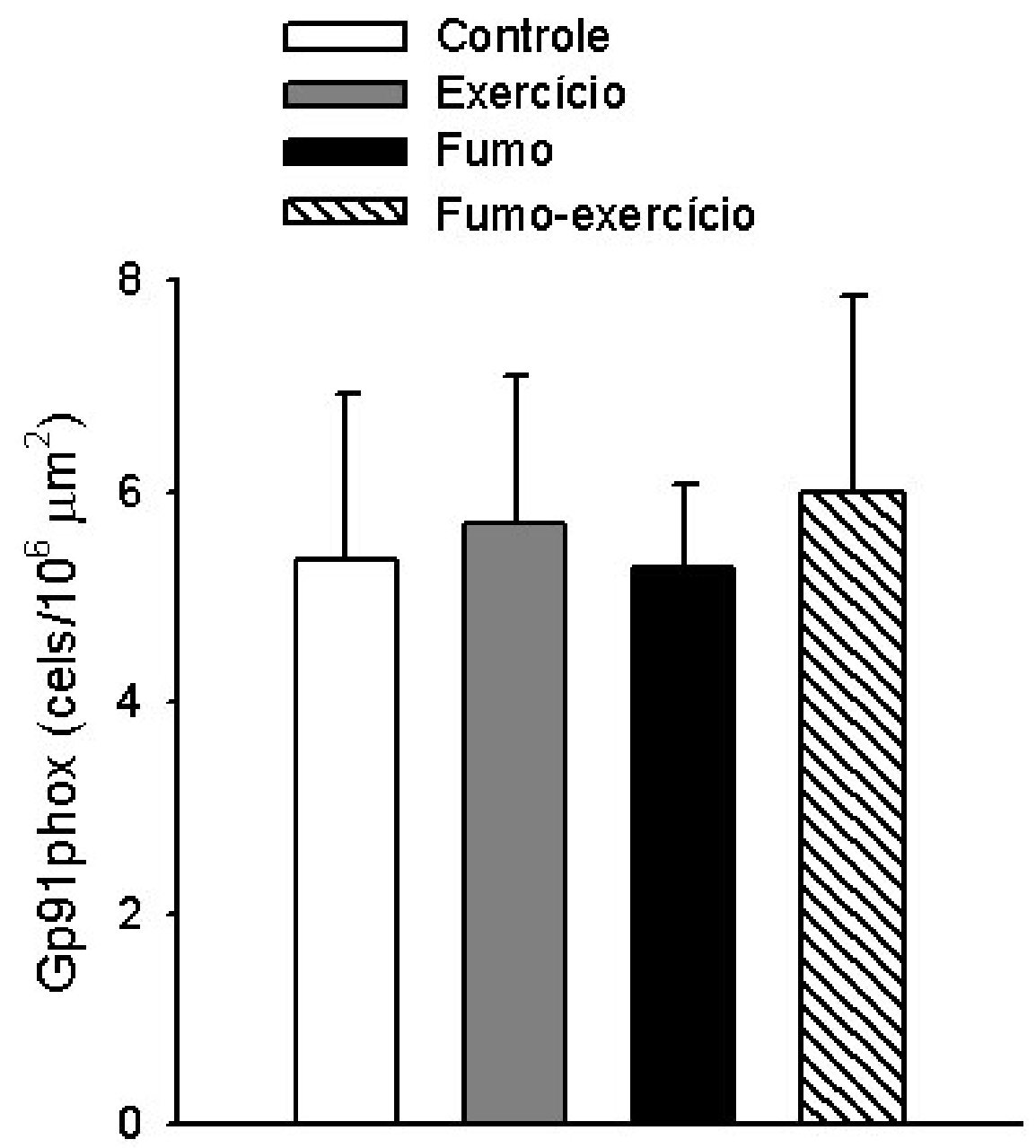

Figura 25 - Efeitos da exposição à fumaça de cigarro e do treinamento físico aeróbio regular de intensidade moderada sobre a densidade de células inflamatórias na parede alveolar positivas para Gp91phox. Valores expressos como média e desvio padrão. Não foram encontradas diferenças estatisticamente significantes entre os grupos. 
A exposição à fumaça de cigarro e o treinamento físico aeróbio de intensidade moderada não modificaram a densidade de células inflamatórias na parede alveolar positivas para MMP9 (Figura 26). Não houve diferenças estatisticamente significantes entre os grupos, ainda que pareça haver uma tendência a aumento nos animais do grupo Exercício essa diferença pode ter ocorrido ao acaso.
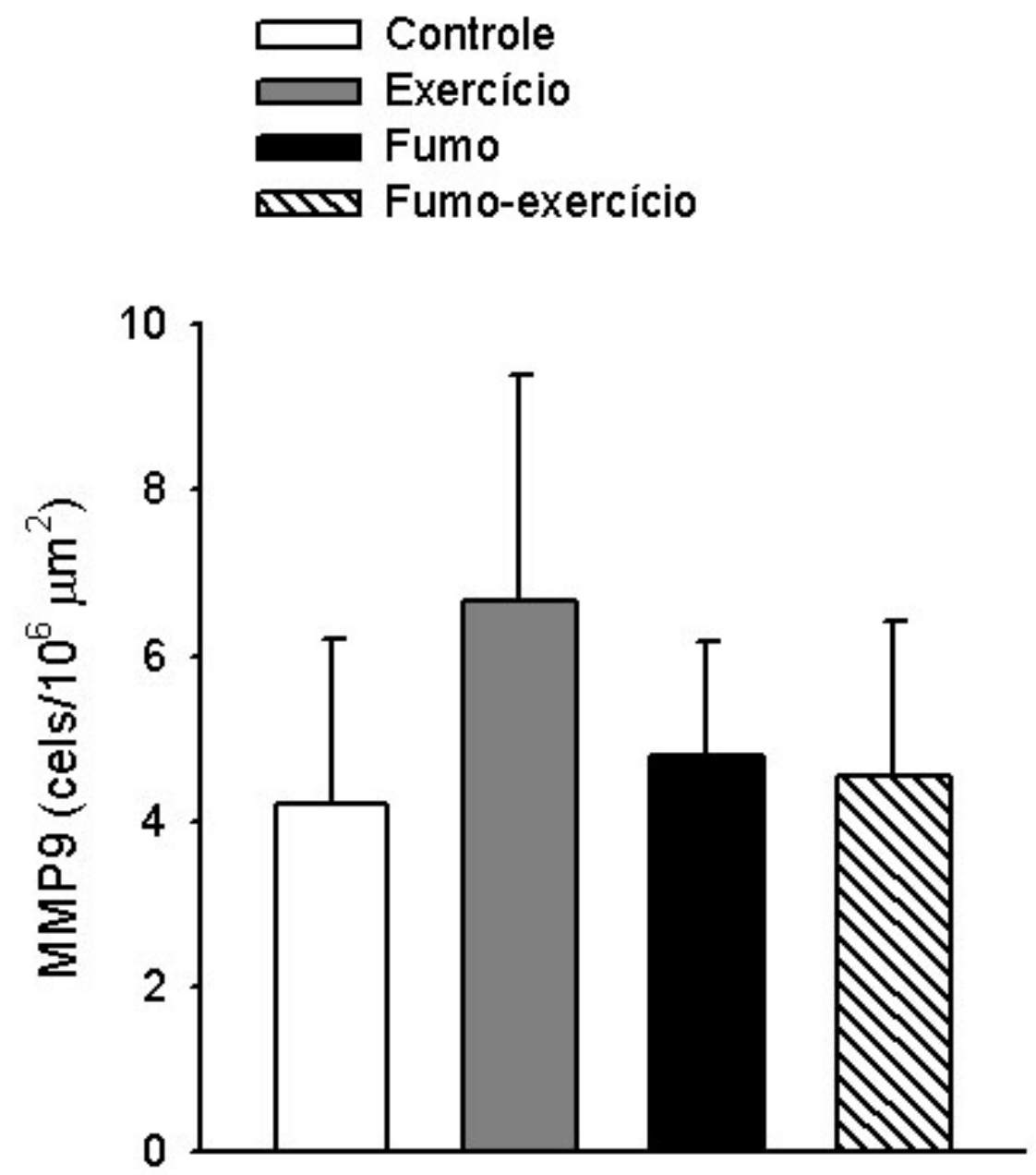

Figura 26 - Efeitos da exposição à fumaça de cigarro e do treinamento físico aeróbio regular de intensidade moderada sobre a densidade de células inflamatórias na parede alveolar positivas para MMP9. Valores expressos como média e desvio padrão. Não houve diferenças estatisticamente significantes entre os grupos. 
A exposição à fumaça de cigarros reduziu a densidade de células inflamatórias na parede alveolar positivas para TIMP1 e o treinamento físico aeróbio de intensidade moderada inibiu esta redução (Figura 27).

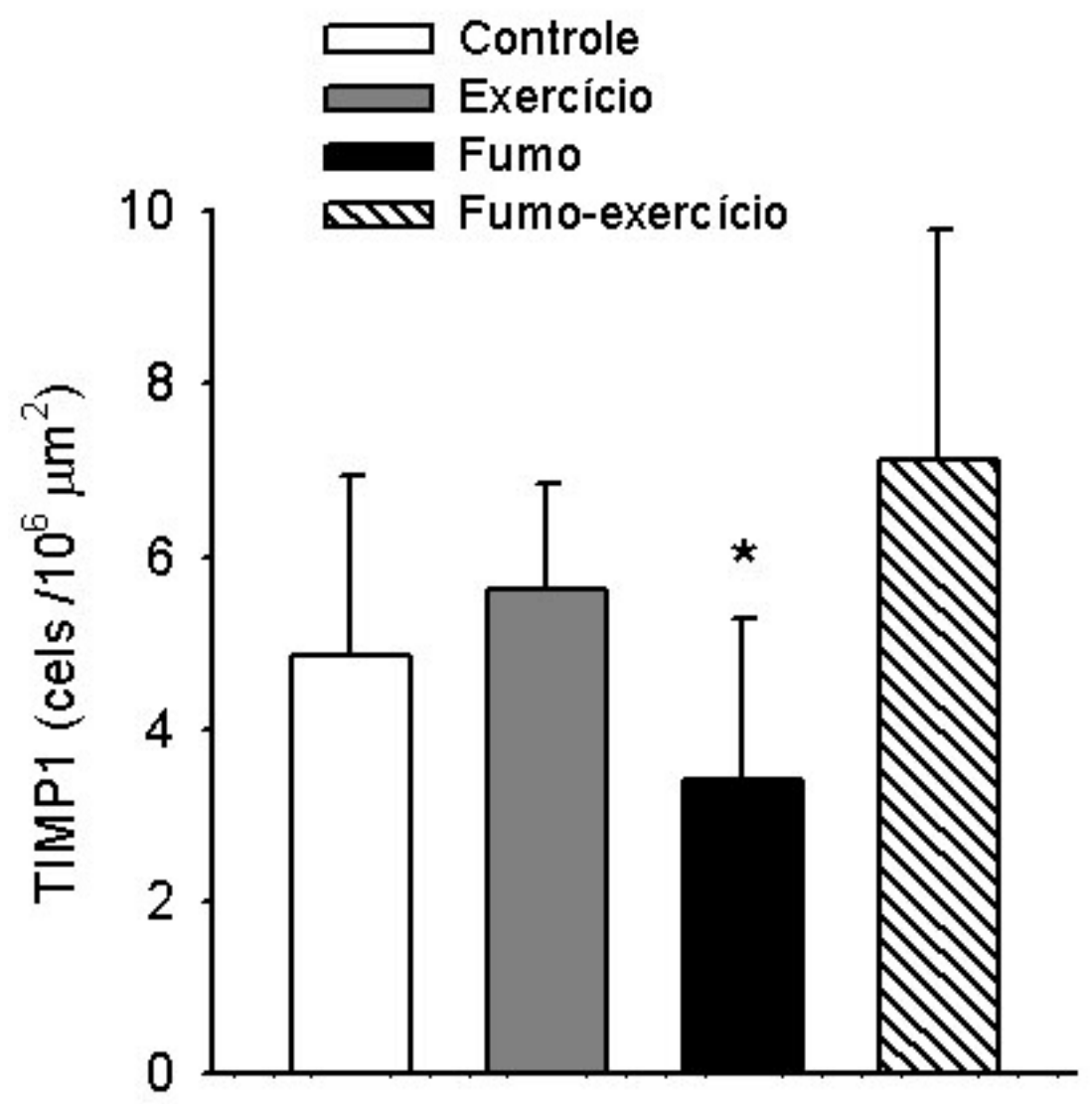

Figura 27 - Efeitos da exposição à fumaça de cigarro e do treinamento físico aeróbio regular de intensidade moderada sobre a densidade de células inflamatórias na parede alveolar positivas para TIMP-1. Valores expressos como média e desvio padrão. ${ }^{*} \mathrm{p}<0,01$ quando comparado ao grupo Fumo/Exercício. 
A exposição à fumaça de cigarros elevou a densidade de células inflamatórias na parede alveolar positivas para MCP1 e o treinamento físico aeróbio de intensidade moderada inibiu esta elevação (Figura 28).
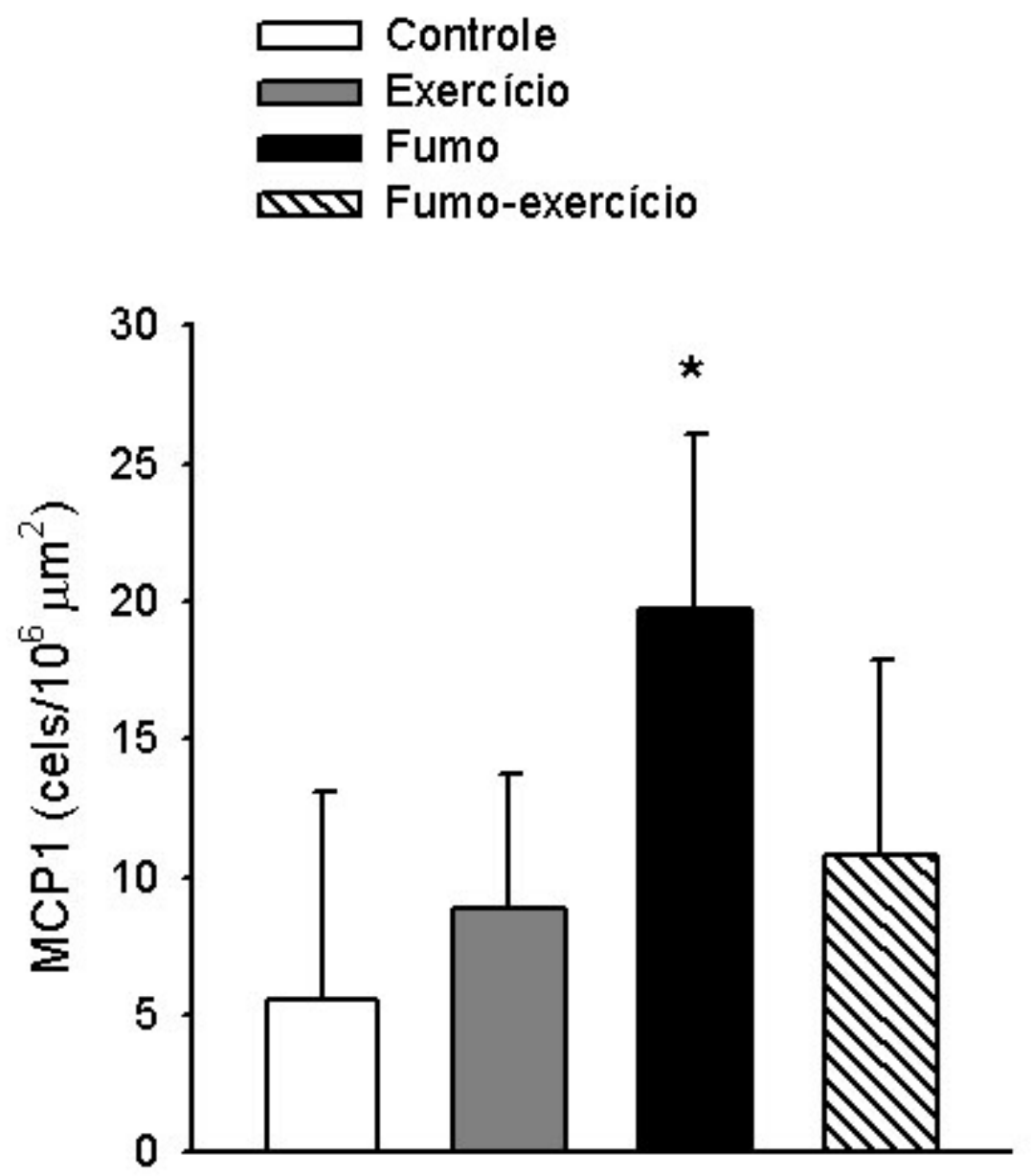

Figura 28 - Efeitos da exposição à fumaça de cigarro e do treinamento físico aeróbio regular de intensidade moderada sobre a densidade de células inflamatórias na parede alveolar positivas para MCP1. Valores expressos como média e desvio padrão. ${ }^{*} p<0,001$ quando comparado aos demais grupos. 
A exposição à fumaça de cigarros parece aumentar a densidade de células inflamatórias na parede alveolar positivas para TNF- $\alpha$ e 0 treinamento físico aeróbio de intensidade moderada parece inibir esta redução (Figura 29).

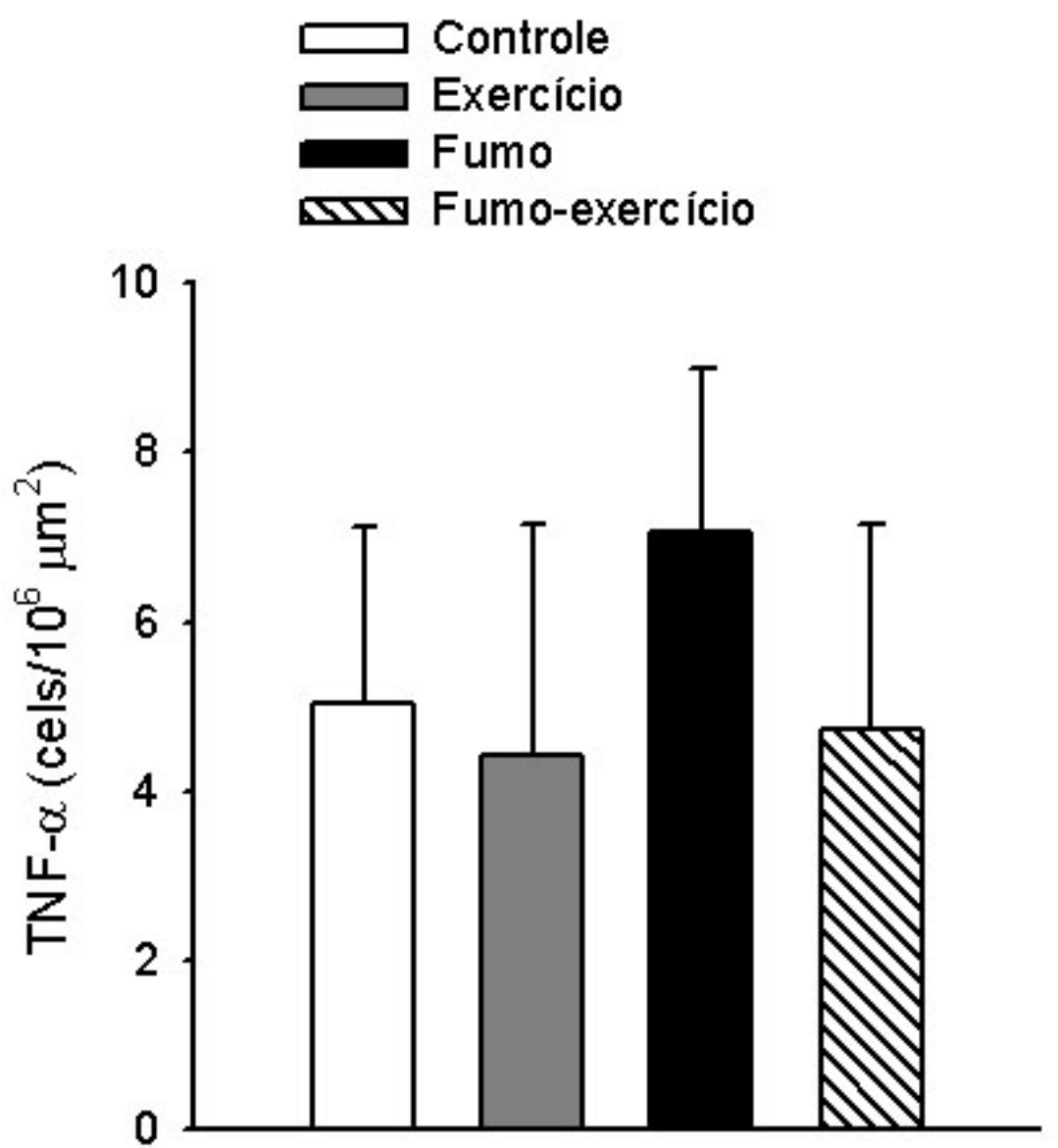

Figura 29 - Efeitos da exposição à fumaça de cigarro e do treinamento físico aeróbio regular de intensidade moderada sobre a densidade de células inflamatórias na parede alveolar positivas para TNF- $\alpha$. Valores expressos como média e desvio padrão. $p=0,053$ quando comparado aos demais grupos. 
A exposição à fumaça de cigarros reduziu a densidade de células inflamatórias na parede alveolar positivas para IL-10 e o treinamento físico aeróbio de intensidade moderada inibiu esta redução (Figura 30).

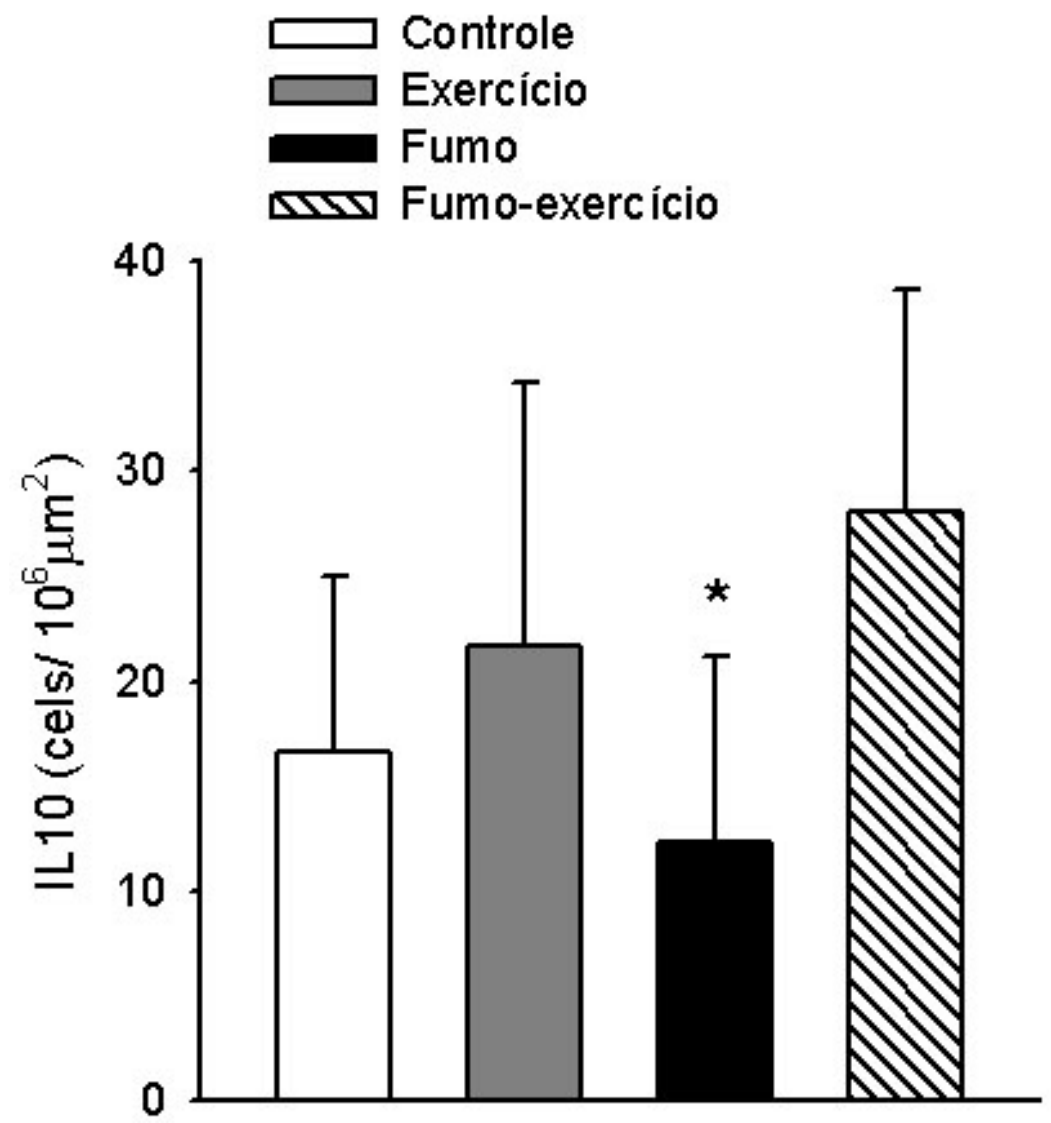

Figura 30 - Efeitos da exposição à fumaça de cigarro e do treinamento físico aeróbio regular de intensidade moderada sobre a densidade de células inflamatórias na parede alveolar positivas para IL-10. Valores expressos como média e desvio padrão. ${ }^{*} \mathrm{p}<0,01$ quando comparado ao grupo Fumo/Exercício. 
A inalação da fumaça de cigarros parece reduzir a densidade de células inflamatórias na parede alveolar positivas para IL-1 ra, mas essa redução não é estatíticamente significativa (Figura 31).

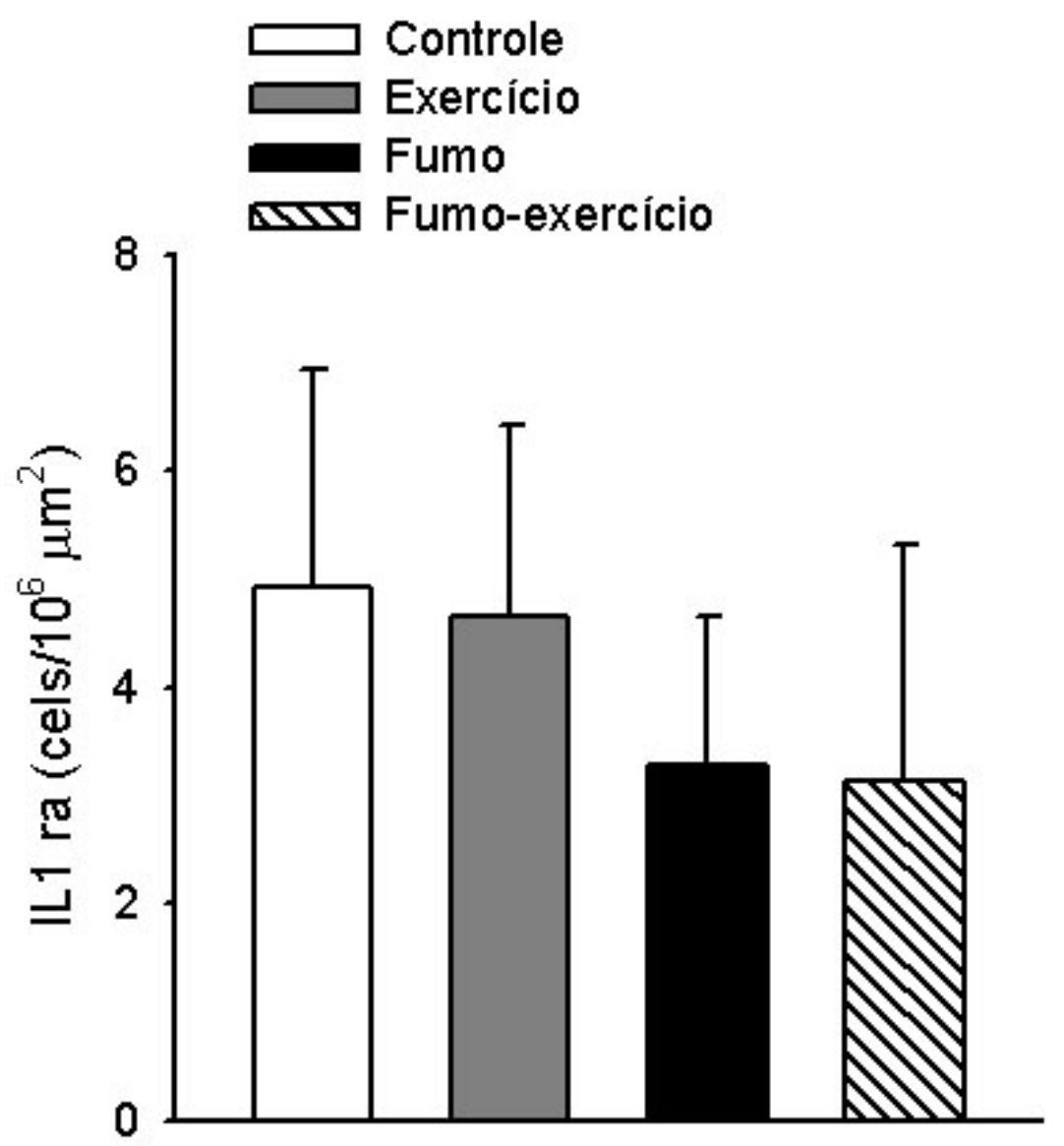

Figura 31 - Efeitos da exposição à fumaça de cigarro e do treinamento físico aeróbio regular de intensidade moderada sobre a densidade de células inflamatórias na parede alveolar positivas para IL-1 ra. Valores expressos como média e desvio padrão. Não foram encontradas diferenças estatisticamente significantes entre os grupos. 


\section{DISCUSSÃO}




\section{DISCUSSÃo}

O presente estudo demonstrou, pela primeira vez, um efeito protetor do treinamento físico aeróbio em alguns aspectos da lesão pulmonar produzida pela exposição à fumaça de cigarro em camundongos.

A doença pulmonar obstrutiva crônica (DPOC) é uma doença caracterizada por limitação ao fluxo aéreo não completamente reversível, geralmente progressiva e associada a uma resposta inflamatória anormal a partículas ou gases tóxicos. O maior fator de risco para o desenvolvimento da DPOC é a exposição à fumaça do cigarro (1). O fumo, diretamente ou por meio das células inflamatórias, pode aumentar a concentração de oxidantes e também levar a uma redução da capacidade antioxidante pulmonar (23, 24).

Os modelos experimentais de DPOC em camundongos são ferramentas importantes no teste de hipóteses e os conhecimentos advindos de modelos animais visam auxiliar o tratamento de pacientes com DPOC. Como a maior causa da doença em humanos é o tabagismo, a exposição à fumaça de cigarro tem sido o modelo experimental de escolha (84). A suscetibilidade à doença em camundongos é dependente da espécie (190) e camundongos $\mathrm{C} 57 \mathrm{BI} 6$ expostos à fumaça de cigarro por 24 semanas podem apresentar alargamento de espaços aéreos e uma histologia semelhante à do enfisema humano $(84,137)$.

O Intercepto Linear Médio (Lm), que é um marcador do grau de distensão de espaços aéros presente no pulmão pode ser calculado por técnicas morfométricas e de imagem. A distensão alveolar também pode ser 
caracterizada pela medida da proporção da área de parênquima sobre a área de espaços aéreos. No entanto, esta medida fornece um valor médio da distensão alveolar e pode ficar prejudicada por uma eventual compressão de espaços aéreos vizinhos à área de destruição. Estas medidas não fornecem uma análise compartimentalizada da lesão pulmonar. Em situações onde a destruição do parênquima concentra-se em determinada região do pulmão, uma medida que avalie a média de toda a área de parênquima tende a perder sensibilidade. Portanto, neste estudo utilizamos o Intercepto Linear Médio (Lm) como um marcador do grau de distensão alveolar e realizamos as medidas em duas regiões: próximo à pleura e próximo às vias aéreas, para observar o comportamento da lesão.

Os dados encontrados neste trabalho são compatíveis com o desenvolvimento de enfisema em camundongos publicados em outros estudos $(137,138,190)$ e o tempo de exposição de 24 semanas utilizados neste estudo, em camundongos C57BI6, foi suficiente para produzir uma lesão detectável pelas medidas tradicionais de Lm. Foi possível observar alargamento dos espaços aéreos nos dois compartimentos pulmonares, definidos pela distância em relação à pleura e às vias aéreas, o que sugere que a lesão que se desenvolve no pulmão é difusa. O efeito da exposição ao cigarro sobre o Lm pode diferir dependendo da linhagem de camundongo estudada. O estudo de Guerassimov (190) demonstrou que o Lm nos camundongos C57B|6 após exposição por 24 semanas à fumaça de cigarro aumentou em 13,2\% comparado ao controle, e as linhagens mais susceptíveis foram em ordem decrescente AKR/J (38\%), A/J $(17,9 \%)$ e SJ/L 
(23,8\%). Além disso, os camundongos C57BI6 expostos à fumaça de cigarro apresentaram uma redução no peso corporal na $24^{a}$ semana comparado ao controle. Em nosso modelo experimental, observamos um aumento no Lm de $8,05 \%$ na região próxima à pleura e de $12,9 \%$ próximo às vias aéreas nos animais expostos à fumaça de cigarro, e uma redução significativa no peso corporal nas primeiras oito semanas de exposição, a partir daí parece haver uma tolerância e o peso se mantém.

A maneira com que os animais são expostos ao cigarro é diferente entre os estudos e são utilizados equipamentos muito diversos para expor os animais à fumaça de cigarro.

Efeitos sistêmicos da DPOC incluem perda de peso, alterações nutricionais e disfunção muscular. A diminuição na capacidade ao exercício é uma conseqüência grave da doença devido à fatores como a dificuldade de ventilação (hiperinsuflação dinâmica), de troca gasosa, alterações na musculatura respiratória e sistêmica e transtornos nutricionais (191). A fadiga nas extremidades inferiores parecem ser as principais causas da limitação ao exercício (Lillian, 1992). Interessantemente, no presente estudo, os animais expostos ao cigarro não mostraram pior desempenho no teste físico quando comparados aos controles. Provavelmente isso ocorreu porque alterações fisiológicas obtidas pelos modelos experimentais de DPOC mimetizem a forma leve da doença em humanos $(138,190,192-194)$.

A inflamação na DPOC tem sido mostrada pelos estudos por um aumento de macrófagos, linfócitos ou neutrófilos no parênquima pulmonar $(105,106,109,110,112)$. Embora a maioria destes estudos tenha 
identificado pelo menos um tipo de célula inflamatória nos pacientes com DPOC, o tipo celular predominante não é o mesmo em todos os casos. Estas diferenças podem ocorrer por variações amostrais. Porém, ainda que as células inflamatórias pareçam essenciais para o desenvolvimento do enfisema, sua exata contribuição não está totalmente esclarecida.

Os macrófagos são as células mais freqüentemente encontradas em estudos de pacientes com DPOC, o que sugere que pode ser uma célula central no desenvolvimento da doença $(23,115,131,195,196)$.

Em uma revisão sobre os mecanismos celulares para o desenvolvimento do enfisema, Di Stefano propõe que as células inicialmente recrutadas seriam os macrófagos e linfócitos, predominantemente encontrados em pacientes com DPOC leve (197). Em fases mais avançadas da doença, neutrófilos e macrófagos seriam recrutados, enquanto linfócitos seriam menos encontrados (198). Muitos outros autores concordam com esta interpretação temporal da resposta inflamatória na DPOC, atribuindo um papel central aos macrófagos, que estariam inicialmente presentes e sinalizariam para os demais mecanismos de lesão $(23,130)$. Os neutrófilos poderiam aparecer apenas em uma fase mais tardia da evolução da doença.

Modelos animais de exposição aguda ao cigarro mostram recrutamento tanto de neutrófilos como de macrófagos para a via aérea, detectados pelo lavado broncoalveolar (109). Não sabemos ao certo como ocorre a evolução desta inflamação aguda observada nos estudos experimentais para o processo inflamatório crônico. É possível que o recrutamento celular encontrado nesta fase desapareça e o processo 
inflamatório secundário à exposição crônica reapareça mais tardiamente, com um papel fisiopatológico diferente (197).

Nosso modelo experimental é um modelo de exposição crônica à fumaça de cigarro no qual a destruição tecidual parece ser mediada pelos macrófagos. Observamos um aumento no número total de células inflamatórias e de macrófagos no LBA, modificações já demonstradas em outros estudos $(94,190)$. Neutrófilos e linfócitos não foram encontrados aumentados no lavado broncoalvolar neste modelo. É possível que essas células tenham sido importantes na fase aguda da lesão. Guerassimov mostrou que as células T (CD4 e CD8) tinham uma tendência a diminuir depois de 24 semanas de exposição ao cigarro (190).

A expressão de IL-10, uma potente citocina antiinflamatória, mostrouse reduzida em nosso modelo nos animais expostos à fumaça de cigarro, em contraste aos resultados mostrados por Guerassimov (190). A IL-10 modula a expressão de citocinas, mediadores solúveis e moléculas da superfície celular por células de origem mielóide, com consequências importantes pela capacidade de ativar e sustentar respostas inflamatórias e imunes (Moore, 2001). A IL-10 inibe a produção de quimiocinas induzíveis que estão envolvidas na inflamação, como MIP-1. Este cenário poderia explicar nossos achados em que a baixa regulação de IL-10 no pulmão estimulou a ativação de macrófagos nos animais expostos ao cigarro (Cosio, 2004).

Investigamos também a expressão de MCP1 e TNF- $\alpha$ em células inflamatórias no parênquima pulmonar. 
O fator de necrose tumoral (TNF- $\alpha$ ) desempenha um papel importante na inflamação da doença pulmonar obstrutiva crônica (DPOC) (198-200). O tabagismo aumenta a liberação de TNF- $\alpha$ pelos macrófagos alveolares (201). Takabatake e colaboradores (202) concluiu que níveis de TNF- $\alpha$ no escarro induzido e no plasma estão aumentados em pacientes com DPOC. Os macrófagos induzidos por substâncias do cigarro, também podem secretar espécies reativas de oxigênio e um peptídeo quimiotático para monócitos (MCP1) (23). A MCP1 é expressa por macrófagos alveolares, linfócitos T e células epiteliais $(203,204)$. A MCP1 também é secretada por pneumócitos tipo II em cultura, e sua liberação é estimulada por LPS, mas é inibida pelo extrato de cigarro (205). Os níveis de MCP1 estão aumentados no escarro, lavado broncoalveolar e em pulmões de pacientes com DPOC (204).

Em nosso modelo experimental observamos um aumento significativo de MCP1 nos animais expostos à inalação de fumaça de cigarro, enquanto o TNF- $\alpha$ mostrou uma tendência em aumentar nesses animais.

A inalação de fumaça de cigarro também pode induzir a secreção de MMP2, MMP9, MMP12, elastase neutrofílica e catepsinas K, L e S, pelos macrófagos (23). Alguns estudos sugerem que os estímulos próinflamatórios induzidos pelo tabagismo podem regular a atividade da MMP-9 na DPOC (206-209). Entretanto, em nosso modelo experimental não encontramos aumento de MMP9 nos animais expostos à inalação de fumaça de cigarro, mas encontramos uma diminuição na TIMP1, seu respectivo inibidor endógeno. Esse resultado foi demonstrado em outros estudos em 
que houve uma diminuição na liberação das TIMPs pelos macrófagos alveolares na DPOC $(209,210)$. É provável que o desequilíbrio entre as proteases macrofagicas e suas respectivas antiproteases tenham um papel patogênico em nosso modelo experimental de enfisema.

Investigamos, pela primeira vez, a produção de óxido nítrico no ar exalado em um modelo experimental induzido pela exposição à fumaça de cigarro, e mostramos um aumento de $\mathrm{NO}$ exalado nos animais expostos ao cigarro. Estudos in vitro têm mostrado que oxidantes podem causar a liberação de mediadores inflamatórios, como o NO (211). Diferente da asma, os estudos de NO exalado em pacientes com doença pulmonar obstrutiva crônica (DPOC) são bastante conflitantes (212-214). Curiosamente, têm sido relatados aumentos nos níveis de óxido nítrico exalado, em um grupo de pacientes com DPOC durante o inverno e no início da exacerbação (215), sugerindo que o acompanhamento da variação do óxido nítrico exalado na DPOC pode ter implicações clínicas (216). Alguns estudos de pacientes com DPOC mostraram elevados níveis de NO (217), mas não tão elevados como os relatados em outros estudos de asma (218-220). Além disso, um estudo recente tem sugerido o óxido nítrico exalado como potencial marcador em pacientes com DPOC (221).

A expressão da iNOS é induzida sob condições inflamatórias e oxidantes, como na $\operatorname{DPOC}(21,222,223)$, entretanto, em nosso estudo não observamos alteração na expressão de iNOS no parênquima pulmonar desses animais. 
Assim, investigamos a quantidade de estresse oxidativo presente no LBA dos animais e visto que, o grau de estresse oxidativo pode ser avaliado utilizando compostos que geralmente resultam de oxidação/nitração de lipídios ou proteínas, investigamos a expressão de 8-isoprostano no parênquima pulmonar, por ter sido sugerido como um dos mais promissores biomarcadores do estresse oxidativo (224).

Encontramos um aumento significativo de espécies reativas de oxigênio no LBA e de 8-isoprostano no parênquima pulmonar nos animais expostos à inalação de fumaça de cigarro. Isoprostano é um produto da peroxidação lipidica do ácido aracdonico mediada pelas espécies reativas de oxigênio. Estudos mostraram um aumento de 8-Isoprostano na urina de pacientes com DPOC, e esse aumento foi maior durante exacerbações (225). 8-Isoprostano também estava aumentado no ar exalado de fumantes, mas em menor grau do que em pacientes com $\operatorname{DPOC}(21,226)$.

Esse aumento na geração de espécies reativas de oxigênio em nosso modelo foi acompanhado de redução na expressão da enzima superóxido dismutase CuZn nos animais expostos à fumaça de cigarro. Outros estudos mostraram que a atividade total antioxidante da SODCuZn estava reduzida no epitélio das vias aéreas de asmáticos (47) e um aumento na produção do ânion superóxido foi observado nesses pacientes (48). Apesar do fato de excessiva produção de espécies reativas de oxigênio, particularmente ânion superóxido, na fisiopatologia da doença pulmonar obstrutiva crônica (227), não há relatos mostrando a expressão da SODCuZn nessa doença (228). Em nosso modelo experimental as SODs Manganês e Extracelular e a 
glutationa peroxidase não estavam alteradas nos animais expostos ao cigarro.

Nossos resultados sugerem que um desequilíbrio oxidante / antioxidante possa ser um dos mediadores do processo lesivo iniciado pelas toxinas do cigarro, bem como efetores da lesão pulmonar, produzindo destruição do parênquima pulmonar.

A medida da função pulmonar em camundongos é essencial para estabelecer a relevância dos modelos murinos nas doenças pulmonares humanas. No entanto, fazer tais medidas representa um desafio técnico, devido ao pequeno tamanho do animal, e à utilização de pequenos fluxos respiratórios. O enfisema apresenta como principal alteração funcional diminuição na pressão de recolhimento elástico do pulmão, no entanto, Guerrassimov não conseguiu mostrar alterações na mecânica pulmonar de camundongos C57BL6 expostos à fumaça de cigarro por 24 semanas, apesar do aumento de Lm em 13,2\%.

Em nosso modelo de exposição crônica à fumaça de cigarro, encontramos uma queda na elastância pulmonar (Htis) desses animais, caracterizando um decréscimo da capacidade de recolhimento elástico, compatível com o perfil funcional do enfisema pulmonar humano. As medidas de resistência de vias aéreas (Raw) e de resistência de tecidos (Gtis) não mostraram diferenças estatisticamente significativas entre os grupos. Houve uma tendência à redução das fibras elásticas e um aumento das fibras colágenas nos grupos expostos ao cigarro. 
A fumaça de cigarro inibiu a reparação pulmonar em modelos animais de enfisema. Em hamster, a lesão induzida pela elastase foi associada a uma rápida perda de fibras de colágeno e elástica no tecido pulmonar (229, 230). Isto foi seguido nos próximos dias ou semanas pela síntese e acumulo de ambos. No entanto, o conteúdo de elastina no pulmão retornou muito próximo aos níveis normais e o conteúdo de colágeno ultrapassou o normal. Esta nova síntese, no entanto, sugere que os mecanismos de reparo pulmonar podem ser ativados. A síntese da elastina também é inibida pela fumaça de cigarro. Após instilação intratraqueal de elastase em hamster, uma nova síntese de elastina é marcadamente inibida pela concomitante exposição à fumaça de cigarro (231). A maturação de fibras elásticas, e provavelmente a sua reparação impõem um processo dependente da atividade da enzima lisil oxidase (232). Esta enzima é inibida pelo fumo (233), sugerindo que o fumo pode inibir tanto a polimerização e maturação da elastina, assim como a sua produção. Morris (234) mostrou que as fibras elásticas foram danificadas em cultura de células de fibroblastos expostos a elastase, no entanto, 22 dias após a exposição, as fibras elásticas foram iguais às fibras do grupo controle. A destruição de fibras elásticas e colágenas podem iniciar em uma fase bem precoce da exposição ao cigarro (109). No entanto, a deposição de novas fibras (remodelamento) parece ser um processo mais lento, que acontece em modelos crônicos.

A Iniciativa Global para a Doença Pulmonar Obstrutiva Crônica (GOLD) propôs potenciais indicadores que deveriam estar presentes em 
modelos animais para a presença de DPOC. A exposição aos fatores de risco, como a fumaça de cigarro, é o primeiro indicador proposto pelo GOLD; e em seguida, a obstrução ao fluxo aéreo, que pode ser acessada com testes de função pulmonar; além de hipersecreção, tosse e dispnéia e presença de enfisema (1)

O modelo experimental proposto neste estudo cumpriu vários indicadores orientados pelo GOLD, como a exposição ao cigarro, como fator de risco, redução na elastância pulmonar e enfisema pulmonar.

O modelo experimental de DPOC em camundongos ainda é o modelo mais favorecido no que diz respeito a mecanismos de imunidade celular e por oferecer a oportunidade de manipulação genética. No entanto, uma das importantes limitações nesses modelos animais é a dificuldade em reproduzir a doença em pequenas vias aéreas, devido aos poucos níveis de ramificação brônquica. Parte do desafio encontra-se na mensuração da função pulmonar em animais muito pequenos, e estes devem ser correlacionados a marcadores inflamatórios e alterações histológicas. Além da dificuldade em avaliar a função pulmonar de camundongos, a fumaça de cigarro tem efeitos sobre o peso corporal e os níveis de carboxihemoglobina nesses animais. Como outros sistemas orgânicos podem ser afetados em pacientes com DPOC é importante que estes efeitos estejam presentes em modelos experimentais (135).

Embora as alterações observadas em modelos animais não sejam totalmente iguais à da situação humana e muitos mediadores envolvidos possam ter diferentes efeitos funcionais especialmente no trato respiratório 
de murinos, os modelos experimentais representam abordagens úteis para investigar mecanismos celulares e moleculares subjacentes ao desenvolvimento e progressão da DPOC.

O modelo experimental aqui utilizado, como demonstrado em outros estudos experimentais de indução de enfisema por exposição ao cigarro, mostra alterações fisiológicas que mimetizam a forma leve da DPOC em humanos $(138,190,192-194,235)$. Nosso estudo sugere que o estresse oxidativo tem grande importância na patogênese da doença, como mostrado pelo aumento de ROS, óxido nítrico e 8-Isoprostano nos pulmões. O estresse oxidativo pode estar envolvido, também, na inativação de antiproteases e no aumento da expressão de mediadores pró inflamatórios.

O tabagismo é o mais importante fator ambiental na patogênese da doença pulmonar obstrutiva crônica, no entanto, apenas cerca de $20 \%$ dos fumantes desenvolvem a doença, independentemente da quantidade de cigarros consumidos (2). No entanto, nenhum dos mecanismos acima descritos explica porque só esse número limitado de indivíduos fumantes desenvolve DPOC. Isso indica que a suscetibilidade à doença provavelmente resulte de múltiplos componentes genéticos e de efeitos ambientais.

O exemplo mais conhecido da influência da variação no genoma e susceptibilidade a DPOC é o polimorfismo genético à $\alpha-1$ antitripsina. No entanto, esse polimorfismo representa apenas 1 a $2 \%$ dos casos da doença (2). 
É possível que haja interferência do ambiente e estilo de vida no desenvolvimento da doença? É possível que a prática regular de exercício físico aeróbio por fumantes influencie no desenvolvimento da doença?

Um estudo prospectivo baseado em uma amostra da população ( $n=$ 6790) realizado em Copenhagem com avaliação a cada 5-10 anos mostrou que a prática de atividade física de moderado ou alto grau por fumantes ativos reduziu o risco de desenvolver DPOC comparado ao grupo que realizava pouca atividade física (11).

Apesar da incidência populacional da DPOC e da perspectiva do aumento da incidência da doença nas próximas décadas, este parece ser um estudo isolado que avaliou os efeitos do treinamento físico aeróbio no desenvolvimento da doença.

A Sociedade Americana de Tórax, a Sociedade Americana de Reabilitação Cardiovascular e Pulmonar e a Sociedade Européia Respiratória publicam anualmente orientações e revisões baseadas em evidências da literatura sobre os benefícios do treinamento físico aeróbio no tratamento da doença já instalada. Os benefícios de programas de reabilitação para pacientes com DPOC são bem estabelecidos como reforço da terapia padrão, a fim de controlar e aliviar os sintomas, otimizar a capacidade funcional, melhorar a qualidade de vida e reduzir o número de hospitalizações, reduzindo os custos com a doença $(236,237)$.

No entanto, o treinamento físico aeróbio parece trazer benefícios importantes para o fumante, e pode-se até mesmo sugerir que possa ter 
influência no desenvolvimento da doença, entretanto os mecanismos pelo qual isto pode ocorrer ainda são pouco compreendidos.

Vários estudos demonstraram que o exercício aeróbio pode apresentar efeitos antiinflamatórios contra a inflamação pulmonar alérgica e não alérgica e que parte dos efeitos antiinflamatórios do exercício é mediada pela liberação de citocinas anti-inflamatórias IL-10 e IL-1ra e também pela regulação direta do exercício na liberação de IL -1ß e TNF- $\alpha$ (5, 238-241).

Em nosso estudo o treinamento físico aeróbio regular de intensidade moderada inibiu a distensão alveolar, o aumento total de células inflamatórias e da produção de espécies reativas de oxigênio no LBA e o aumento na geração de óxido nítrico no ar exalado induzido pela exposição à fumaça de cigarro, assim como reduziu a expressão de 8-isoprostano e MCP1 e aumentou a expressão de GPx, SODCuZn, TIMP1 e IL-10, pelas células inflamatórias na parede alveolar. O estudo também demonstrou que o treinamento físico aeróbio foi capaz de inibir a queda da elastância pulmonar induzida pela exposição ao cigarro. Esses resultados sugerem que o treinamento físico aeróbio regular de intensidade moderada pode exercer um importante papel durante a instalação da doença, devido aos seus possíveis efeitos antioxidantes e antiinflamatórios.

Os animais expostos ao cigarro e que realizaram exercício físico mostraram uma redução de peso na $16^{a}$ e $24^{a}$ semana quando comparados ao grupo Exercício. Em relação aos testes físicos, o treinamento físico regular melhorou o condicionamento físico aeróbio dos animais expostos ao cigarro. 
A expressão de MMP9 não foi diferente entre os grupos, mas encontramos uma diminuição na TIMP1 nos animais expostos à inalação de fumaça de cigarro, que foi revertida pelo exercício aeróbio. Alguns estudos mostraram que a IL-10 suprime a liberação de MMP-9 a partir de monócitos de pacientes com DPOC e ao mesmo tempo, estimula a liberação de seus principais inibidores endógenos, a TIMP-1 $(242,243)$. Este cenário poderia explicar nossos achados em que o exercício aumentou a expressão de IL-10 no pulmão e pode ter estimulado a expressão da TIMP1 nos animais expostos ao cigarro, o que poderia contribuir na proteção contra o desenvolvimento do enfisema.

De forma aguda o exercício físico reduz o aumento de TNF- $\alpha$ em voluntários saudáveis após uma injeção de baixa dose de Escherichia coli (244), esse achado foi confirmado por Keller e colaboradores (245). O exercício regular tem um papel antiinflamatório mediado pela IL-6 derivada do músculo, essa citocina estimula o surgimento, de citocinas antiinflamatórias como IL-1ra e IL-10 e inibe a produção de citocinas pró inflamatórias como o TNF- $\alpha$ (246-248). A IL-1ra é um membro da família da IL-1 que se liga aos receptores IL-1, mas não induz qualquer resposta intracelular. Em nosso modelo experimental, a inalação da fumaça de cigarro parece reduzir a densidade de células inflamatórias na parede alveolar positivas para TNF- $\alpha$ e IL-1ra, mas essa redução não é estatíticamente significativa.

Alguns estudos têm demonstrado que parte dos efeitos antiinflamatórios do treinamento físico ocorre através da redução dos níveis 
de MCP-1 (249, 250). Em nosso modelo experimental, o treinamento físico aeróbio reduziu a expressão de MCP-1 por células inflamatórias no parênquima pulmonar induzido pela exposição à fumaça de cigarro. Estes resultados sugerem que este poderia ser um dos mecanismos envolvidos na redução da migração das células inflamatórias para o parênquima pulmonar nos animais expostos ao cigarro.

Além disso, neste estudo observamos um aumento do óxido nítrico exalado nos animais que realizaram exercício aeróbio.

O exercício tem um grande impacto na disponibilidade e bioatividade do óxido nítrico (NO) derivado do endotélio $(251,252)$. O estímulo à produção endotelial de NO é o aumento do fluxo sanguineo através dos vasos, o que resulta em aumento da bioativação da óxido nítrico sintase endotelial (eNOS) $(252,253)$. A produção do NO, por sua vez, aumenta o fluxo sanguíneo muscular pela vasodilatação, melhorando a disponibilidade de substratos energéticos e antioxidantes pela circulação. Assim, um aumento da produção de NO, regulado pelas NOs é visualizada como benéfica durante o exercício (254). Estudos sugerem que, pelo menos, dez semanas de exercício são necessárias para melhorar significativamente a vasodilatação endotélio-dependente em homens jovens saudáveis (251), enquanto que para pacientes com redução na bioatividade de NO, mesmo quatro semanas de treinamento são benéficas (255-257).

Ao contrário de outras formas de NOs, a iNOS não é regulamentada por íons cálcio, mas é induzida principalmente por ROS e citocinas inflamatórias (258). A iNOS foi relatada elevada em músculos esqueléticos 
de ratos após exercício agudo $(254,259)$. No entanto, outro estudo relatou que o exercício crônico aumentou a atividade e expressão protéica da nNOS e eNOS, e não da iNOS nos músculos gastrocnêmio e diafragma (260).

A expressão da eNOS induzida pelo exercício é transitória e reversível e regulada por fatores tais como a angiogênese, e aumento de antioxidantes incluindo efeitos de superóxido dismutase CuZn e Extracelular e redução de $N A D(P) H$ oxidase, com provável redução no estresse oxidativo. Com base nestas observações, parece razoável supor que o exercício possa ser visto como um eficaz antioxidante (253).

Em nosso modelo experimental o exercício aeróbio inibiu a redução da SODCuZn encontrada nos animais expostos ao cigarro, no entanto as SODs manganês e extracelular não foram diferentes entre os grupos. Um estudo experimental mostrou uma elevação da SODCuZn no endotélio da aorta de cobaias treinadas (261) e embora os níveis protéicos de superóxido dismutase manganês não terem sido alterados, os níveis de p67phox, uma subunidade da enzima pró-oxidante $\mathrm{NAD}(\mathrm{P}) \mathrm{H}$ oxidase, foram reduzidas pelo exercício. Essas observações sugerem que o efeito antioxidante do exercício pode ser não só mediado pelo aumento da expressão de enzimas antioxidantes, mas também por uma expressão reduzida de enzimas próoxidantes.

Em nosso estudo a expressão de Gp91phox, uma subunidade de membrana da enzima pró-oxidante $\mathrm{NAD}(\mathrm{P}) \mathrm{H}$ oxidase, não foi alterada em nenhum dos grupos estudados, no entanto, o exercício aeróbio reduziu significativamente os níveis de ROS no lavado broncoalveolar e a expressão 
de 8-isoprostano no parênquima pulmonar encontrada nos animais expostos ao cigarro. Além disso, em nosso modelo experimental, a expressão da GPx pelos macrófagos alveolares não foi diferente entre os animais expostos ao cigarro comparado ao controle, entretanto o exercício físico aeróbio aumentou significativamente a expressão dessa enzima.

Outros estudos também não mostraram quaisquer mudanças apreciáveis na atividade de GPx em macrófagos alveolares ou tecido pulmonar obtido a partir de fumantes crônicos $(262,263)$. No entanto, em modelos experimentais a exposição aguda das células epiteliais alveolares in vitro de pulmões de roedores à fumaça do cigarro ou o seu condensado resultou em uma redução nas atividades da GPx (264-266). Em um outro estudo, quando ratos foram expostos cronicamente à fumaça de cigarro, as atividades da GPx aumentaram (267). O aumento na atividade enzimática pode estar associado a uma tolerância ao tabagismo.

É provável que a GSH mitocondrial desempenhe um papel fundamental na manutenção do sistema de defesa antioxidante celular e assim na integridade celular sob condições de estresse oxidativo. Estudos (268, 269) mostraram que a transferência de genes mitocondriais da glutationa redutase e a superexpressão da GPx em várias linhas celulares levaram a proteção contra o estresse oxidativo. Isso sugere que o sistema GSH redox e as suas enzimas como a glutationa redutase e a GPx podem ser importantes na proteção mitocondrial e das funções celulares em relação ao estresse oxidativo, como o produzido pela fumaça de cigarro nos pulmões, sugerindo que a GPx pode ter sido uma das maiores responsáveis 
pela redução nas espécies reativas de oxigênio em nosso modelo experimental.

O treinamento físico aeróbio protegeu os animais quanto à queda na elastância pulmonar (Htis) observada nos animais expostos à fumaça de cigarro. $\mathrm{O}$ valor de Htis foi normalizado pelo peso do animal, uma vez que houve diferença de peso corporal entre os grupos devido aos diferentes tratamentos e, sobretudo porque os nossos parâmetros de mecânica refletem não só os pulmões, mas também as propriedades da parede torácica $(270,271)$.

As limitações dos modelos animais de DPOC precisam ser consideradas, mas os resultados obtidos a partir desses modelos podem proporcionar avanços significativos em termos de compreensão dos mecanismos envolvidos na doença.

Os resultados do presente estudo sugerem que o treinamento físico aeróbio regular de intensidade moderada em fumantes reduz o estresse oxidativo e protege contra o desenvolvimento do enfisema. A compreensão dos mecanismos relacionados a essa proteção pode fornecer a base para a compreensão da fisiologia molecular da doença e poderá ter grandes implicações na prática clínica. 
CONCLUSÃO 


\section{CONCLUSÃO}

Neste estudo, estabelecemos um modelo de lesão pulmonar crônica induzida por cigarro e mostramos um efeito protetor do treinamento físico aeróbio no desenvolvimento do enfisema pulmonar de camundongos C57BL6. 
REFERÊNCIAS 


\section{REFERÊNCIAS}

1. GOLD GIfCOLD. Global Strategy for the Diagnosis, Management and Prevention of Chronic Obstructive Pulmonary Disease. 2008.

2. Silverman EK, Mosley JD, Palmer LJ, Barth M, Senter JM, Brown A, et al. Genome-wide linkage analysis of severe, early-onset chronic obstructive pulmonary disease: airflow obstruction and chronic bronchitis phenotypes. Hum Mol Genet. 2002 Mar 15;11(6):623-32.

3. Burrows B, Knudson RJ, Cline MG, Lebowitz MD. Quantitative relationships between cigarette smoking and ventilatory function. Am Rev Respir Dis. 1977 Feb;115(2):195-205.

4. Anthonisen NR, Connett JE, Murray RP. Smoking and lung function of Lung Health Study participants after 11 years. Am J Respir Crit Care Med. 2002 Sep 1;166(5):675-9.

5. Petersen AM, Pedersen BK. The anti-inflammatory effect of exercise. J Appl Physiol. 2005 Apr;98(4):1154-62.

6. Lee IM, Rexrode KM, Cook NR, Manson JE, Buring JE. Physical activity and coronary heart disease in women: is "no pain, no gain" passe? Jama. 2001 Mar 21;285(11):1447-54.

7. Lee CD, Blair SN. Cardiorespiratory fitness and smoking-related and total cancer mortality in men. Med Sci Sports Exerc. 2002 May;34(5):735-9.

8. Ferrucci L, Izmirlian G, Leveille S, Phillips CL, Corti MC, Brock DB, et al. Smoking, physical activity, and active life expectancy. Am J Epidemiol. 1999 Apr 1;149(7):645-53. 
9. Naslund GK, Fredrikson M, Hellenius ML, de Faire U. Effect of diet and physical exercise intervention programmes on coronary heart disease risk in smoking and non-smoking men in Sweden. J Epidemiol Community Health. 1996 Apr;50(2):131-6.

10. Flo C, Lopes FD, Kasahara DI, Silva AC, Jesus RC, Rivero DH, et al. Effects of exercise training on papain-induced pulmonary emphysema in Wistar rats. J Appl Physiol. 2006 Jan;100(1):281-5.

11. Garcia-Aymerich J, Lange P, Benet M, Schnohr P, Anto JM. Regular physical activity modifies smoking-related lung function decline and reduces risk of chronic obstructive pulmonary disease: a population-based cohort study. Am J Respir Crit Care Med. 2007 Mar 1;175(5):458-63.

12. Smith CA, Harrison DJ. Association between polymorphism in gene for microsomal epoxide hydrolase and susceptibility to emphysema. Lancet. 1997 Aug 30;350(9078):630-3.

13. Halbert RJ, Natoli JL, Gano A, Badamgarav E, Buist AS, Mannino DM. Global burden of COPD: systematic review and meta-analysis. Eur Respir J. 2006 Sep;28(3):523-32.

14. Menezes AM, Perez-Padilla R, Jardim JR, Muino A, Lopez MV, Valdivia G, et al. Chronic obstructive pulmonary disease in five Latin American cities (the PLATINO study): a prevalence study. Lancet. 2005 Nov 26;366(9500):1875-81.

15. Menezes A, Macedo SC, Gigante DP, da Costa JD, Olinto MT, Fiss E, et al. Prevalence and risk factors for chronic obstructive pulmonary disease according to symptoms and spirometry. Copd. 2004;1(2):173-9. 
16. Viegi G, Pistelli F, Sherrill DL, Maio S, Baldacci S, Carrozzi L. Definition, epidemiology and natural history of COPD. Eur Respir J. 2007 Nov;30(5):993-1013.

17. Murray CJ, Lopez AD. Alternative projections of mortality and disability by cause 1990-2020: Global Burden of Disease Study. Lancet. 1997 May $24 ; 349(9064): 1498-504$.

18. Feenstra TL, van Genugten ML, Hoogenveen RT, Wouters EF, Rutten-van Molken MP. The impact of aging and smoking on the future burden of chronic obstructive pulmonary disease: a model analysis in the Netherlands. Am J Respir Crit Care Med. 2001 Aug 15;164(4):590-6.

19. de Marco R, Accordini S, Cerveri I, Corsico A, Anto JM, Kunzli N, et al. Incidence of chronic obstructive pulmonary disease in a cohort of young adults according to the presence of chronic cough and phlegm. Am J Respir Crit Care Med. 2007 Jan 1;175(1):32-9.

20. Sullivan SD, Ramsey SD, Lee TA. The economic burden of COPD. Chest. 2000 Feb;117(2 Suppl):5S-9S.

21. Biernacki WA, Kharitonov SA, Barnes PJ. Increased leukotriene B4 and 8-isoprostane in exhaled breath condensate of patients with exacerbations of COPD. Thorax. 2003 Apr;58(4):294-8.

22. Bowler RP, Barnes PJ, Crapo JD. The role of oxidative stress in chronic obstructive pulmonary disease. Copd. 2004;1(2):255-77.

23. Barnes PJ, Shapiro SD, Pauwels RA. Chronic obstructive pulmonary disease: molecular and cellular mechanisms. Eur Respir J. 2003 Oct;22(4):672-88. 
24. Macnee W, Rahman I. Oxidants and antioxidants as therapeutic targets in chronic obstructive pulmonary disease. Am J Respir Crit Care Med. 1999 Nov;160(5 Pt 2):S58-65.

25. Janssen YM, Van Houten B, Borm PJ, Mossman BT. Cell and tissue responses to oxidative damage. Lab Invest. 1993 Sep;69(3):261-74.

26. Church DF, Pryor WA. Free-radical chemistry of cigarette smoke and its toxicological implications. Environ Health Perspect. 1985 Dec;64:111-26.

27. Droge W. Free radicals in the physiological control of cell function. Physiol Rev. 2002 Jan;82(1):47-95.

28. Halliwell B, Aruoma OI. DNA damage by oxygen-derived species. Its mechanism and measurement in mammalian systems. FEBS Lett. $1991 \mathrm{Apr}$ 9;281(1-2):9-19.

29. El-Benna J, Dang PM, Gougerot-Pocidalo MA, Elbim C. Phagocyte NADPH oxidase: a multicomponent enzyme essential for host defenses. Arch Immunol Ther Exp (Warsz). 2005 May-Jun;53(3):199-206.

30. Di Meo S, Venditti P. Mitochondria in exercise-induced oxidative stress. Biol Signals Recept. 2001 Jan-Apr;10(1-2):125-40.

31. Li Y, Trush MA. Diphenyleneiodonium, an NAD(P)H oxidase inhibitor, also potently inhibits mitochondrial reactive oxygen species production. Biochem Biophys Res Commun. 1998 Dec 18;253(2):295-9.

32. Urso ML, Clarkson PM. Oxidative stress, exercise, and antioxidant supplementation. Toxicology. 2003 Jul 15;189(1-2):41-54. 
33. Nakayama T, Church DF, Pryor WA. Quantitative analysis of the hydrogen peroxide formed in aqueous cigarette tar extracts. Free Radic Biol Med. 1989;7(1):9-15.

34. Eiserich JP, van der Vliet A, Handelman GJ, Halliwell B, Cross CE. Dietary antioxidants and cigarette smoke-induced biomolecular damage: a complex interaction. Am J Clin Nutr. 1995 Dec;62(6 Suppl):1490S-500S.

35. Kinnula VL, Crapo JD, Raivio KO. Generation and disposal of reactive oxygen metabolites in the lung. Lab Invest. 1995 Jul;73(1):3-19.

36. Holland JA, Pritchard KA, Pappolla MA, Wolin MS, Rogers NJ, Stemerman MB. Bradykinin induces superoxide anion release from human endothelial cells. J Cell Physiol. 1990 Apr;143(1):21-5.

37. Kinnula VL, Chang L, Everitt JI, Crapo JD. Oxidants and antioxidants in alveolar epithelial type II cells: in situ, freshly isolated, and cultured cells. Am J Physiol. 1992 Jan;262(1 Pt 1):L69-77.

38. Kinnula VL, Chang LY, Ho YS, Crapo JD. Hydrogen peroxide release from alveolar macrophages and alveolar type II cells during adaptation to hyperoxia in vivo. Exp Lung Res. 1992 Sep-Oct;18(5):655-73.

39. Crapo JD, Oury T, Rabouille C, Slot JW, Chang LY. Copper,zinc superoxide dismutase is primarily a cytosolic protein in human cells. Proc Natl Acad Sci U S A. 1992 Nov 1;89(21):10405-9.

40. Shull S, Heintz NH, Periasamy M, Manohar M, Janssen YM, Marsh $J P$, et al. Differential regulation of antioxidant enzymes in response to oxidants. J Biol Chem. 1991 Dec 25;266(36):24398-403.

41. Fridovich I, Freeman B. Antioxidant defenses in the lung. Annu Rev Physiol. 1986;48:693-702. 
42. Fridovich I. Superoxide dismutases. Annu Rev Biochem. 1975;44:14759.

43. Coursin DB, Cihla HP, Oberley TD, Oberley LW. Immunolocalization of antioxidant enzymes and isozymes of glutathione S-transferase in normal rat lung. Am J Physiol. 1992 Dec;263(6 Pt 1):L679-91.

44. Chang LY, Kang BH, Slot JW, Vincent R, Crapo JD. Immunocytochemical localization of the sites of superoxide dismutase induction by hyperoxia in rat lungs. Lab Invest. 1995 Jul;73(1):29-39.

45. Kinnula VL, Yankaskas JR, Chang L, Virtanen I, Linnala A, Kang BH, et al. Primary and immortalized (BEAS 2B) human bronchial epithelial cells have significant antioxidative capacity in vitro. Am J Respir Cell Mol Biol. 1994 Nov;11(5):568-76.

46. Coursin DB, Cihla HP, Sempf J, Oberley TD, Oberley LW. An immunohistochemical analysis of antioxidant and glutathione S-transferase enzyme levels in normal and neoplastic human lung. Histol Histopathol. 1996 Oct;11(4):851-60.

47. Smith LJ, Shamsuddin M, Sporn PH, Denenberg M, Anderson J. Reduced superoxide dismutase in lung cells of patients with asthma. Free Radic Biol Med. 1997;22(7):1301-7.

48. Jarjour NN, Busse WW, Calhoun WJ. Enhanced production of oxygen radicals in nocturnal asthma. Am Rev Respir Dis. 1992 Oct;146(4):905-11.

49. Nishikawa M, Kakemizu N, Ito T, Kudo M, Kaneko T, Suzuki M, et al. Superoxide mediates cigarette smoke-induced infiltration of neutrophils into the airways through nuclear factor-kappaB activation and IL-8 mRNA expression in guinea pigs in vivo. Am J Respir Cell Mol Biol. 1999 Feb;20(2):189-98. 
50. Kinnula VL, Crapo JD. Superoxide dismutases in the lung and human lung diseases. Am J Respir Crit Care Med. 2003 Jun 15;167(12):1600-19.

51. Davis JM, Parad RB, Michele T, Allred E, Price A, Rosenfeld W. Pulmonary outcome at 1 year corrected age in premature infants treated at birth with recombinant human CuZn superoxide dismutase. Pediatrics. 2003 Mar;111(3):469-76.

52. Li Y, Huang TT, Carlson EJ, Melov S, Ursell PC, Olson JL, et al. Dilated cardiomyopathy and neonatal lethality in mutant mice lacking manganese superoxide dismutase. Nat Genet. 1995 Dec;11(4):376-81.

53. Tsan MF, White JE, Caska B, Epstein CJ, Lee CY. Susceptibility of heterozygous MnSOD gene-knockout mice to oxygen toxicity. Am J Respir Cell Mol Biol. 1998 Jul;19(1):114-20.

54. Wispe JR, Warner BB, Clark JC, Dey CR, Neuman J, Glasser SW, et al. Human Mn-superoxide dismutase in pulmonary epithelial cells of transgenic mice confers protection from oxygen injury. J Biol Chem. 1992 Nov 25;267(33):23937-41.

55. Tsan MF. Superoxide dismutase and pulmonary oxygen toxicity: lessons from transgenic and knockout mice (Review). Int J Mol Med. 2001 Jan;7(1):13-9.

56. Lebovitz RM, Zhang H, Vogel H, Cartwright J, Jr., Dionne L, Lu N, et al. Neurodegeneration, myocardial injury, and perinatal death in mitochondrial superoxide dismutase-deficient mice. Proc Natl Acad Sci U S A. 1996 Sep 3;93(18):9782-7.

57. Harju T, Kaarteenaho-Wiik R, Sirvio R, Paakko P, Crapo JD, Oury TD, et al. Manganese superoxide dismutase is increased in the airways of smokers' lungs. Eur Respir J. 2004 Nov;24(5):765-71. 
58. Comhair SA, Erzurum SC. Antioxidant responses to oxidant-mediated lung diseases. Am J Physiol Lung Cell Mol Physiol. 2002 Aug;283(2):L24655.

59. Marklund SL. Extracellular superoxide dismutase in human tissues and human cell lines. J Clin Invest. 1984 Oct;74(4):1398-403.

60. Marklund SL. Human copper-containing superoxide dismutase of high molecular weight. Proc Natl Acad Sci U S A. 1982 Dec;79(24):7634-8.

61. Oury TD, Day BJ, Crapo JD. Extracellular superoxide dismutase in vessels and airways of humans and baboons. Free Radic Biol Med. 1996;20(7):957-65.

62. Marklund SL. Regulation by cytokines of extracellular superoxide dismutase and other superoxide dismutase isoenzymes in fibroblasts. J Biol Chem. 1992 Apr 5;267(10):6696-701.

63. Loenders B, Van Mechelen E, Nicolai S, Buyssens N, Van Osselaer N, Jorens PG, et al. Localization of extracellular superoxide dismutase in rat lung: neutrophils and macrophages as carriers of the enzyme. Free Radic Biol Med. 1998 May;24(7-8):1097-106.

64. Su WY, Folz R, Chen JS, Crapo JD, Chang LY. Extracellular superoxide dismutase mRNA expressions in the human lung by in situ hybridization. Am J Respir Cell Mol Biol. 1997 Feb;16(2):162-70.

65. Folz RJ, Crapo JD, Peno-Green LA. Elevated levels of extracellular superoxide dismutase in chronic lung disease and characterization of genetic variants. Chest. 1997 Jun;111(6 Suppl):74S. 
66. Halliwell B. Free radicals, reactive oxygen species and human disease: a critical evaluation with special reference to atherosclerosis. $\mathrm{Br} \mathrm{J}$ Exp Pathol. 1989 Dec;70(6):737-57.

67. Heffner JE, Repine JE. Pulmonary strategies of antioxidant defense. Am Rev Respir Dis. 1989 Aug;140(2):531-54.

68. Ursini F, Maiorino M, Gregolin C. The selenoenzyme phospholipid hydroperoxide glutathione peroxidase. Biochim Biophys Acta. 1985 Mar 29;839(1):62-70.

69. Chu FF, Doroshow JH, Esworthy RS. Expression, characterization, and tissue distribution of a new cellular selenium-dependent glutathione peroxidase, GSHPx-GI. J Biol Chem. 1993 Feb 5;268(4):2571-6.

70. Avissar N, Finkelstein JN, Horowitz S, Willey JC, Coy E, Frampton MW, et al. Extracellular glutathione peroxidase in human lung epithelial lining fluid and in lung cells. Am J Physiol. 1996 Feb;270(2 Pt 1):L173-82.

71. Mbemba F, Houbion A, Raes M, Remacle J. Subcellular localization and modification with ageing of glutathione, glutathione peroxidase and glutathione reductase activities in human fibroblasts. Biochim Biophys Acta. 1985 Feb 15;838(2):211-20.

72. Esworthy RS, Ho YS, Chu FF. The Gpx1 gene encodes mitochondrial glutathione peroxidase in the mouse liver. Arch Biochem Biophys. $1997 \mathrm{Apr}$ $1 ; 340(1): 59-63$.

73. Cantin AM, North SL, Hubbard RC, Crystal RG. Normal alveolar epithelial lining fluid contains high levels of glutathione. J Appl Physiol. 1987 Jul;63(1):152-7. 
74. Jornot L, Junod AF. Response of human endothelial cell antioxidant enzymes to hyperoxia. Am J Respir Cell Mol Biol. 1992 Jan;6(1):107-15.

75. Tsan MF, White JE, Santana TA, Lee CY. Tracheal insufflation of tumor necrosis factor protects rats against oxygen toxicity. J Appl Physiol. 1990 Mar;68(3):1211-9.

76. Avissar NE, Reed CK, Cox C, Frampton MW, Finkelstein JN. Ozone, but not nitrogen dioxide, exposure decreases glutathione peroxidases in epithelial lining fluid of human lung. Am J Respir Crit Care Med. 2000 Oct;162(4 Pt 1):1342-7.

77. Liao MF, Chen CC, Hsu MH. Evaluation of the serum antioxidant status in asthmatic children. Acta Paediatr Taiwan. 2004 Jul-Aug;45(4):2137.

78. Dauletbaev N, Rickmann J, Viel K, Diegel H, von Mallinckrodt C, Stein $\mathrm{J}$, et al. Antioxidant properties of cystic fibrosis sputum. Am J Physiol Lung Cell Mol Physiol. 2005 May;288(5):L903-9.

79. Dauletbaev N, Viel K, Buhl R, Wagner TO, Bargon J. Glutathione and glutathione peroxidase in sputum samples of adult patients with cystic fibrosis. J Cyst Fibros. 2004 Jun;3(2):119-24.

80. Halliwell B. Reactive oxygen species in living systems: source, biochemistry, and role in human disease. Am J Med. 1991 Sep $30 ; 91(3 \mathrm{C}): 14 \mathrm{~S}-22 \mathrm{~S}$.

81. Wu L, Chau J, Young RP, Pokorny V, Mills GD, Hopkins R, et al. Transforming growth factor-beta1 genotype and susceptibility to chronic obstructive pulmonary disease. Thorax. 2004 Feb;59(2):126-9. 
82. Huang SL, Su CH, Chang SC. Tumor necrosis factor-alpha gene polymorphism in chronic bronchitis. Am J Respir Crit Care Med. 1997 Nov;156(5):1436-9.

83. Gross P, Pfitzer EA, Tolker E, Babyak MA, Kaschak M. Experimental Emphysema: Its Production with Papain in Normal and Silicotic Rats. Arch Environ Health. 1965 Jul;11:50-8.

84. Shapiro SD. Animal models for COPD. Chest. 2000 May;117(5 Suppl 1):223S-7S.

85. MacNee W. Pathogenesis of chronic obstructive pulmonary disease. Proc Am Thorac Soc. 2005;2(4):258-66; discussion 90-1.

86. Churg A, Wright JL. Proteases and emphysema. Curr Opin Pulm Med. 2005 Mar;11(2):153-9.

87. Morrison HM, Kramps JA, Burnett D, Stockley RA. Lung lavage fluid from patients with alpha 1-proteinase inhibitor deficiency or chronic obstructive bronchitis: anti-elastase function and cell profile. Clin Sci (Lond). 1987 Mar;72(3):373-81.

88. Kidokoro Y, Kravis TC, Moser KM, Taylor JC, Crawford IP. Relationship of leukocyte elastase concentration to severity of emphysema in homozygous alpha1-antitrypsin-deficient persons. Am Rev Respir Dis. 1977 May;115(5):793-803.

89. Reilly JJ, Jr., Mason RW, Chen P, Joseph LJ, Sukhatme VP, Yee R, et al. Synthesis and processing of cathepsin L, an elastase, by human alveolar macrophages. Biochem J. 1989 Jan 15;257(2):493-8.

90. Reilly JJ, Jr., Chen P, Sailor LZ, Wilcox D, Mason RW, Chapman HA, Jr. Cigarette smoking induces an elastolytic cysteine proteinase in 
macrophages distinct from cathepsin L. Am J Physiol. 1991 Aug;261(2 Pt 1):L41-8.

91. Senior RM, Griffin GL, Fliszar CJ, Shapiro SD, Goldberg GI, Welgus HG. Human 92- and 72-kilodalton type IV collagenases are elastases. J Biol Chem. 1991 Apr 25;266(12):7870-5.

92. Shi GP, Munger JS, Meara JP, Rich DH, Chapman HA. Molecular cloning and expression of human alveolar macrophage cathepsin $\mathrm{S}$, an elastinolytic cysteine protease. J Biol Chem. 1992 Apr 15;267(11):7258-62.

93. Shapiro SD, Kobayashi DK, Ley TJ. Cloning and characterization of a unique elastolytic metalloproteinase produced by human alveolar macrophages. J Biol Chem. 1993 Nov 15;268(32):23824-9.

94. Dhami R, Gilks B, Xie C, Zay K, Wright JL, Churg A. Acute cigarette smoke-induced connective tissue breakdown is mediated by neutrophils and prevented by alpha1-antitrypsin. Am J Respir Cell Mol Biol. 2000 Feb;22(2):244-52.

95. Gadek JE, Fells GA, Crystal RG. Cigarette smoking induces functional antiprotease deficiency in the lower respiratory tract of humans. Science. 1979 Dec 14;206(4424):1315-6.

96. Carp H, Miller F, Hoidal JR, Janoff A. Potential mechanism of emphysema: alpha 1-proteinase inhibitor recovered from lungs of cigarette smokers contains oxidized methionine and has decreased elastase inhibitory capacity. Proc Natl Acad Sci U S A. 1982 Mar;79(6):2041-5.

97. Stone PJ, Calore JD, McGowan SE, Bernardo J, Snider GL, Franzblau C. Functional alpha 1-protease inhibitor in the lower respiratory tract of cigarette smokers is not decreased. Science. 1983 Sep 16;221(4616):11879. 
98. Boudier C, Pelletier A, Pauli G, Bieth JG. The functional activity of alpha 1-proteinase inhibitor in bronchoalveolar lavage fluids from healthy human smokers and non-smokers. Clin Chim Acta. 1983 Aug 31;132(3):30915.

99. Abboud RT, Fera T, Richter A, Tabona MZ, Johal S. Acute effect of smoking on the functional activity of alpha1-protease inhibitor in bronchoalveolar lavage fluid. Am Rev Respir Dis. 1985 Jan;131(1):79-85.

100. MacNee W. Oxidative stress and lung inflammation in airways disease. Eur J Pharmacol. 2001 Oct 19;429(1-3):195-207.

101. Teramoto S. 1. COPD pathogenesis from the viewpoint of risk factors. Intern Med. 2007;46(2):77-9.

102. Yanbaeva DG, Dentener MA, Creutzberg EC, Wesseling G, Wouters EF. Systemic effects of smoking. Chest. 2007 May;131(5):1557-66.

103. Lapperre TS, Postma DS, Gosman MM, Snoeck-Stroband JB, ten Hacken NH, Hiemstra PS, et al. Relation between duration of smoking cessation and bronchial inflammation in COPD. Thorax. 2006 Feb;61(2):11521.

104. Sparrow D, Glynn RJ, Cohen M, Weiss ST. The relationship of the peripheral leukocyte count and cigarette smoking to pulmonary function among adult men. Chest. 1984 Sep;86(3):383-6.

105. Di Stefano A, Capelli A, Lusuardi M, Balbo P, Vecchio C, Maestrelli P, et al. Severity of airflow limitation is associated with severity of airway inflammation in smokers. Am J Respir Crit Care Med. 1998 Oct;158(4):127785. 
106. Bosken $\mathrm{CH}$, Hards J, Gatter K, Hogg JC. Characterization of the inflammatory reaction in the peripheral airways of cigarette smokers using immunocytochemistry. Am Rev Respir Dis. 1992 Apr;145(4 Pt 1):911-7.

107. Kuschner WG, D'Alessandro A, Wong H, Blanc PD. Dose-dependent cigarette smoking-related inflammatory responses in healthy adults. Eur Respir J. 1996 Oct;9(10):1989-94.

108. Thompson AB, Daughton D, Robbins RA, Ghafouri MA, Oehlerking M, Rennard SI. Intraluminal airway inflammation in chronic bronchitis. Characterization and correlation with clinical parameters. Am Rev Respir Dis. 1989 Dec;140(6):1527-37.

109. Churg A, Zay K, Shay S, Xie C, Shapiro SD, Hendricks R, et al. Acute cigarette smoke-induced connective tissue breakdown requires both neutrophils and macrophage metalloelastase in mice. Am J Respir Cell Mol Biol. 2002 Sep;27(3):368-74.

110. Shapiro SD, Goldstein NM, Houghton AM, Kobayashi DK, Kelley D, Belaaouaj A. Neutrophil elastase contributes to cigarette smoke-induced emphysema in mice. Am J Pathol. 2003 Dec;163(6):2329-35.

111. O'Shaughnessy TC, Ansari TW, Barnes NC, Jeffery PK. Inflammation in bronchial biopsies of subjects with chronic bronchitis: inverse relationship of CD8+ T lymphocytes with FEV1. Am J Respir Crit Care Med. 1997 Mar;155(3):852-7.

112. Di Stefano A, Turato G, Maestrelli P, Mapp CE, Ruggieri MP, Roggeri $A$, et al. Airflow limitation in chronic bronchitis is associated with Tlymphocyte and macrophage infiltration of the bronchial mucosa. Am J Respir Crit Care Med. 1996 Feb;153(2):629-32. 
113. Saetta M, Di Stefano A, Maestrelli P, Ferraresso A, Drigo R, Potena A, et al. Activated T-lymphocytes and macrophages in bronchial mucosa of subjects with chronic bronchitis. Am Rev Respir Dis. 1993 Feb;147(2):301-6.

114. Saetta M, Di Stefano A, Turato G, Facchini FM, Corbino L, Mapp CE, et al. CD8+ T-lymphocytes in peripheral airways of smokers with chronic obstructive pulmonary disease. Am J Respir Crit Care Med. 1998 Mar;157(3 Pt 1):822-6.

115. Finkelstein R, Fraser RS, Ghezzo H, Cosio MG. Alveolar inflammation and its relation to emphysema in smokers. Am J Respir Crit Care Med. 1995 Nov;152(5 Pt 1):1666-72.

116. Saetta M, Turato G, Facchini FM, Corbino L, Lucchini RE, Casoni G, et al. Inflammatory cells in the bronchial glands of smokers with chronic bronchitis. Am J Respir Crit Care Med. 1997 Nov;156(5):1633-9.

117. Hautamaki RD, Kobayashi DK, Senior RM, Shapiro SD. Requirement for macrophage elastase for cigarette smoke-induced emphysema in mice. Science. 1997 Sep 26;277(5334):2002-4.

118. Hogg JC, Chu F, Utokaparch S, Woods R, Elliott WM, Buzatu L, et al. The nature of small-airway obstruction in chronic obstructive pulmonary disease. N Engl J Med. 2004 Jun 24;350(26):2645-53.

119. van der Strate BW, Postma DS, Brandsma CA, Melgert BN, Luinge MA, Geerlings M, et al. Cigarette smoke-induced emphysema: A role for the B cell? Am J Respir Crit Care Med. 2006 Apr 1;173(7):751-8.

120. Brightling CE, Monteiro W, Ward R, Parker D, Morgan MD, Wardlaw AJ, et al. Sputum eosinophilia and short-term response to prednisolone in chronic obstructive pulmonary disease: a randomised controlled trial. Lancet. 2000 Oct 28;356(9240):1480-5. 
121. Keatings VM, Barnes PJ. Granulocyte activation markers in induced sputum: comparison between chronic obstructive pulmonary disease, asthma, and normal subjects. Am J Respir Crit Care Med. 1997 Feb;155(2):449-53.

122. Takizawa H, Tanaka M, Takami K, Ohtoshi T, Ito K, Satoh M, et al. Increased expression of transforming growth factor-beta1 in small airway epithelium from tobacco smokers and patients with chronic obstructive pulmonary disease (COPD). Am J Respir Crit Care Med. 2001 May;163(6):1476-83.

123. Kasahara Y, Tuder RM, Taraseviciene-Stewart L, Le Cras TD, Abman S, Hirth PK, et al. Inhibition of VEGF receptors causes lung cell apoptosis and emphysema. J Clin Invest. 2000 Dec;106(11):1311-9.

124. Tuder RM, Zhen L, Cho CY, Taraseviciene-Stewart L, Kasahara Y, Salvemini D, et al. Oxidative stress and apoptosis interact and cause emphysema due to vascular endothelial growth factor receptor blockade. Am J Respir Cell Mol Biol. 2003 Jul;29(1):88-97.

125. Rennard SI, Togo S, Holz O. Cigarette smoke inhibits alveolar repair: a mechanism for the development of emphysema. Proc Am Thorac Soc. 2006 Nov;3(8):703-8.

126. Henson PM, Vandivier RW, Douglas IS. Cell death, remodeling, and repair in chronic obstructive pulmonary disease? Proc Am Thorac Soc. 2006 Nov;3(8):713-7.

127. Demedts IK, Demoor T, Bracke KR, Joos GF, Brusselle GG. Role of apoptosis in the pathogenesis of COPD and pulmonary emphysema. Respir Res. 2006;7:53. 
128. Lange P, Nyboe J, Appleyard M, Jensen G, Schnohr P. Relation of ventilatory impairment and of chronic mucus hypersecretion to mortality from obstructive lung disease and from all causes. Thorax. 1990 Aug;45(8):57985.

129. Prescott E, Lange $P$, Vestbo J. Chronic mucus hypersecretion in COPD and death from pulmonary infection. Eur Respir J. 1995 Aug;8(8):1333-8.

130. Shapiro SD, Ingenito EP. The pathogenesis of chronic obstructive pulmonary disease: advances in the past 100 years. Am J Respir Cell Mol Biol. 2005 May;32(5):367-72.

131. Niewoehner DE, Kleinerman J, Rice DB. Pathologic changes in the peripheral airways of young cigarette smokers. N Engl J Med. 1974 Oct 10;291(15):755-8.

132. Kielty CM, Raghunath $M$, Siracusa LD, Sherratt MJ, Peters $R$, Shuttleworth CA, et al. The Tight skin mouse: demonstration of mutant fibrillin-1 production and assembly into abnormal microfibrils. J Cell Biol. 1998 Mar 9;140(5):1159-66.

133. Martorana PA, Brand T, Gardi C, van Even P, de Santi MM, Calzoni P, et al. The pallid mouse. A model of genetic alpha 1-antitrypsin deficiency. Lab Invest. 1993 Feb;68(2):233-41.

134. Mahadeva R, Shapiro SD. Chronic obstructive pulmonary disease * 3 : Experimental animal models of pulmonary emphysema. Thorax. 2002 Oct;57(10):908-14.

135. Groneberg DA, Chung KF. Models of chronic obstructive pulmonary disease. Respir Res. 2004;5:18. 
136. Kasagi S, Seyama K, Mori H, Souma S, Sato T, Akiyoshi T, et al. Tomato juice prevents senescence-accelerated mouse P1 strain from developing emphysema induced by chronic exposure to tobacco smoke. Am J Physiol Lung Cell Mol Physiol. 2006 Feb;290(2):L396-404.

137. Bartalesi B, Cavarra E, Fineschi S, Lucattelli M, Lunghi B, Martorana PA, et al. Different lung responses to cigarette smoke in two strains of mice sensitive to oxidants. Eur Respir J. 2005 Jan;25(1):15-22.

138. Takubo Y, Guerassimov A, Ghezzo H, Triantafillopoulos A, Bates JH, Hoidal JR, et al. Alpha1-antitrypsin determines the pattern of emphysema and function in tobacco smoke-exposed mice: parallels with human disease. Am J Respir Crit Care Med. 2002 Dec 15;166(12 Pt 1):1596-603.

139. Biselli PJC. Efeito da exposição à fumaça de cigarro e ao resíduo de óleo diesel (ROFA) em pulmões de camundongos C57BI6. São Paulo: Faculdade de Medicina da Universidade de São Paulo; 2008.

140. McArdle W, Katch FI, Katch VL. Fisiologia do Exercício, Energia, Nutrição e Desempenho Humano. 4a ed. Rio de Janeiro: Ed. Guanabara Koogan; 1998.

141. Denadai BS. Índices Fisiológicos de Avaliação Aeróbia: Conceitos e Aplicações. Ribeirão Preto: UNESP; 1999.

142. Pate RR, Pratt M, Blair SN, Haskell WL, Macera CA, Bouchard C, et al. Physical activity and public health. A recommendation from the Centers for Disease Control and Prevention and the American College of Sports Medicine. Jama. 1995 Feb 1;273(5):402-7.

143. Hu FB, Stampfer MJ, Solomon C, Liu S, Colditz GA, Speizer FE, et al. Physical activity and risk for cardiovascular events in diabetic women. Ann Intern Med. 2001 Jan 16;134(2):96-105. 
144. Hakim AA, Petrovitch H, Burchfiel CM, Ross GW, Rodriguez BL, White $\mathrm{LR}$, et al. Effects of walking on mortality among nonsmoking retired men. $\mathrm{N}$ Engl J Med. 1998 Jan 8;338(2):94-9.

145. Manson JE, Hu FB, Rich-Edwards JW, Colditz GA, Stampfer MJ, Willett WC, et al. A prospective study of walking as compared with vigorous exercise in the prevention of coronary heart disease in women. $\mathrm{N}$ Engl $\mathrm{J}$ Med. 1999 Aug 26;341(9):650-8.

146. LaCroix AZ, Leveille SG, Hecht JA, Grothaus LC, Wagner EH. Does walking decrease the risk of cardiovascular disease hospitalizations and death in older adults? J Am Geriatr Soc. 1996 Feb;44(2):113-20.

147. Hu FB, Sigal RJ, Rich-Edwards JW, Colditz GA, Solomon CG, Willett WC, et al. Walking compared with vigorous physical activity and risk of type 2 diabetes in women: a prospective study. Jama. 1999 Oct 20;282(15):1433-9.

148. Mueller PJ. Exercise training and sympathetic nervous system activity: evidence for physical activity dependent neural plasticity. Clin Exp Pharmacol Physiol. 2007 Apr;34(4):377-84.

149. Fagard RH, Cornelissen VA. Effect of exercise on blood pressure control in hypertensive patients. Eur J Cardiovasc Prev Rehabil. 2007 Feb;14(1):12-7.

150. Pedersen BK, Hoffman-Goetz L. Exercise and the immune system: regulation, integration, and adaptation. Physiol Rev. 2000 Jul;80(3):1055-81.

151. Ji LL. Antioxidants and oxidative stress in exercise. Proc Soc Exp Biol Med. 1999 Dec;222(3):283-92. 
152. Alessio HM, Goldfarb AH. Lipid peroxidation and scavenger enzymes during exercise: adaptive response to training. J Appl Physiol. 1988 Apr;64(4):1333-6.

153. Radak Z, Sasvari M, Nyakas C, Pucsok J, Nakamoto H, Goto S. Exercise preconditioning against hydrogen peroxide-induced oxidative damage in proteins of rat myocardium. Arch Biochem Biophys. 2000 Apr $15 ; 376(2): 248-51$.

154. Radak Z, Naito H, Kaneko T, Tahara S, Nakamoto H, Takahashi R, et al. Exercise training decreases DNA damage and increases DNA repair and resistance against oxidative stress of proteins in aged rat skeletal muscle. Pflugers Arch. 2002 Nov;445(2):273-8.

155. Radak Z, Chung HY, Goto S. Systemic adaptation to oxidative challenge induced by regular exercise. Free Radic Biol Med. 2008 Jan 15;44(2):153-9.

156. Calabrese EJ, Baldwin LA. Hormesis: the dose-response revolution. Annu Rev Pharmacol Toxicol. 2003;43:175-97.

157. Li H, Wallerath T, Munzel T, Forstermann U. Regulation of endothelialtype NO synthase expression in pathophysiology and in response to drugs. Nitric Oxide. 2002 Nov;7(3):149-64.

158. Radak Z, Chung HY, Goto S. Exercise and hormesis: oxidative stressrelated adaptation for successful aging. Biogerontology. 2005;6(1):71-5.

159. Moldoveanu Al, Shephard RJ, Shek PN. The cytokine response to physical activity and training. Sports Med. 2001 Feb;31(2):115-44.

160. Zieker D, Zieker J, Dietzsch J, Burnet M, Northoff H, Fehrenbach E. CDNA-microarray analysis as a research tool for expression profiling in 
human peripheral blood following exercise. Exerc Immunol Rev. 2005;11:8696.

161. Aoi W, Naito $Y$, Takanami $Y$, Kawai $Y$, Sakuma K, Ichikawa H, et al. Oxidative stress and delayed-onset muscle damage after exercise. Free Radic Biol Med. 2004 Aug 15;37(4):480-7.

162. Costa Rosa L, Vaisberg, MW,. Influências do exercício na resposta imune. Rev Bras Med Esporte. 2002;8:167-72.

163. Jonsdottir $\mathrm{IH}$, Hoffmann $\mathrm{P}$, Thoren $\mathrm{P}$. Physical exercise, endogenous opioids and immune function. Acta Physiol Scand Suppl. 1997;640:47-50.

164. Curi R, Newsholme P, Pithon-Curi TC, Pires-de-Melo M, Garcia C, Homem-de-Bittencourt Junior PI, et al. Metabolic fate of glutamine in lymphocytes, macrophages and neutrophils. Braz J Med Biol Res. 1999 Jan;32(1):15-21.

165. Evans WJ, Cannon JG. The metabolic effects of exercise-induced muscle damage. Exerc Sport Sci Rev. 1991;19:99-125.

166. Cannon JG, Meydani SN, Fielding RA, Fiatarone MA, Meydani M, Farhangmehr M, et al. Acute phase response in exercise. II. Associations between vitamin E, cytokines, and muscle proteolysis. Am J Physiol. 1991 Jun;260(6 Pt 2):R1235-40.

167. Lakier Smith L. Overtraining, excessive exercise, and altered immunity: is this a $\mathrm{T}$ helper-1 versus $\mathrm{T}$ helper-2 lymphocyte response? Sports Med. 2003;33(5):347-64.

168. Jolliffe JA, Rees K, Taylor RS, Thompson D, Oldridge N, Ebrahim S. Exercise-based rehabilitation for coronary heart disease. Cochrane Database Syst Rev. 2000(4):CD001800. 
169. Piepoli MF, Davos C, Francis DP, Coats AJ. Exercise training metaanalysis of trials in patients with chronic heart failure (ExTraMATCH). Bmj. 2004 Jan 24;328(7433):189.

170. Boule NG, Haddad E, Kenny GP, Wells GA, Sigal RJ. Effects of exercise on glycemic control and body mass in type 2 diabetes mellitus: a meta-analysis of controlled clinical trials. Jama. 2001 Sep 12;286(10):121827.

171. Lacasse Y, Brosseau L, Milne S, Martin S, Wong E, Guyatt GH, et al. Pulmonary rehabilitation for chronic obstructive pulmonary disease. Cochrane Database Syst Rev. 2002(3):CD003793.

172. Ambrosino N, Strambi S. New strategies to improve exercise tolerance in chronic obstructive pulmonary disease. Eur Respir J. 2004 Aug;24(2):31322.

173. Celli BR. Pulmonary rehabilitation in patients with COPD. Am J Respir Crit Care Med. 1995 Sep;152(3):861-4.

174. Lacasse Y, Wong E, Guyatt GH, King D, Cook DJ, Goldstein RS. Meta-analysis of respiratory rehabilitation in chronic obstructive pulmonary disease. Lancet. 1996 Oct 26;348(9035):1115-9.

175. Buchi S, Villiger B, Sensky T, Schwarz F, Wolf C, Buddeberg C. Psychosocial predictors of long-term success of in-patient pulmonary rehabilitation of patients with COPD. Eur Respir J. 1997 Jun;10(6):1272-7.

176. Finnerty JP, Keeping I, Bullough I, Jones J. The effectiveness of outpatient pulmonary rehabilitation in chronic lung disease: a randomized controlled trial. Chest. 2001 Jun;119(6):1705-10. 
177. Garuti G, Cilione C, Dell'Orso D, Gorini P, Lorenzi MC, Totaro L, et al. Impact of comprehensive pulmonary rehabilitation on anxiety and depression in hospitalized COPD patients. Monaldi Arch Chest Dis. 2003 JanMar;59(1):56-61.

178. Ketelaars CA, Abu-Saad HH, Schlosser MA, Mostert R, Wouters EF. Long-term outcome of pulmonary rehabilitation in patients with COPD. Chest. 1997 Aug;112(2):363-9.

179. van Stel HF, Maille AR, Colland VT, Everaerd W. Interpretation of change and longitudinal validity of the quality of life for respiratory illness questionnaire (QoLRIQ) in inpatient pulmonary rehabilitation. Qual Life Res. 2003 Mar;12(2):133-45.

180. Wijkstra PJ, Van Altena R, Kraan J, Otten V, Postma DS, Koeter GH. Quality of life in patients with chronic obstructive pulmonary disease improves after rehabilitation at home. Eur Respir J. 1994 Feb;7(2):269-73.

181. Dawkins PA, Stockley RA. Animal models of chronic obstructive pulmonary disease. Thorax. $2001 \mathrm{Dec} ; 56(12): 972-7$.

182. Biselli PJC. Efeito da exposição à fumaça de cigarro e ao resíduo de óleo diesel (ROFA) em pulmões de camundongos C57/BI6. São Paulo: Faculdade de Medicina da Universidade de São Paulo; 2008.

183. Witschi H, Espiritu I, Peake JL, Wu K, Maronpot RR, Pinkerton KE. The carcinogenicity of environmental tobacco smoke. Carcinogenesis. 1997 Mar;18(3):575-86.

184. Hantos Z, Daroczy B, Suki B, Nagy S, Fredberg JJ. Input impedance and peripheral inhomogeneity of dog lungs. J Appl Physiol. 1992 Jan;72(1):168-78. 
185. Mehta S, Boudreau J, Lilly CM, Drazen JM. Endogenous pulmonary nitric oxide in the regulation of airway microvascular leak. Am J Physiol. 1998 Nov;275(5 Pt 1):L961-8.

186. Leick-Maldonado EA, Kay FU, Leonhardt MC, Kasahara DI, Prado CM, Fernandes FT, et al. Comparison of glucocorticoid and cysteinyl leukotriene receptor antagonist treatments in an experimental model of chronic airway inflammation in guinea-pigs. Clin Exp Allergy. 2004 Jan;34(1):145-52.

187. Jungsuwadee $P$, Benkovszky M, Dekan G, Stingl G, Epstein MM. Repeated aerosol allergen exposure suppresses inflammation in B-celldeficient mice with established allergic asthma. Int Arch Allergy Immunol. 2004 Jan;133(1):40-8.

188. Xisto DG, Farias LL, Ferreira HC, Picanco MR, Amitrano D, Lapa ESJR, et al. Lung parenchyma remodeling in a murine model of chronic allergic inflammation. Am J Respir Crit Care Med. 2005 Apr 15;171(8):82937.

189. Lancas T, Kasahara DI, Prado CM, Tiberio IF, Martins MA, Dolhnikoff M. Comparison of early and late responses to antigen of sensitized guinea pig parenchymal lung strips. J Appl Physiol. 2006 May;100(5):1610-6.

190. Guerassimov A, Hoshino Y, Takubo Y, Turcotte A, Yamamoto M, Ghezzo $\mathrm{H}$, et al. The development of emphysema in cigarette smokeexposed mice is strain dependent. Am J Respir Crit Care Med. 2004 Nov 1;170(9):974-80.

191. Belman MJ. Exercise in patients with chronic obstructive pulmonary disease. Thorax. 1993 Sep;48(9):936-46. 
192. Wright JL, Churg A. Cigarette smoke causes physiologic and morphologic changes of emphysema in the guinea pig. Am Rev Respir Dis. 1990 Dec;142(6 Pt 1):1422-8.

193. Churg A, Wang R, Wang X, Onnervik PO, Thim K, Wright JL. Effect of an MMP-9/MMP-12 inhibitor on smoke-induced emphysema and airway remodelling in guinea pigs. Thorax. 2007 Aug;62(8):706-13.

194. Wright JL, Cosio M, Churg A. Animal models of chronic obstructive pulmonary disease. Am J Physiol Lung Cell Mol Physiol. 2008 Jul;295(1):L115.

195. Muley T, Wiebel M, Schulz V, Ebert W. Elastinolytic activity of alveolar macrophages in smoking-associated pulmonary emphysema. Clin Investig. 1994 Mar;72(4):269-76.

196. Abboud RT, Ofulue AF, Sansores RH, Muller NL. Relationship of alveolar macrophage plasminogen activator and elastase activities to lung function and CT evidence of emphysema. Chest. 1998 May;113(5):1257-63.

197. Di Stefano A, Caramori G, Ricciardolo FL, Capelli A, Adcock IM, Donner CF. Cellular and molecular mechanisms in chronic obstructive pulmonary disease: an overview. Clin Exp Allergy. 2004 Aug;34(8):1156-67.

198. Churg A, Dai J, Tai H, Xie C, Wright JL. Tumor necrosis factor-alpha is central to acute cigarette smoke-induced inflammation and connective tissue breakdown. Am J Respir Crit Care Med. 2002 Sep 15;166(6):849-54.

199. Churg A, Wang RD, Tai H, Wang X, Xie C, Dai J, et al. Macrophage metalloelastase mediates acute cigarette smoke-induced inflammation via tumor necrosis factor-alpha release. Am J Respir Crit Care Med. 2003 Apr 15;167(8):1083-9. 
200. Dentener MA, Creutzberg EC, Schols AM, Mantovani A, van't Veer C, Buurman WA, et al. Systemic anti-inflammatory mediators in COPD: increase in soluble interleukin 1 receptor II during treatment of exacerbations. Thorax. 2001 Sep;56(9):721-6.

201. Dubar V, Gosset P, Aerts C, Voisin C, Wallaert B, Tonnel AB. In vitro acute effects of tobacco smoke on tumor necrosis factor alpha and interleukin-6 production by alveolar macrophages. Exp Lung Res. 1993 MayJun;19(3):345-59.

202. Takabatake N, Nakamura H, Abe S, Inoue S, Hino T, Saito H, et al. The relationship between chronic hypoxemia and activation of the tumor necrosis factor-alpha system in patients with chronic obstructive pulmonary disease. Am J Respir Crit Care Med. 2000 Apr;161(4 Pt 1):1179-84.

203. Capelli A, Di Stefano A, Gnemmi I, Balbo P, Cerutti CG, Balbi B, et al. Increased MCP-1 and MIP-1beta in bronchoalveolar lavage fluid of chronic bronchitics. Eur Respir J. 1999 Jul;14(1):160-5.

204. Traves SL, Culpitt SV, Russell RE, Barnes PJ, Donnelly LE. Increased levels of the chemokines GROalpha and MCP-1 in sputum samples from patients with COPD. Thorax. 2002 Jul;57(7):590-5.

205. Witherden IR, Vanden Bon EJ, Goldstraw P, Ratcliffe C, Pastorino U, Tetley TD. Primary human alveolar type II epithelial cell chemokine release: effects of cigarette smoke and neutrophil elastase. Am J Respir Cell Mol Biol. 2004 Apr;30(4):500-9.

206. Finlay GA, O'Driscoll LR, Russell KJ, D'Arcy EM, Masterson JB, FitzGerald MX, et al. Matrix metalloproteinase expression and production by alveolar macrophages in emphysema. Am J Respir Crit Care Med. 1997 Jul;156(1):240-7. 
207. Ohnishi K, Takagi M, Kurokawa Y, Satomi S, Konttinen YT. Matrix metalloproteinase-mediated extracellular matrix protein degradation in human pulmonary emphysema. Lab Invest. 1998 Sep;78(9):1077-87.

208. Lim S, Roche N, Oliver BG, Mattos W, Barnes PJ, Chung KF. Balance of matrix metalloprotease- 9 and tissue inhibitor of metalloprotease- 1 from alveolar macrophages in cigarette smokers. Regulation by interleukin-10. Am J Respir Crit Care Med. 2000 Oct;162(4 Pt 1):1355-60.

209. Russell RE, Culpitt SV, DeMatos C, Donnelly L, Smith M, Wiggins J, et al. Release and activity of matrix metalloproteinase- 9 and tissue inhibitor of metalloproteinase- 1 by alveolar macrophages from patients with chronic obstructive pulmonary disease. Am J Respir Cell Mol Biol. 2002 May;26(5):602-9.

210. Hirano K, Sakamoto T, Uchida Y, Morishima Y, Masuyama K, Ishii Y, et al. Tissue inhibitor of metalloproteinases- 2 gene polymorphisms in chronic obstructive pulmonary disease. Eur Respir J. 2001 Nov;18(5):748-52.

211. Antonicelli F, Parmentier, M., Hirani, N., Drost, E., Rahman, I., Donaldson,, K. M, W., editors. LPS stimulation of IL-8 release is inhibited by thiol antioxidant at the transcriptional level in THP-1macrophage cells. ; 2000.

212. Schafroth Torok S, Leuppi JD. Bronchial hyper-responsiveness and exhaled nitric oxide in chronic obstructive pulmonary disease. Swiss Med Wkly. 2007 Jul 14;137(27-28):385-91.

213. Sterk PJ, De Gouw HW, Ricciardolo FL, Rabe KF. Exhaled nitric oxide in COPD: glancing through a smoke screen. Thorax. 1999 Jul;54(7):565-7.

214. Ricciardolo FL, Sterk PJ, Gaston B, Folkerts G. Nitric oxide in health and disease of the respiratory system. Physiol Rev. 2004 Jul;84(3):731-65. 
215. Bhowmik A, Seemungal TA, Donaldson GC, Wedzicha JA. Effects of exacerbations and seasonality on exhaled nitric oxide in COPD. Eur Respir J. 2005 Dec;26(6):1009-15.

216. Montuschi P, Kharitonov SA, Barnes PJ. Exhaled carbon monoxide and nitric oxide in COPD. Chest. 2001 Aug;120(2):496-501.

217. Ziora D, Dworniczak S, Kozielski J. Induced sputum metalloproteinases and their inhibitors in relation to exhaled nitrogen oxide and sputum nitric oxides and other inflammatory cytokines in patients with chronic obstructive pulmonary disease. J Physiol Pharmacol. 2008 Dec;59 Suppl 6:809-17.

218. Delen FM, Sippel JM, Osborne ML, Law S, Thukkani N, Holden WE. Increased exhaled nitric oxide in chronic bronchitis: comparison with asthma and COPD. Chest. 2000 Mar;117(3):695-701.

219. Maziak W, Loukides S, Culpitt S, Sullivan P, Kharitonov SA, Barnes PJ. Exhaled nitric oxide in chronic obstructive pulmonary disease. Am J Respir Crit Care Med. 1998 Mar;157(3 Pt 1):998-1002.

220. Corradi M, Majori M, Cacciani GC, Consigli GF, de'Munari E, Pesci A. Increased exhaled nitric oxide in patients with stable chronic obstructive pulmonary disease. Thorax. 1999 Jul;54(7):572-5.

221. Cazzola M, MacNee W, Martinez FJ, Rabe KF, Franciosi LG, Barnes PJ, et al. Outcomes for COPD pharmacological trials: from lung function to biomarkers. Eur Respir J. 2008 Feb;31(2):416-69.

222. Ichinose M, Sugiura H, Yamagata S, Koarai A, Shirato K. Increase in reactive nitrogen species production in chronic obstructive pulmonary disease airways. Am J Respir Crit Care Med. 2000 Aug;162(2 Pt 1):701-6. 
223. Maestrelli P, Paska C, Saetta M, Turato G, Nowicki Y, Monti S, et al. Decreased haem oxygenase-1 and increased inducible nitric oxide synthase in the lung of severe COPD patients. Eur Respir J. 2003 Jun;21(6):971-6.

224. Montuschi P, Ciabattoni G, Paredi P, Pantelidis P, du Bois RM, Kharitonov SA, et al. 8-Isoprostane as a biomarker of oxidative stress in interstitial lung diseases. Am J Respir Crit Care Med. 1998 Nov;158(5 Pt 1):1524-7.

225. Pratico D, Basili S, Vieri M, Cordova C, Violi F, Fitzgerald GA. Chronic obstructive pulmonary disease is associated with an increase in urinary levels of isoprostane F2alpha-III, an index of oxidant stress. Am J Respir Crit Care Med. 1998 Dec;158(6):1709-14.

226. Nowak D, Kasielski M, Antczak A, Pietras T, Bialasiewicz P. Increased content of thiobarbituric acid-reactive substances and hydrogen peroxide in the expired breath condensate of patients with stable chronic obstructive pulmonary disease: no significant effect of cigarette smoking. Respir Med. 1999 Jun;93(6):389-96.

227. Rahman I. Oxidative stress in pathogenesis of chronic obstructive pulmonary disease: cellular and molecular mechanisms. Cell Biochem Biophys. 2005;43(1):167-88.

228. Rahman I, Biswas SK, Kode A. Oxidant and antioxidant balance in the airways and airway diseases. Eur J Pharmacol. 2006 Mar 8;533(1-3):222-39.

229. Kuhn C, Yu SY, Chraplyvy M, Linder HE, Senior RM. The induction of emphysema with elastase. II. Changes in connective tissue. Lab Invest. 1976 Apr;34(4):372-80. 
230. Karlinsky J, Fredette J, Davidovits G, Catanese A, Snider R, Faris B, et al. The balance of lung connective tissue elements in elastase-induced emphysema. J Lab Clin Med. 1983 Aug;102(2):151-62.

231. Osman M, Cantor JO, Roffman S, Keller S, Turino GM, Mandl I. Cigarette smoke impairs elastin resynthesis in lungs of hamsters with elastase-induced emphysema. Am Rev Respir Dis. 1985 Sep;132(3):640-3.

232. Rosenbloom J, Abrams WR, Mecham R. Extracellular matrix 4: the elastic fiber. FASEB J. 1993 Oct;7(13):1208-18.

233. Laurent $P$, Janoff $A$, Kagan HM. Cigarette smoke blocks cross-linking of elastin in vitro. Am Rev Respir Dis. 1983 Feb;127(2):189-92.

234. Morris SM, Thomas KM, Rich CB, Stone PJ. Degradation and repair of elastic fibers in rat lung interstitial fibroblast cultures. Anat Rec. 1998 Apr;250(4):397-407.

235. March TH, Wilder JA, Esparza DC, Cossey PY, Blair LF, Herrera LK, et al. Modulators of cigarette smoke-induced pulmonary emphysema in $\mathrm{A} / \mathrm{J}$ mice. Toxicol Sci. 2006 Aug;92(2):545-59.

236. Nici L, Donner C, Wouters E, Zuwallack R, Ambrosino N, Bourbeau J, et al. American Thoracic Society/European Respiratory Society statement on pulmonary rehabilitation. Am J Respir Crit Care Med. 2006 Jun $15 ; 173(12): 1390-413$.

237. Ries AL, Bauldoff GS, Carlin BW, Casaburi R, Emery CF, Mahler DA, et al. Pulmonary Rehabilitation: Joint ACCP/AACVPR Evidence-Based Clinical Practice Guidelines. Chest. 2007 May;131(5 Suppl):4S-42S. 
238. Chen HI, Hsieh SY, Yang FL, Hsu YH, Lin CC. Exercise training attenuates septic responses in conscious rats. Med Sci Sports Exerc. 2007 Mar;39(3):435-42.

239. Mussi RK, Camargo EA, Ferreira T, De Moraes C, Delbin MA, Toro IF, et al. Exercise training reduces pulmonary ischaemia-reperfusion-induced inflammatory responses. Eur Respir J. 2008 Mar;31(3):645-9.

240. Vieira RP, Claudino RC, Duarte AC, Santos AB, Perini A, Faria Neto $\mathrm{HC}$, et al. Aerobic exercise decreases chronic allergic lung inflammation and airway remodeling in mice. Am J Respir Crit Care Med. 2007 Nov 1;176(9):871-7.

241. Vieira RP, de Andrade VF, Duarte AC, Dos Santos AB, Mauad T, Martins MA, et al. Aerobic conditioning and allergic pulmonary inflammation in mice. II. Effects on lung vascular and parenchymal inflammation and remodeling. Am J Physiol Lung Cell Mol Physiol. 2008 Oct;295(4):L670-9.

242. Lacraz S, Nicod LP, Chicheportiche R, Welgus HG, Dayer JM. IL-10 inhibits metalloproteinase and stimulates TIMP-1 production in human mononuclear phagocytes. J Clin Invest. 1995 Nov;96(5):2304-10.

243. Mostafa Mtairag E, Chollet-Martin S, Oudghiri M, Laquay N, Jacob MP, Michel JB, et al. Effects of interleukin-10 on monocyte/endothelial cell adhesion and MMP-9/TIMP-1 secretion. Cardiovasc Res. 2001 Mar;49(4):882-90.

244. Starkie R, Ostrowski SR, Jauffred S, Febbraio M, Pedersen BK. Exercise and IL-6 infusion inhibit endotoxin-induced TNF-alpha production in humans. Faseb J. 2003 May;17(8):884-6. 
245. Keller C, Keller P, Giralt M, Hidalgo J, Pedersen BK. Exercise normalises overexpression of TNF-alpha in knockout mice. Biochem Biophys Res Commun. 2004 Aug 13;321(1):179-82.

246. Fiers W. Tumor necrosis factor. Characterization at the molecular, cellular and in vivo level. FEBS Lett. 1991 Jul 22;285(2):199-212.

247. Matthys P, Mitera T, Heremans H, Van Damme J, Billiau A. Antigamma interferon and anti-interleukin-6 antibodies affect staphylococcal enterotoxin B-induced weight loss, hypoglycemia, and cytokine release in Dgalactosamine-sensitized and unsensitized mice. Infect Immun. 1995 Apr;63(4):1158-64.

248. Mizuhara H, O'Neill E, Seki N, Ogawa T, Kusunoki C, Otsuka K, et al. $\mathrm{T}$ cell activation-associated hepatic injury: mediation by tumor necrosis factors and protection by interleukin 6. J Exp Med. 1994 May 1;179(5):152937.

249. Troseid M, Lappegard KT, Claudi T, Damas JK, Morkrid L, Brendberg $\mathrm{R}$, et al. Exercise reduces plasma levels of the chemokines MCP-1 and IL-8 in subjects with the metabolic syndrome. Eur Heart J. 2004 Feb;25(4):34955.

250. Adamopoulos S, Parissis J, Kroupis C, Georgiadis M, Karatzas D, Karavolias G, et al. Physical training reduces peripheral markers of inflammation in patients with chronic heart failure. Eur Heart J. 2001 May;22(9):791-7.

251. Clarkson P, Montgomery HE, Mullen MJ, Donald AE, Powe AJ, Bull T, et al. Exercise training enhances endothelial function in young men. J Am Coll Cardiol. 1999 Apr;33(5):1379-85. 
252. McAllister RM, Laughlin MH. Vascular nitric oxide: effects of physical activity, importance for health. Essays Biochem. 2006;42:119-31.

253. Kojda G, Hambrecht R. Molecular mechanisms of vascular adaptations to exercise. Physical activity as an effective antioxidant therapy? Cardiovasc Res. 2005 Aug 1;67(2):187-97.

254. Balon TW. Integrative biology of nitric oxide and exercise. Exerc Sport Sci Rev. 1999;27:219-53.

255. Hambrecht R, Wolf A, Gielen S, Linke A, Hofer J, Erbs S, et al. Effect of exercise on coronary endothelial function in patients with coronary artery disease. N Engl J Med. 2000 Feb 17;342(7):454-60.

256. Hambrecht R, Hilbrich L, Erbs S, Gielen S, Fiehn E, Schoene N, et al. Correction of endothelial dysfunction in chronic heart failure: additional effects of exercise training and oral L-arginine supplementation. J Am Coll Cardiol. 2000 Mar 1;35(3):706-13.

257. Hamilton KL, Powers SK, Sugiura T, Kim S, Lennon S, Tumer N, et al. Short-term exercise training can improve myocardial tolerance to $I / R$ without elevation in heat shock proteins. Am J Physiol Heart Circ Physiol. 2001 Sep;281(3):H1346-52.

258. Adams V, Nehrhoff B, Spate U, Linke A, Schulze PC, Baur A, et al. Induction of iNOS expression in skeletal muscle by IL-1beta and NFkappaB activation: an in vitro and in vivo study. Cardiovasc Res. 2002 Apr;54(1):95104.

259. Gomez-Cabrera MC, Borras C, Pallardo FV, Sastre J, Ji LL, Vina J. Decreasing xanthine oxidase-mediated oxidative stress prevents useful cellular adaptations to exercise in rats. J Physiol. 2005 Aug 15;567(Pt 1):11320. 
260. Vassilakopoulos T, Deckman G, Kebbewar M, Rallis G, Harfouche R, Hussain SN. Regulation of nitric oxide production in limb and ventilatory muscles during chronic exercise training. Am J Physiol Lung Cell Mol Physiol. 2003 Mar;284(3):L452-7.

261. Rush JW, Turk JR, Laughlin MH. Exercise training regulates SOD-1 and oxidative stress in porcine aortic endothelium. Am J Physiol Heart Circ Physiol. 2003 Apr;284(4):H1378-87.

262. McCusker K, Hoidal J. Selective increase of antioxidant enzyme activity in the alveolar macrophages from cigarette smokers and smokeexposed hamsters. Am Rev Respir Dis. 1990 Mar;141(3):678-82.

263. Pasquini R, Sforzolini GS, Cavaliere A, Savino A, Monarca S, Puccetti $P$, et al. Enzymatic activities of human lung tissue: relationship with smoking habits. Carcinogenesis. 1988 Aug;9(8):1411-6.

264. Joshi UM, Kodavanti PR, Mehendale HM. Glutathione metabolism and utilization of external thiols by cigarette smoke-challenged, isolated rat and rabbit lungs. Toxicol Appl Pharmacol. 1988 Nov;96(2):324-35.

265. Moldeus P, Berggren M, Grafstrom R. N-acetylcysteine protection against the toxicity of cigarette smoke and cigarette smoke condensates in various tissues and cells in vitro. Eur J Respir Dis Suppl. 1985;139:123-9.

266. Rahman I, Li XY, Donaldson K, Harrison DJ, MacNee W. Glutathione homeostasis in alveolar epithelial cells in vitro and lung in vivo under oxidative stress. Am J Physiol. 1995 Sep;269(3 Pt 1):L285-92.

267. York GK, Peirce TH, Schwartz LW, Cross CE. Stimulation by cigarette smoke of glutathione peroxidase system enzyme activities in rat lung. Arch Environ Health. 1976 Nov-Dec;31(6):286-90. 
268. Arai $\mathrm{M}$, Imai $\mathrm{H}$, Koumura $\mathrm{T}$, Yoshida $\mathrm{M}$, Emoto $\mathrm{K}$, Umeda $\mathrm{M}$, et al. Mitochondrial phospholipid hydroperoxide glutathione peroxidase plays a major role in preventing oxidative injury to cells. J Biol Chem. 1999 Feb 19;274(8):4924-33.

269. O'Donovan DJ, Katkin JP, Tamura T, Husser R, Xu X, Smith CV, et al. Gene transfer of mitochondrially targeted glutathione reductase protects H441 cells from t-butyl hydroperoxide-induced oxidant stresses. Am J Respir Cell Mol Biol. 1999 Feb;20(2):256-63.

270. Fisher JT, Mortola JP. Statics of the respiratory system in newborn mammals. Respir Physiol. 1980 Aug;41(2):155-72.

271. Gomes RF, Shen X, Ramchandani R, Tepper RS, Bates JH. Comparative respiratory system mechanics in rodents. J Appl Physiol. 2000 Sep;89(3):908-16. 